\title{
A MULTIPHASE MODIFIED BOOST CONVERTER WITH REDUCED INPUT CURRENT RIPPLE: SPLIT INDUCTANCE AND CAPACITANCE CONFIGURATION
}

\author{
A Thesis \\ presented to \\ the Faculty of California Polytechnic State University, \\ San Luis Obispo
}

\author{
In Partial Fulfillment \\ of the Requirements for the Degree \\ Master of Science in Electrical Engineering
}

by

Zoe M. Hay

June 2018 
(C) 2018

Zoe M. Hay

ALL RIGHTS RESERVED 


\section{COMMITTEE MEMBERSHIP}

TITLE: A Multiphase Modified Boost Converter with Reduced Input Current Ripple: Split Inductance and Capacitance Configuration

AUTHOR: Zoe M. Hay

DATE SUBMITTED: June 2018

COMMITTEE CHAIR: Taufik, Ph.D.

Professor of Electrical Engineering

COMMITTEE MEMBER: Dennis Derickson, Ph.D.

Electrical Engineering Department Chair

COMMITTEE MEMBER: Vladimir Prodanov, Ph.D.

Associate Professor of Electrical Engineering 


\begin{abstract}
A Multiphase Modified Boost Converter with Reduced Input Current Ripple: Split Inductance and Capacitance Configuration Zoe M. Hay
\end{abstract}

This thesis presents the simulation, design, and hardware implementation of a modified multiphase boost converter. Converter design must consider noise imposed on input and output nodes which connect to and influence the operation of other devices. Excessive noise introduces EMI which can damage sensitive circuits or impede their operation. High ripple current degrades battery lifetime and reduces operating efficiency in connected systems such as PV arrays. Converters with high ripple current also experience greater peak conduction loss and require larger components. A two-phase implementation of a modified boost converter demonstrates the input current filtering benefits of the modified topology with increased power capacity. In a $12 \mathrm{~V}$ to $19 \mathrm{~V} 95 \mathrm{~W}$ design, the modified multiphase design exhibits a reduced input current ripple of $1.103 \%$ compared to the $9.096 \%$ of the standard multiphase design while imposing minimal detriment to overall converter efficiency. The modified topology uses two inductors and one feedback capacitance per phase. Larger value inductors generally exhibit lower current ratings as well as larger size. The split inductance of the modified multiphase topology can be designed for occupation of less total volume than the single inductance of the standard multiphase topology.

Keywords: DC-DC power converters, switching converters, boost, multiphase, modified, input current ripple 


\section{TABLE OF CONTENTS}

Page

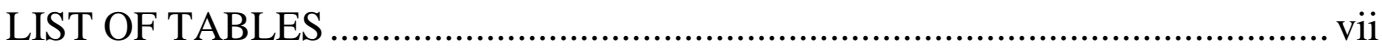

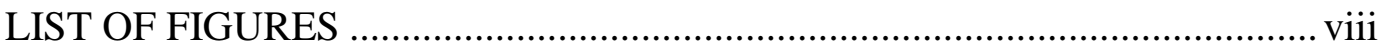

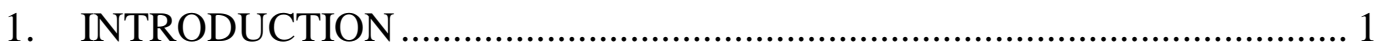

2. BACKGROUND …………………………....................................... 4

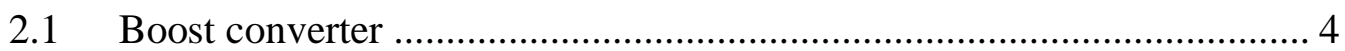

2.2 Electromagnetic Interference …………………….......................... 5

2.3 Boost Converter Input Characteristics ……………………………….... 7

2.4 Boost Converter Output Characteristics .................................................... 9

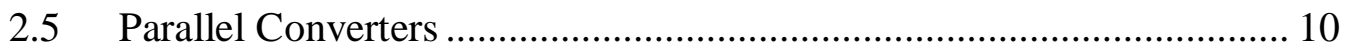

2.6 Modified Boost Topologies................................................................. 14

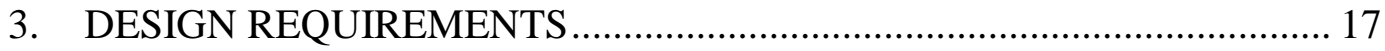

3.1. Converter Performance Characteristics.................................................. 17

3.2. Design Functional Parameters ............................................................... 18

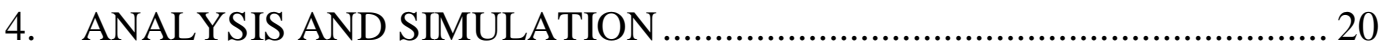

4.1. Standard Boost Design ....................................................................... 20

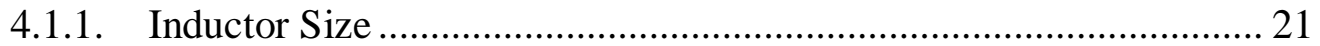

4.1.2. Input Capacitor Size ...................................................................... 23

4.1.3. Output Capacitor Selection ............................................................. 23

4.2. Modified Boost Converter Design .......................................................... 24

4.3. Behavioral Model Multiphase Boost Converter Simulation ................... 25

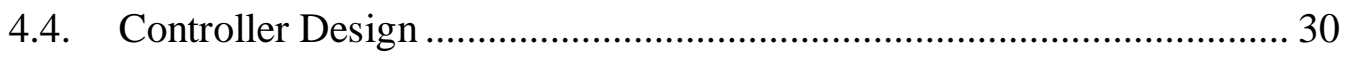

4.4.1. Feedback Resistor Size .............................................................. 30

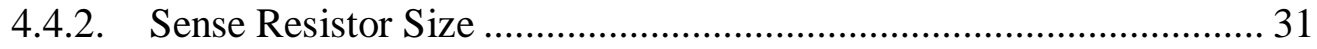

4.4.3. Controller Simulation...................................................................... 31 
5.1. Power Component Selection ........................................................... 39

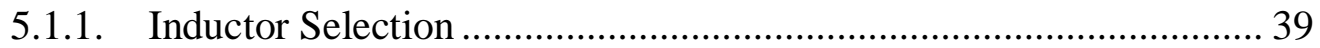

5.1.2. Switch and Diode ................................................................... 41

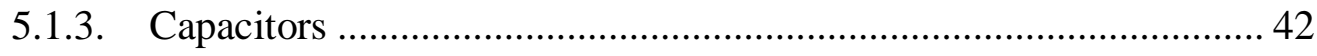

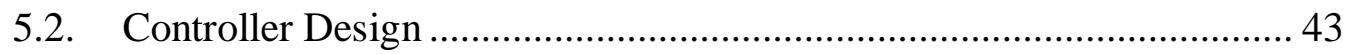

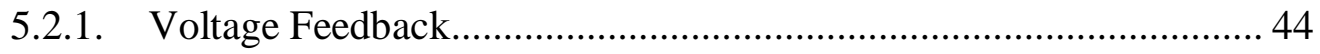

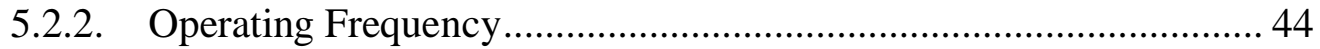

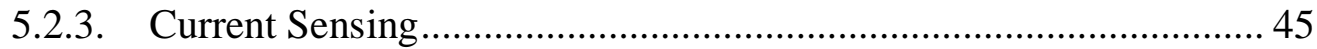

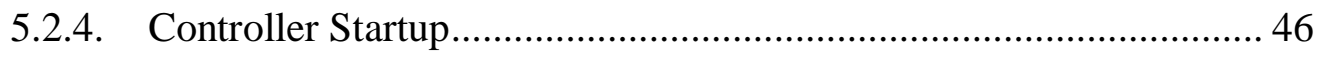

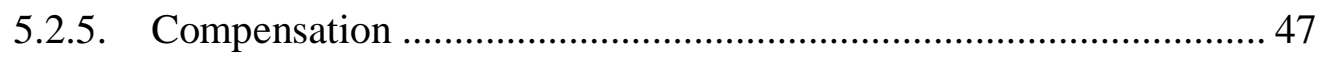

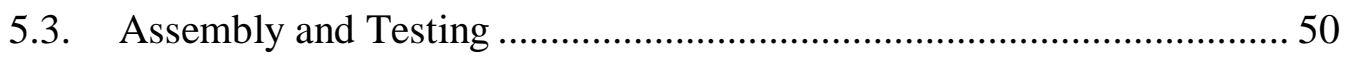

5.3.1. Test Configuration .......................................................... 52

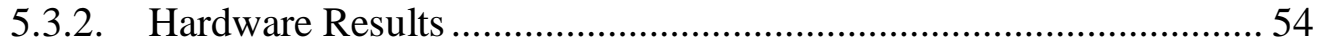

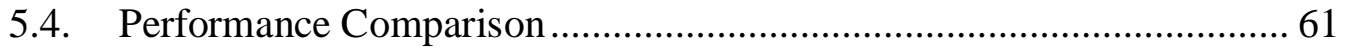

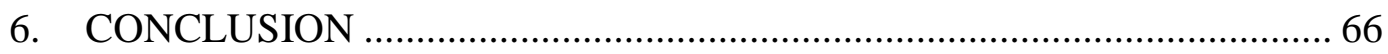

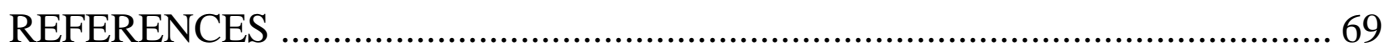

APPENDICES

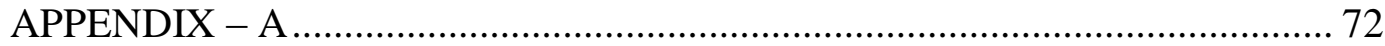

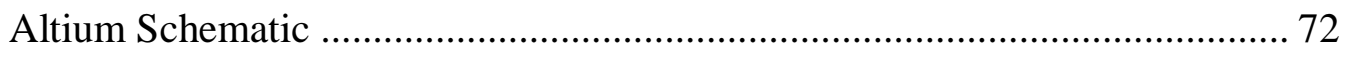

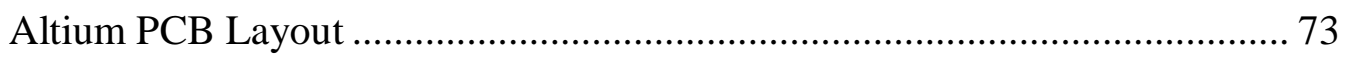

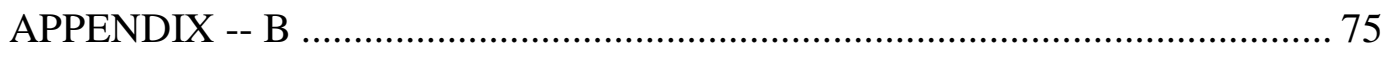

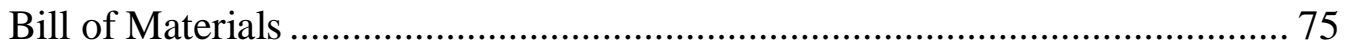




\section{LIST OF TABLES}

Table

Table 3-1. Modified Multiphase Boost Converter Design Functional

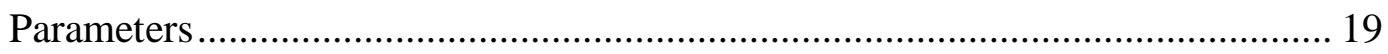

Table 4-1. Parameters for Converter Simulation Using Behavioral Models ........ 24

Table 4-2. Standard Multiphase Boost Converter Simulation Using Behavioral

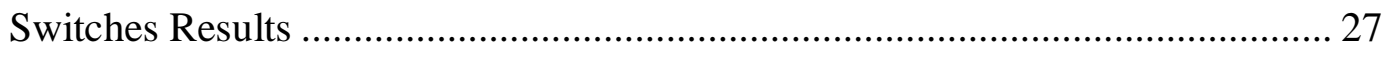

Table 4-3. Modified Multiphase Boost Converter Simulation Using Behavioral

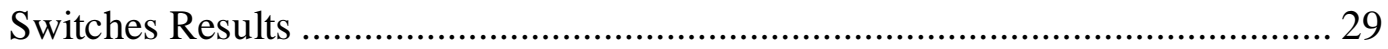

Table 4-4. Standard Multiphase Boost Converter Simulation Using Controller

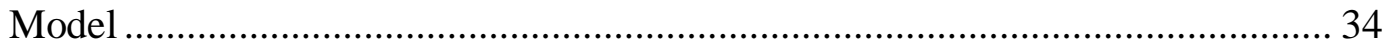

Table 4-5. Modified Multiphase Boost Converter Simulation Using Controller

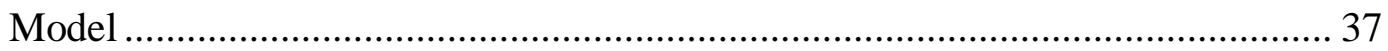

Table 4-6. Summary of Simulation Results ....................................................... 37

Table 5-1. Inductor Selection WE-HCC High Current Inductor Series ............... 40

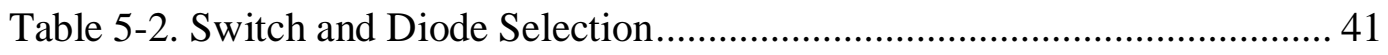

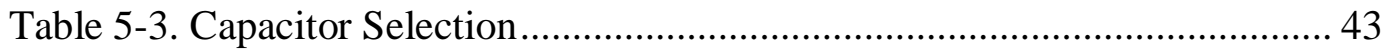

Table 5-4. Capacitor Selection Configurations ................................................. 43

Table 5-5. Hardware Full Load DC Characteristics Comparison ........................ 55

Table 5-6. Standard Boost Converter Hardware Test Results ............................. 57

Table 5-7. Modified Boost Converter Hardware Test Results ............................ 60

Table 5-8. Hardware Line and Load Regulation Comparison ............................ 62

Table 5-9. Hardware Input Current Ripple Comparison ................................... 64

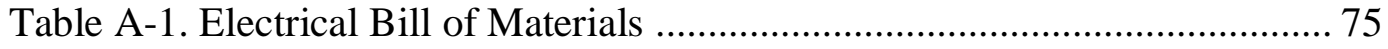




\section{LIST OF FIGURES}

Figure

Page

Figure 2-1. A Standard Boost Converter ......................................................... 4

Figure 2-2. Turn off Snubber Circuit to Slow Rate of Voltage Change ................. 7

Figure 2-3. Current Through the Inductor and Voltage Across the Switch in

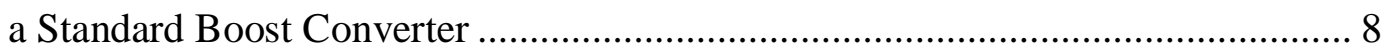

Figure 2-4. Current Through the Output Capacitor and Output Voltage of a

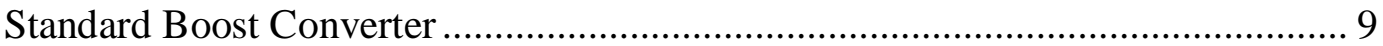

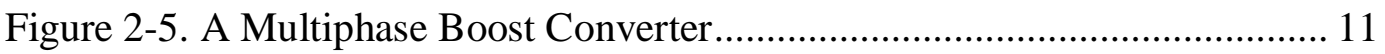

Figure 2-6. Switch Control Signals and Output Voltage Ripple of a

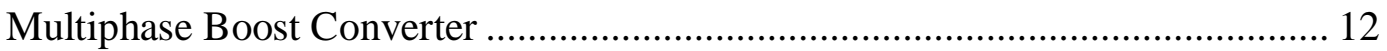

Figure 2-7. Switch Control Signal and Output Voltage Ripple of a Standard

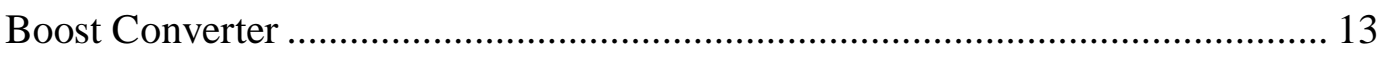

Figure 2-8. Modified Boost Converter Evaluated by Lentz [16] ........................ 15

Figure 2-9. Multiphase Modified Boost Converter............................................ 16

Figure 4-1. A Standard Multiphase Boost Converter ......................................... 26

Figure 4-2. Output Voltage and Switch Control Signals of a Standard

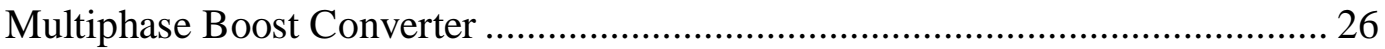

Figure 4-3. Switch Node Voltage, Inductor Current, and Output Capacitor

Current of a Standard Multiphase Boost Converter ........................................... 27

Figure 4-4. The Proposed Modified Multiphase Boost Converter ....................... 27

Figure 4-5. Output Voltage and Switch Control Signals of Modified

Multiphase Boost Converter ........................................................................ 28

Figure 4-6. Switch Node Voltage, Inductor Current, and Output Capacitor Current of Modified Multiphase Boost Converter .............................................. 29

Figure 4-7. LT3782A Standard Multiphase Boost Converter Schematic ............. 32

Figure 4-8. Output Voltage and Switch Control Signals of LT3782A

Standard Boost Converter.

Figure 4-9. Switch Node Voltage, Inductor Current, and Output Capacitor

Current of LT3782A Standard Boost Converter 33 
Figure 4-10. LT3782A Modified Multiphase Boost Converter Schematic

Figure 4-11. Output Voltage and Switch Control Signals of LT3782A

Modified Multiphase Boost Converter

Figure 4-12. Switch Node Voltage, Inductor Current, and Output Capacitor

Current of LT3782A Modified Multiphase Boost Converter .............................. 36

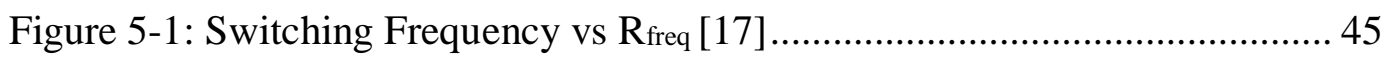

Figure 5-2: LT3286A External Current Sensing Component Connections .......... 46

Figure 5-3: LT3286A External Control Component Connections ...................... 49

Figure 5-4. Top and Bottom Layers of Final PCB …...................................... 51

Figure 5-5. Standard Multiphase Boost Hardware ........................................... 51

Figure 5-6: Modified Multiphase Boost Hardware .............................................. 52

Figure 5-7: Standard Multiphase Converter Test Configuration ......................... 53

Figure 5-8: Modified Multiphase Converter Test Configuration ........................ 53

Figure 5-9: Laboratory Test Configuration..................................................... 54

Figure 5-10: Standard Multiphase Boost Inductor Current (C1:M1,

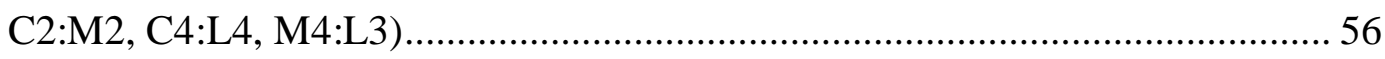

Figure 5-11: Standard Multiphase Boost Output Voltage ................................. 56

Figure 5-12: Modified Multiphase Boost Input Inductor Currents (C1:M1, C2:M2, C4:L2, M4:L1).

Figure 5-13: Modified Multiphase Boost Secondary Inductor Currents

(C1:M1, C2:M2, C4:L4, M4:L3)

Figure 5-14: Modified Multiphase Boost Feedback Phase 1 Capacitor

Voltage (C1:M1, C2:M2, C3:X1, M3:Vout, F1:Vout-X1)....

Figure 5-15: Modified Multiphase Boost Phase 2 Feedback Capacitor

Voltage (C1:M1, C2:M2, C3:X2, M3:Vout, F1:Vout-X2).............................. 59

Figure 5-16: Modified Multiphase Boost Output Voltage................................... 60

Figure 5-17: Hardware Efficiency VS Output Current Comparison .................... 61

Figure 5-18: Hardware Inductor Current Comparison...................................... 63

Figure 5-19: Hardware Input Current Comparison............................................ 64 


\section{INTRODUCTION}

The control and conversion of electrical energy enables modern technology in electrical systems. This relationship corresponds to the ever-increasing demand for electrical energy to power these systems and the need for more efficient conversion and management of energy. While access to energy improves the standard of living, consideration must be allotted to the environmental impact of practices of energy consumption. These pressures encourage research in the areas of energy efficiency renewable resources. These trends drive the need for better technologies to meet rising demands. The topic of power electronics unites concepts from power systems, electronics, and controls to allow more efficient use of energy. Power electronics explores the control of electrical energy using electronic circuits capable of handling higher

power than their individual components [1]. The development of power electronics supports the world's growing energy needs.

Converters using power electronics accomplish a variety of functions for different applications. For example, the use of AC for power distribution in combination with the use of DC for many household appliances necessitates conversion between the two. Power electronics provides conversion between different $\mathrm{AC}$ voltage levels, DC voltage levels, and between $\mathrm{AC}$ and DC. Many applications require internal DC power at different voltages supplied by a single DC source making DC-DC converters widely employed. In non-isolated DC-DC converter topologies, conversion is accomplished using a power switch, inductor, and diode, while the isolated topologies add a transformer to their power stage [1]. The configuration and control of these components determines converter functionality. The characteristic equations of the components and simple circuit analysis describe the relationship between switch operation and 
input and output voltages. DC-DC converters may provide an output stepped down from the input, such as a buck converter, or an output stepped up from the input, such as a boost converter. Other applications require the functionality provided by multiple converter topologies. An inverter, which converts $\mathrm{DC}$ to $\mathrm{AC}$, may require a boost pre-regulator to bring the voltage to the peak value of the AC wave. Many renewable energy sources, such as solar and wind generators, require this extra boost converter before the inverter can convert the generated power to an AC level compatible with a standard power grid. The pursuit of efficiency and sustainability as goals of power electronics results in the high priority of technology enabling use of renewable energy.

While DC-DC converters run efficiently, switching converter operation inherently introduces excessive noise. Voltage across the switches inside DC-DC converters alternates between the full input voltage when off and ideally no voltage when on. Noise can detrimentally affect other more sensitive systems and necessitates filtering or other reduction techniques. Stronger noise requires larger filtering capacitors which consume limited board space.

While single-phase DC-DC converters deliver the needed performance for many applications, efficiency decreases with higher currents and greater power dissipation [2]. Generally, higher switching frequency offers improved efficiency, ripple, and output response for a given converter design. However, higher frequency incurs greater switching losses in single-phase converters [3]. Multiphase converters use two of the same converter topology driven out of phase resulting in an effectively doubled operating frequency. The combination of the two power stage's waveforms decreases input and output ripple. Smaller ripple decreases filtering requirements, allowing use of smaller filtering capacitors. Because of the smaller RMS losses in the capacitor, the capacitor will also experience less self-heating and longer lifetime. 
Higher switching frequency also improves transient behavior [3]. Sharing current between phases decreases component stress and spreads heat dissipation over a greater area of a printed circuit board [2]. Multiphase converters are well suited to applications requiring high current, low voltage, low ripple, and size constraints.

Power electronics revolutionized modern energy usage. Basic converter designs achieve acceptable operation but can be altered to better meet the increasing requirements of the technologies they power. Power electronics technology also increases energy availability by enabling use of more renewable energy sources. Growing energy needs demand the continual improvement of converter design and performance. 


\section{BACKGROUND}

\subsection{Boost converter}

DC-DC converters provide multiple benefits over non-switching, dissipative converters such as linear regulators. In addition to increase efficiency, the boost DC-DC converter provides the ability to supply an output voltage stepped up above the input voltage. Figure 2-2 shows a conventional boost converter constructed for analysis of general circuit behavior.

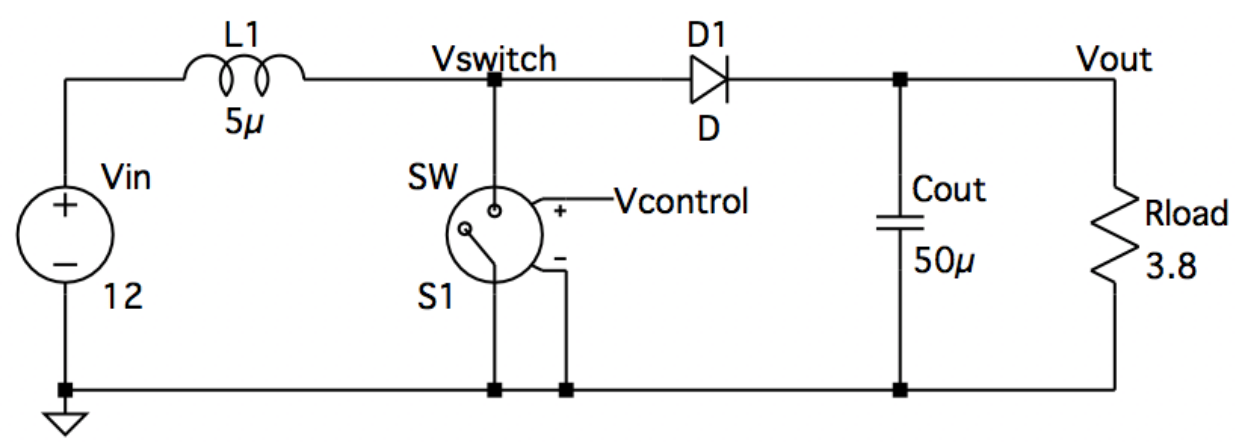

Figure 2-1. A Standard Boost Converter

When the switch conducts, the inductor charges from the input source. This state connects the load across the output capacitor which transfers its stored energy. Switch conduction reverse biases the diode, which ideally acts like an open circuit. During the switch off state, the diode conducts, allowing stored energy to flow from the inductor to the load and the capacitor [1]. The ratio of switch time spent in the on state to time in off state, or duty cycle, determines the increase in output voltage relative to input voltage (2-1).

$$
\frac{V_{\text {out }}}{V_{\text {in }}}=\frac{1}{1-D}
$$


Circuit analysis of the switch off state and switch on state aids component selection to meet the requirements of a specific application. Component selection must also adhere to the required voltage and RMS current ratings demanded by operation of the converter. Conduction losses and switching losses in the switch and diode impact the overall efficiency of the converter, adding an additional constraint in their selection. The boost converter provides a simple and versatile solution for many applications and allows tailoring to meet specific needs. Despite the many benefits of switch-mode converters, such as the boost converter, they exhibit some drawbacks. Careful design considerations and modifications allow some mitigation of the undesirable qualities of switch-mode converters.

\subsection{Electromagnetic Interference}

While switch-mode converters offer the advantages of greater efficiency and voltage boosting, they operate with large changes in voltage and current at high frequencies and generate electromagnetic interference (EMI). EMI defines the interference in a circuit's operation caused by the transfer of electromagnetic energy from another circuit. As developments in power electronics reduce component sizes used in converters, the smaller converters fit closer to the circuits they power. This proximity increases the necessity of converters with non-disruptive EMI performance. Because EMI can result in fault or failure of a system, EMI is regulated by government agencies such as the Federal Communications Commission (FCC) in the United States. Types of EMI are specified as conducted noise, over the frequency range of around $150 \mathrm{kHz}$ to $30 \mathrm{MHz}$, and radiated noise, over the range of $30 \mathrm{MHz}$ to $1 \mathrm{GHz}$ or more [2]. Regulatory agencies set limits for peak acceptable energy within this frequency range [3]. Noise can conduct through electric current in connecting wires, electric field through capacitive 
coupling, or by magnetic field through inductive coupling. Noise can also spread by radiation, where conductors transmit electromagnetic energy [3]. EMI performance represents an essential consideration in converter design.

Many approaches can reduce EMI issues in switch-mode converters. PCB layout significantly impacts the EMI characteristics of a converter. Factors such as component placement, and layout of the ground plane and high-voltage AC nodes greatly influence EMI performance [4]. Design of the loop area of the input-current path represents another key issue [3]. Because the magnetic field of a current loop is the result of inductance, calculated from the area enclosed by the loop, minimizing this area can significantly reduce radiated noise [2]. The components selected for a design also influence noise performance. Heat-sinks, for example, can introduce parasitic capacitance that reacts with high current at the output and changes in voltage [3]. This coupling mechanism can be reduced by minimizing the parasitic capacitance or reducing the switch turn on speed [3]. Filters are often added to reduce a design's emissions but require additional components, weight, and cost. Filter design must also consider the effects introduced by parasitic components on filter performance.

Snubbers or soft switching techniques can accomplish slower transitions between the switch and diodes on and off states. A snubber may simply entail a resistor and capacitor. The $\mathrm{RC}$ time constant of the two components limits the rate of change in voltage across the switch. Figure 2-2 shows the components and configuration of a resistor-diode-capacitor turn off snubber across the switching MOSFET of a converter. 


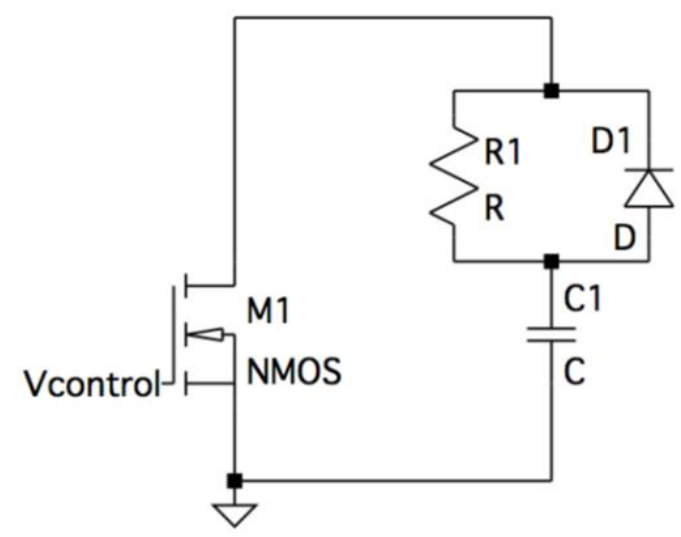

Figure 2-2. Turn off Snubber Circuit to Slow Rate of Voltage Change

This type of snubber allows the capacitor to charge through the diode while the switch does not conduct. At switch turn on, the capacitor discharges through the path of the resistor. The addition of a snubber circuit dissipates energy instead of allowing it to radiate but may increase switching losses and reduce overall efficiency if not designed properly [3]. The passive components of the snubber also add weight and complexity to the system. Soft switching converters use resonant transition circuits to reduce peak stress and radiated EMI but also require increased control complexity to facilitate the soft switching transition [5]. These methods benefit EMI performance at the cost of complexity, additional losses, and limits on switching frequency.

In addition to voltage and power specifications, converter design must adhere to EMI constraints. Options for minimizing EMI can provide significant improvement but often introduce secondary effects which require careful consideration.

\subsection{Boost Converter Input Characteristics}

Due to the charging and discharging of the inductor as controlled by switch duty cycle, the inductor current cycles between maximum and minimum values. The difference between maximum and minimum current defines the converter's inductor current ripple. In the boost 
converter, current ripple in the inductor reflects to the power supply input of the converter. If the converter operates from a shared power bus, ripple introduced by the converter could affect other connected devices. Boost converters can also step up a battery voltage to a more useful level.

Ripple current induces stress and decreases battery life and should be minimized in this application [6]. Figure 2-3 shows the current in the inductor of the boost converter of Figure 2-1 as well as the voltage across the switch as controlled by operating frequency.

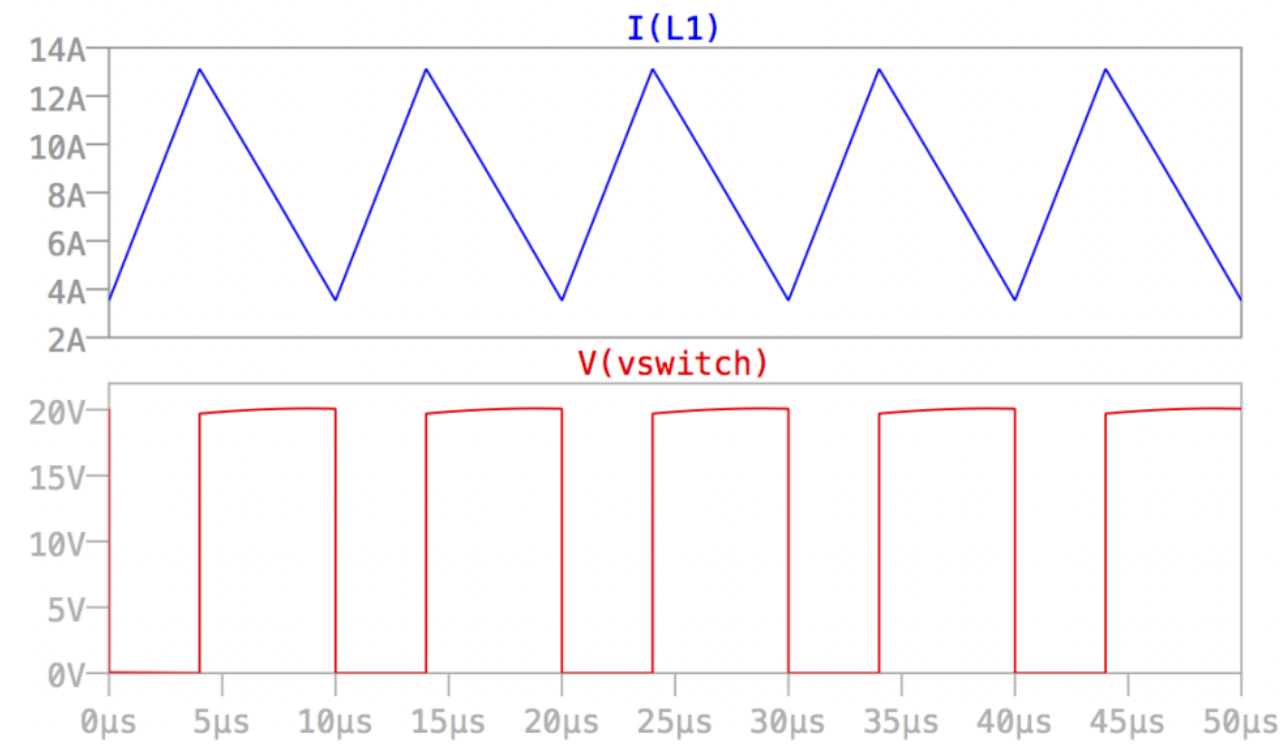

Figure 2-3. Current Through the Inductor and Voltage Across the Switch in a Standard Boost Converter

The inductor represents the component of interest for determining input current characteristics. Inductance and peak current correspond to physical inductor size. Consequently, inductors with large inductance value and high current rating can contribute significant size and weight to converter construction. Because inductance increases with frequency, a higher operating frequency reduces required inductor size for given performance. Frequency increase comes with the cost of core eddy current, switching, and rectifier losses as well as increased electromagnetic emissions [7]. Attention to input characteristics represent a significant aspect of 
converter design. Improving these characteristics involves trade off with other converter qualities.

\subsection{Boost Converter Output Characteristics}

While a DC-DC converter such as a boost ideally attempts to provide a perfectly constant output voltage, the principles of switching converter operation imply a certain amount of change, or ripple, in the output voltage. Excessive ripple could be detrimental or unacceptable depending on the load and application. Extreme noise at the output can also radiate to other surrounding systems. The output capacitor supplies output voltage during the switch off state and plays a key role in output characteristics. Increasing this capacitance allows greater energy storage and provides a smoother output. Figure 2-4 shows the current through the output capacitor of the boost converter shown in Figure 2-1 as well as the corresponding output voltage.

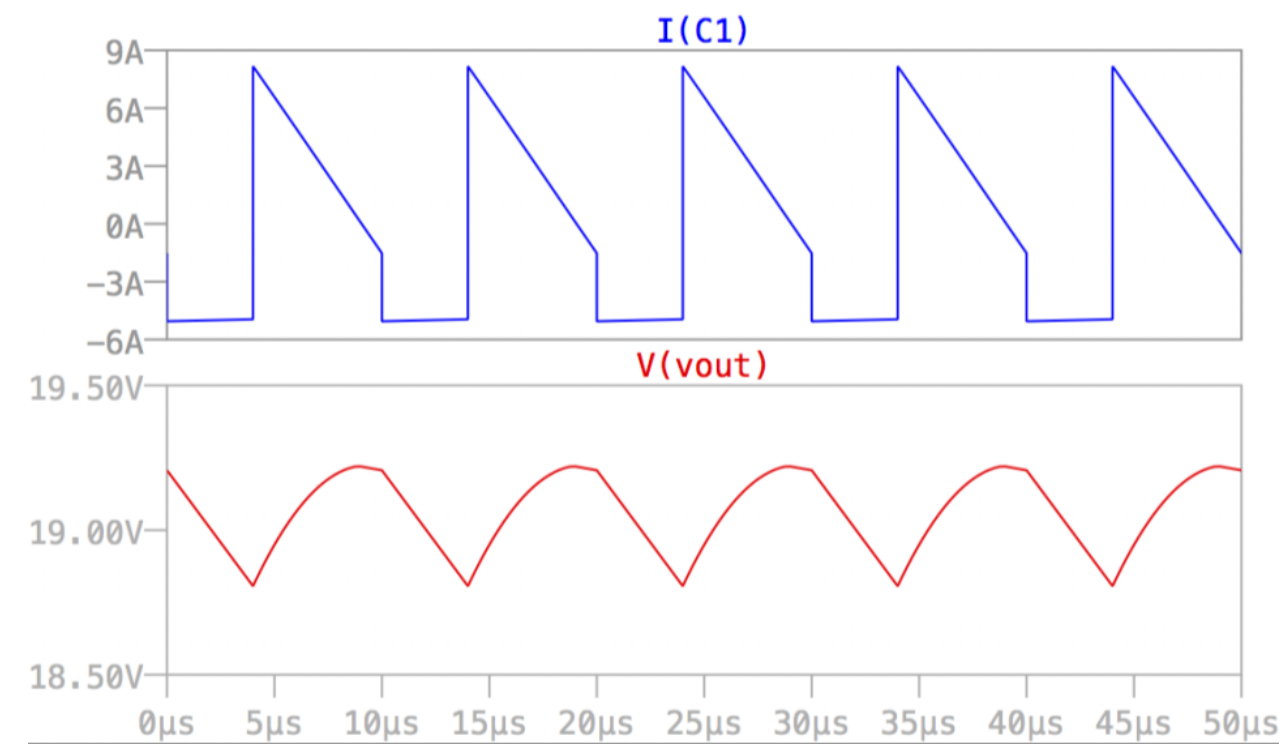

Figure 2-4. Current Through the Output Capacitor and Output Voltage of a Standard Boost Converter

The selected output capacitor must possess sufficient capacitive value as well as voltage and RMS current rating as determined by the application. Operating conditions also factor into 
capacitor selection. Effective capacitance of a given component decreases with frequency and applied DC bias. These concerns often necessitate selection of a component with greater specified capacitance than the value determined by calculation. The peak-to-peak value of current through the output capacitor includes both the inductor peak current and load current. This implies the selected capacitor requires a high RMS current rating, especially in high power applications [7]. The output capacitor must tolerate a ripple voltage equal to the ripple current multiplied by the capacitors equivalent series resistance (ESR) [8]. Low ESR is also desirable as resistance corresponds to power loss and decreased efficiency. Output capacitor selection faces the tradeoff between performance and size, which increases with capacitance and rating. Selection of higher operating frequency can improve output characteristics. Switching frequency directly increases the frequency of the output ripple, decreasing filtering requirements. This approach could also allow the use of lower rated components because most aluminum electrolytic capacitors exhibit higher RMS current ratings at higher frequency operation [7]. As previously stated, however, higher switching frequency can increase other losses in the system. The many benefits of switching converters are not without drawbacks. Careful design considerations and modified topologies help address these issues.

\subsection{Parallel Converters}

The boost converter encounters more limitations as the high side voltage of the converter and the amount of current delivered to the load increases. Large output voltage ripple and input current ripple indicate not only low performance, but also increased stress on components. This leads to larger, heavier converters due to the larger size of more highly rated components. Repeated stress on components also reduces the converter's lifetime and overall reliability. High 
current ripple necessitates larger output diodes to carry a greater RMS current component. Ripple current also causes temperature rise in electrolytic capacitors needed for output voltage filtering. From ideal circuit analysis, the peak voltage across a switch in a conventional boost converter equals the output voltage. High voltages imposed across the switch and diode causes large switching losses and output diode reverse-recovery losses [9]. In high voltage, high current applications, conventional boost converters exhibit poorer performance and require more highly rated components making them large and heavy.

To provide the required power and reduce strain on the system components, multiple converters can operate in parallel to form a multiphase converter. Figure 2-5 shows a two-phase multiphase boost converter.

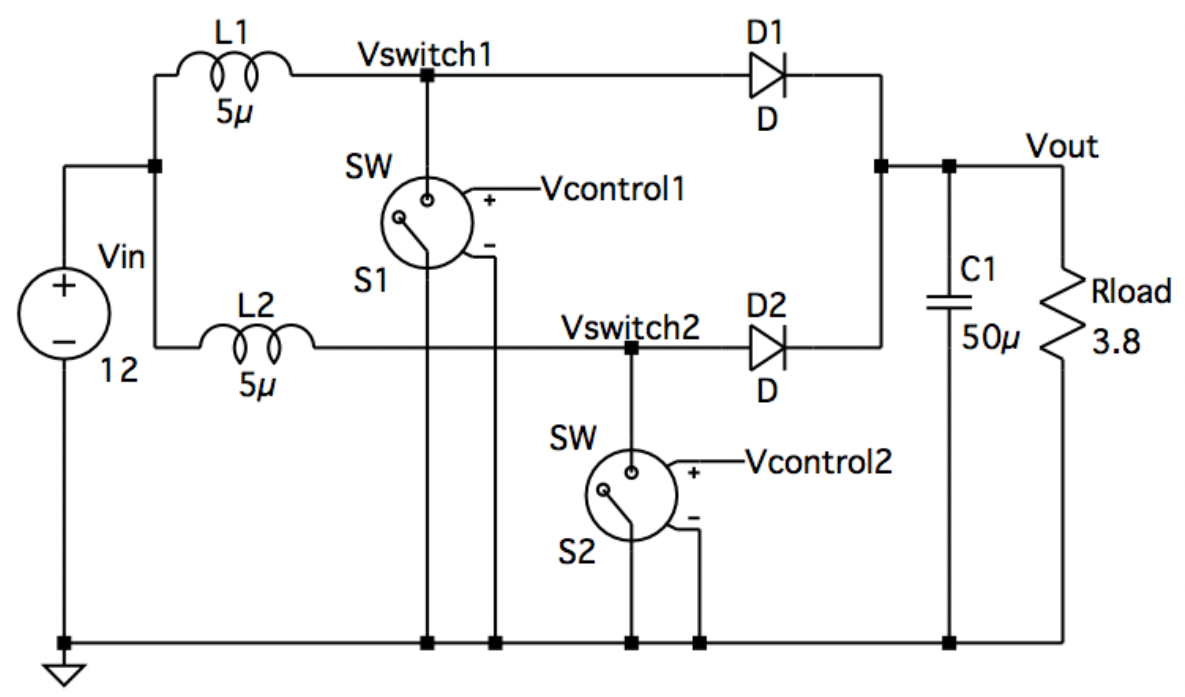

Figure 2-5. A Multiphase Boost Converter

In this configuration, each converter cell operates at the same switching frequency with a phase shift. For a given multiple phase topology, the PWM control signals are phase shifted by $360^{\circ}$ divided by the number of phases. Figure 2-6 shows a multiphase converter's switching control signals and the resulting output voltage. In this example, two switches are operated $180^{\circ}$ 
out of phase at a $40 \%$ duty cycle. The resulting output voltage ripple contrasts Figure 2-7 which shows the switching control signal and output voltage of a single phase conventional boost converter shown in Figure 2-1. Selecting the number of phases must balance the benefits with the increase in cost and complexity. Benefits versus costs of more phases tends to decrease after a relatively low number of phases [7]. Multiphase converters offer various benefits over conventional single-phase converters. The use of two phases effectively doubles the operating frequency of the converter. A two-phase implementation provides the benefits of higher switching frequency without as much of the drawbacks and switching losses associated with increasing the switching frequency of a single-phase converter.

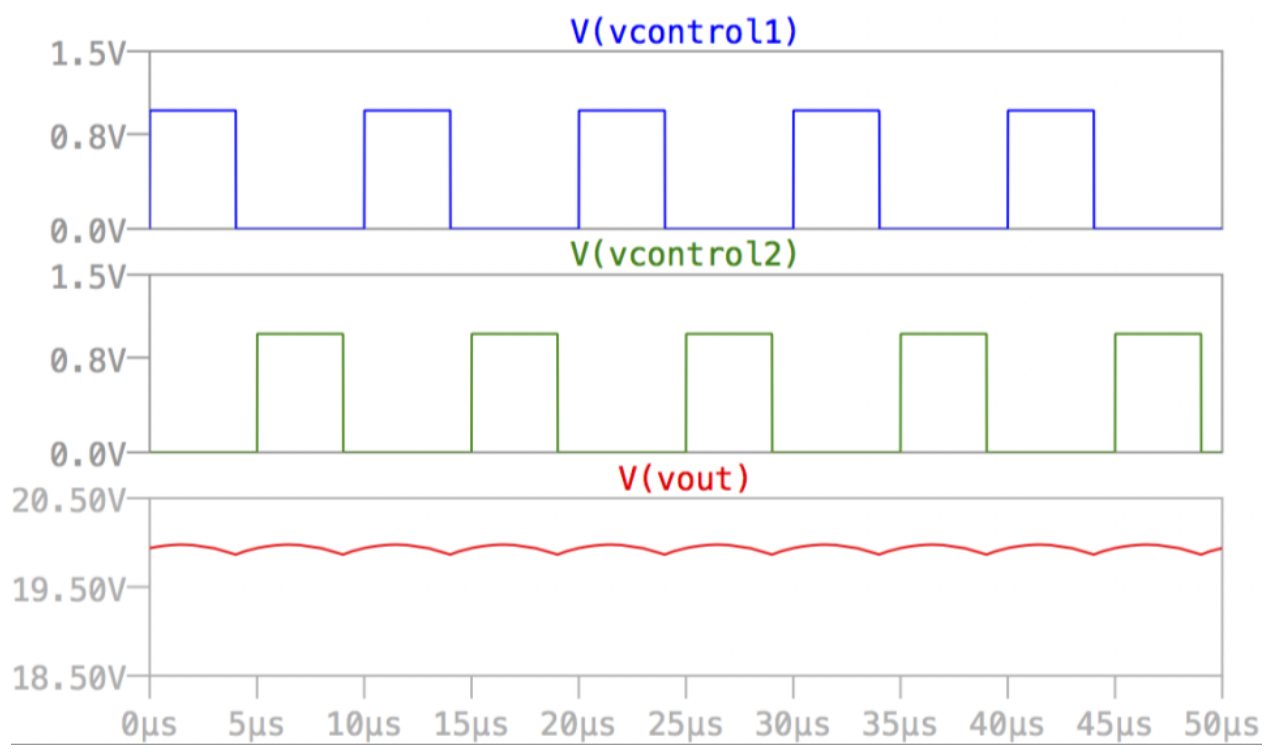

Figure 2-6. Switch Control Signals and Output Voltage Ripple of a Multiphase Boost Converter 


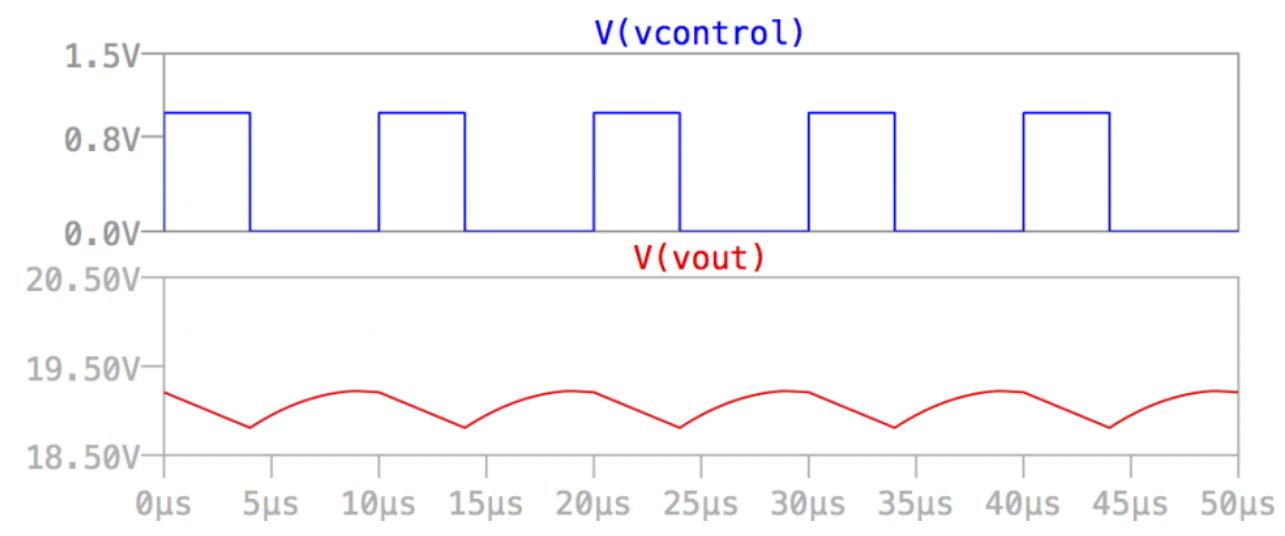

Figure 2-7. Switch Control Signal and Output Voltage Ripple of a Standard Boost Converter

The use of multiple phases improves both the input and output characteristics of the converter. The input current ripple exhibits lower amplitude and harmonics [9]. Because the total input ripple represents the combination of the two input inductors charging and discharging out of phase, ripple cancellation occurs. This effect results in the peak to peak ripple of the input current equaling half that of each phase's inductor [10]. Multiphase operation also improves quality of the output voltage. The output voltage ripple frequency effectively doubles, reducing filtering requirements. Ripple reduction significantly reduces stress applied to the capacitor, which generally has the shortest lifetime of all the components. While most components generally operate within the tens or hundreds of thousands of hours, electrolytic capacitors demonstrate lifetimes of below ten thousand hours when operated at full load [7]. As shown by the topology of Figure 2-5, in addition to reduced output filtering requirements, the output capacitor of each boost converter is combined into a single output capacitor [10]. Comparison of Figure 2-6 and Figure 2-7 shows how the phase shifted operation of the two switches doubles the ripple frequency of the output voltage and reduces the magnitude of the ripple.

Multiple phase converters also exhibit better thermal performance. The use of an additional switching cell effectively splits the current in the converter. This implies reduced 
power dissipation and stress per component as well as heat dissipation spread over a greater area of the PCB.

The qualities of multiphase boost converters lend themselves to many applications. Multiphase topologies are suited to high current applications due to the increased capacity provided by the additional components. The power capacity and low input current and output voltage ripple make them ideal for high power photovoltaic systems [9]. The input characteristics of a multiphase boost provide reduced ripple on the photovoltaic array and the improved dynamic response of the converter aids in tracking the maximum power point of the array [11]. By effectively increasing the switching frequency, the use of multiple phases improves input and output characteristics of the converter. This allows the use of smaller, less highly rated components and improves EMI performance. Multiphase converters deliver increased power with improved performance for higher voltage and current applications.

\subsection{Modified Boost Topologies}

Many research efforts explore modifications to the boost converter with the goal of improving converter performance. Modifications include approaches such as the addition of passive components, different control schemes, and multiphase implementations. The addition of an LC branch in parallel with the diode offers reduced input current ripple [12]. Experimental results show reduced voltage and current stress on the switches for a converter incorporating the LC branch. Results from the modified converter demonstrate reduced conduction and switching losses and improved overall efficiency. The design explored in [13] uses a switched-capacitor and coupled inductor. The design uses an active snubber for zero-voltage soft switching and multiple phases for high power. This more complicated circuit achieved a maximum power of 
$1 \mathrm{~kW}$ with an average efficiency consistently near $90 \%$. A converter explained in [14] replaces the boost converter inductor with a structure of two inductors and three diodes. In a single-phase implementation, this design achieved a voltage ratio greater than a standard boost converter by a factor of $(D+1)$ with the drawback of high stress on the input and output capacitors. A two-phase implementation of this design reduces the ripple and filtering requirements with excellent results achieving $93.6 \%$ efficiency when converting $40 \mathrm{~V}$ to $120 \mathrm{~V}$ at $120 \mathrm{~W}$ output power. A simulated design explored in [15] used direct coupled inductors in a multiphase boost converter. The coupled inductors reduced the amount of core material and component count. Using coupled inductors allowed the ripple of one winding to be transferred to another winding. Simulation results of the proposed design showed reduced ripple an efficiency of around $86 \%$.

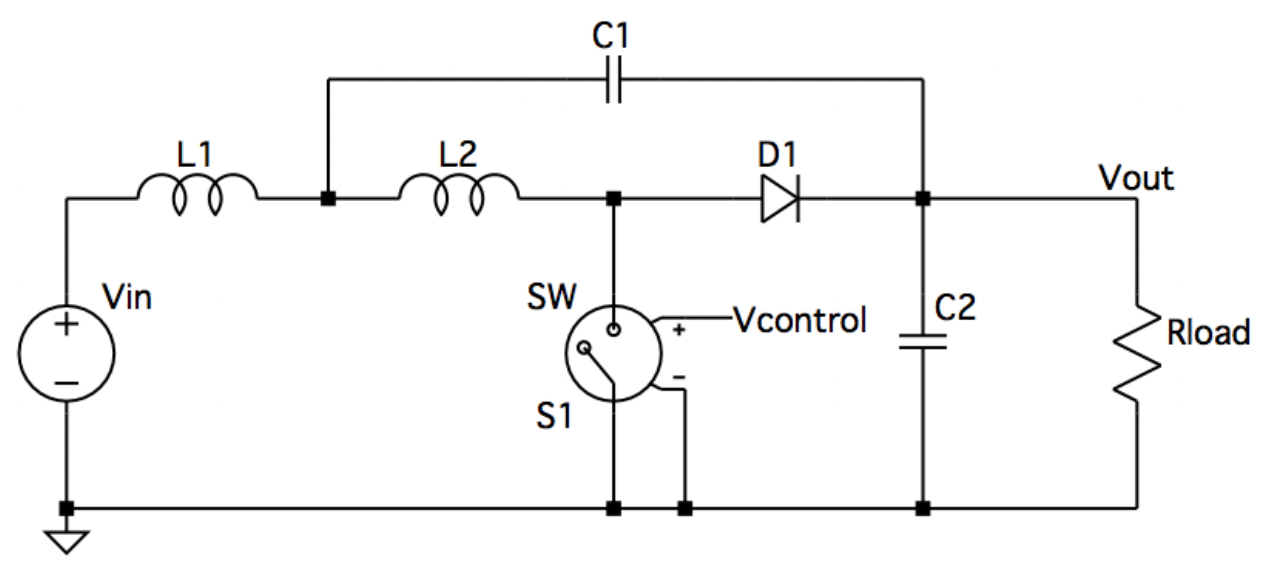

Figure 2-8. Modified Boost Converter Evaluated by Lentz [16]

Figure 2-8 shows a modified boost converter implemented and analyzed by Lentz [16]. This design replaces the standard boost's single inductor with two uncoupled inductors of smaller values. Lentz's implementation achieved $87.01 \%$ efficiency converting $5.3 \mathrm{~V}$ to $17.86 \mathrm{~V}$ at $30.79 \mathrm{~W}$ with a $52.45 \%$ inductor current ripple and $1.67 \%$ output voltage ripple [16]. 


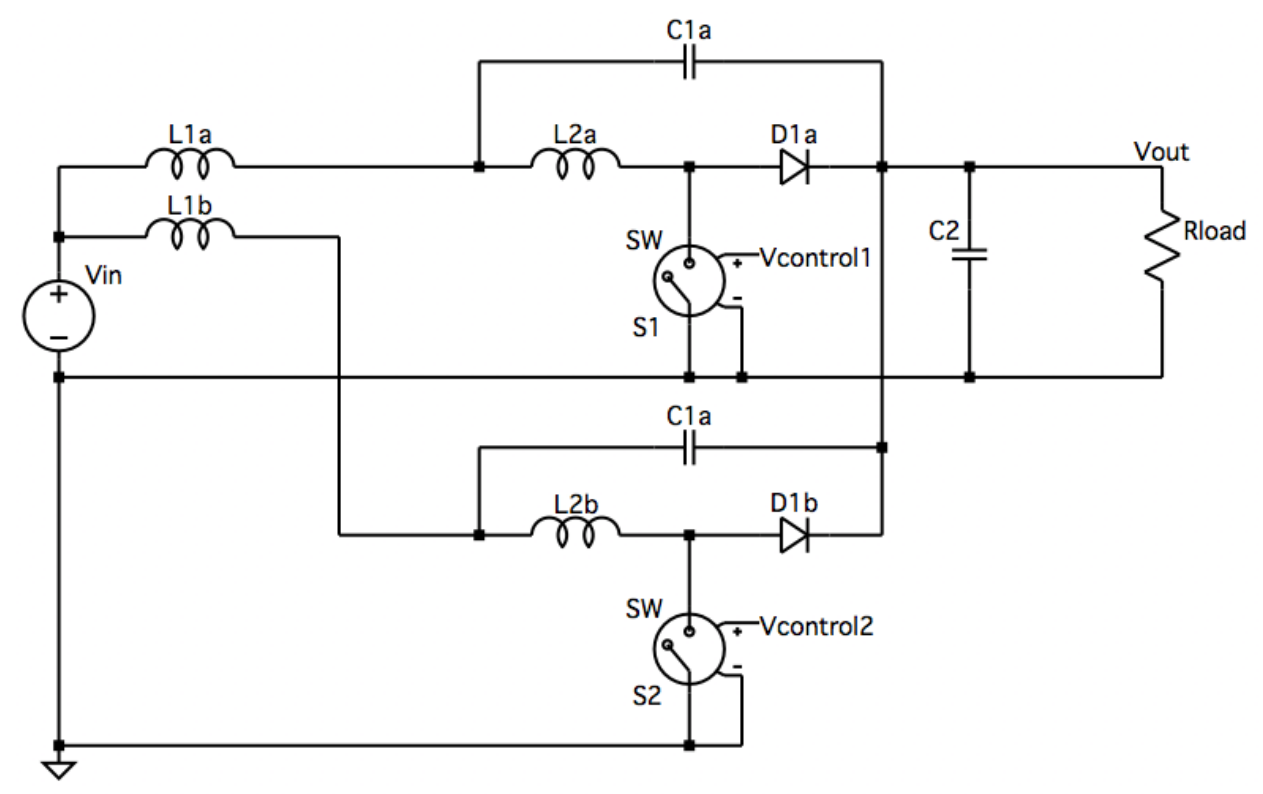

Figure 2-9. Multiphase Modified Boost Converter

A multiphase implementation of this topology as shown in Figure 2-9 could offer low input current and output voltage ripples with the additional benefits of a multiphase design. This thesis demonstrates a steady-state, CCM analysis and implementation of a multiphase modified boost converter. This design will exhibit the low input current and output voltage ripple of the modified topology with higher input and output ripple frequency, higher output current, and faster transient response. 


\section{DESIGN REQUIREMENTS}

A valid converter design requires balancing and optimization of many conflicting parameters. Increasing component values and ratings improves performance characteristics at the cost of consuming more space and adding weight. Increasing switching frequency reduces inductor size but increases switching losses. This pattern of tradeoff between characteristics holds true for every decision in design of a converter.

\subsection{Converter Performance Characteristics}

While the basic requirements of a converter include input and output voltages and currents, the design must meet additional performance requirements. As previously discussed, some applications may specify very stringent input and output characteristics. Input current ripple and output voltage ripple represent key factors in determining if a converter can connect to the source and load without introducing performance issues. For boost converter, these parameters can be based on component sizes and converter operation (3-1)(3-2).

$$
\begin{gathered}
\text { Peak }- \text { to }- \text { Peak Inductor Current Ripple }=\Delta i_{\text {in }}=\frac{V_{\text {in }} D}{L f}[A] \\
\text { Output Voltage Ripple }=\Delta V_{o}=\frac{V_{o} D}{f R_{o(\min )} C_{o}}[V]
\end{gathered}
$$

As previously emphasized, power electronics strives for the efficient use of energy as measured by ratio of output power produced to power supplied into the system (3-3). Other measures of performance include ability of the converter to maintain output voltage with change in input line voltage or line regulation (3-4), as well as ability to maintain output voltage with change in power demanded by the load or load regulation (3-5). These measurements represent 
important parameters for functionality of a converter in a non-ideal environment where supply voltage and load current vary.

$$
\begin{gathered}
\text { Efficiency }=\eta=\frac{P_{\text {OUT }}}{P_{I N}} \\
\text { Line Regulation }=\frac{V_{\text {OUT(High Input })}-V_{\text {OUT (Low Input })}}{V_{\text {OUT (Nominal Input })}} 100 \% \\
\text { Load Regulation }=\frac{V_{\text {OUT }(\text { Low Load })}-V_{\text {OUT }(\text { High Load })}}{V_{\text {OUT(High Load })}} 100 \%
\end{gathered}
$$

\subsection{Design Functional Parameters}

Low input current ripple and high efficiency represent primary goals of the proposed boost design. This goal conflicts with the desirable parameters of minimizing physical size, weight and cost. Design starts with selection of a useful voltage conversion range and practical performance parameters, as listed in Table 3-1. For example, the $12 \mathrm{~V}$ output voltage represents a common battery voltage level as well as the output of PV, which may serve as the source connected to the converter. The $19 \mathrm{~V}$ output voltage represents a load voltage level that typically draws significant power, as well as the voltage level projected for use in future high-power USB-C applications. The output power is limited to $95 \mathrm{~W}$ which represents a sufficient value for the prototyping phase of the proposed multiphase boost topology. 
Table 3-1. Modified Multiphase Boost Converter Design Functional Parameters

\begin{tabular}{|c|c|}
\hline Parameter & Value \\
\hline Output Power (Pout) & $95 \mathrm{~W}$ \\
\hline Output Voltage (Vout) & $19 \mathrm{~V}$ \\
\hline Input Voltage (VIN) & $12 \mathrm{~V}$ \\
\hline Output Voltage Ripple ( $\left.\% \Delta V_{\text {ouT }}\right)$ & $2 \%$ \\
\hline Input Current Ripple $\left(\% \Delta \mathrm{IIIN}_{\mathrm{IN}}\right.$ & $10 \%$ \\
\hline Line Regulation & $10 \%$ \\
\hline Load Regulation & $5 \%$ \\
\hline
\end{tabular}

This design will provide the desired output with an emphasis on low input current and output voltage ripple. The converter will not violate any EMI standards or interfere with surrounding systems. Converter design will also emphasize small size and light weight. 


\section{ANALYSIS AND SIMULATION}

Basic circuit analysis forms the basis of all converter design. The definitions of inductance and capacitance, combined with the circuits formed by the different states of the converter circuit, allow selection of properly sized components. Essential components such as the inductor and input and output capacitors determine converter performance. Calculation of these values allow simulation of a behavior model. The selected controller determines the remainder of the design process. Mathematical analysis of the converter also yields approximations of required component ratings. These approximations, combined with verification from the behavioral switch and controller simulations, allow selection and purchase of suitable components in the hardware section of the design.

\subsection{Standard Boost Design}

Design of a multiphase boost proceeds similarly to the process for a standard boost with some adjustments accounting for the current split between the phases. For evaluation of the modified multiphase topology, a standard multiphase boost is also designed. Initial design begins with calculation of modeling values based on the design parameters declared in Chapter 3 . Output voltage and power of the converter determine the value of the output resistance to model a maximum load condition of the converter (4-1).

$$
\begin{gathered}
R=\frac{V_{\text {OUT }}^{2}}{P_{\text {OUT }}} \\
R=\frac{12 V^{2}}{95 W}=3.8 \Omega
\end{gathered}
$$


The ratio by which the converter steps the output voltage above the input determines the amount of time the switches conduct, or duty cycle (4-2). This value, combined with the selected switching frequency, defines the control signal functions driving the switches in simulation with behavioral models. This equation provides an approximation without considering losses such as the voltage drop across the diode to the output. The model, while imperfect, still provides insight and aids in converter analysis.

$$
\begin{gathered}
D=1-\frac{V_{I N}}{V_{O U T}} \\
D=1-\frac{12 V}{19 V}=0.368
\end{gathered}
$$

\subsubsection{Inductor Size}

The converter's inductor stores and delivers energy to the load. Inductor size plays a key role in determining converter performance. Selection of the maximum peak to peak ripple of the inductor current allows approximation of a minimum inductance. A standard approximation assumes a ripple $40 \%$ of the maximum average inductor current as calculated in (4-3). In this case, the quantity divides by two to account for the current splitting between phases in a twophase converter. After determining the value of the ripple current, (4-4) gives the corresponding inductance for the specified ripple.

$$
\begin{aligned}
\Delta I_{L} & =40 \% \frac{I_{O(M A X)} \cdot V_{O U T}}{2 \cdot V_{I N}} \\
\Delta I_{L} & =40 \% \frac{5 \cdot 19}{2 \cdot 12}=1.583 \mathrm{~A}
\end{aligned}
$$




$$
\begin{gathered}
L=\frac{V_{I N} \cdot D}{\Delta i_{L} \cdot f} \\
L=\frac{12 \cdot 0.368}{1.583 \cdot 200 \mathrm{kHz}}=13.948 u \mathrm{H}
\end{gathered}
$$

Completing the process for using a $40 \%$ ripple gives a $13.9 \mu \mathrm{H}$ inductor. From this value, a $10 \mu \mathrm{H}$ inductor represents the closest most widely available standard size. Further analysis based on the shape of the charging and discharging inductor current waveform allows approximation of inductor current characteristics. Reflecting maximum output current back to the input side gives the maximum input current (4-5). Half of the total inductor current ripple (46) indicates the amount above average current the peak inductor current reaches. The peak current each inductor experiences includes half the maximum input current and half the ripple current (4-7). The rating for the inductors must consider the current they will carry. The saturation current of each inductor must be larger than the peak current at maximum load condition.

$$
\begin{gathered}
I_{I N(M A X)}=\frac{I_{O(M A X)}}{1-D_{M A X}} \\
\frac{\Delta i_{L}}{2}=\frac{\frac{V_{i n}}{L} * D T}{2} \\
I_{L(P E A K)}=\frac{I_{I N(A V G M A X)}}{2}+\frac{\Delta i_{L}}{2} \\
\frac{\Delta i_{L}}{2}=\frac{\frac{12}{10 u} * 0.368 * 5 u s}{2}=1.104 \mathrm{~A}
\end{gathered}
$$




$$
\begin{gathered}
I_{I N(M A X)}=\frac{5 A}{1-0.371}=7.956 A \\
I_{L(P E A K)}=\frac{7.956}{2}+1.104=5.082
\end{gathered}
$$

Values estimated by this analysis allow selection of properly rated inductors in the hardware selection portion of the design.

\subsubsection{Input Capacitor Size}

A capacitor at the input of the converter provides support against disruption in supply voltage. Operating frequency and relative acceptable variation in input voltage determine selected capacitance. A general equation estimates input capacitance (4-8). From this calculation, the standard value $22 \mu \mathrm{F}$ provides a standard value close to the estimation. Analysis of the input current waveform discussed in 4.1.1 describes the shape of the input capacitor current. Current calculations and voltage parameters determine the specific capacitor to select in the hardware design of the converter.

$$
\begin{gathered}
C_{\text {in }}=\frac{D \cdot T_{s}{ }^{2}}{8 L \cdot \frac{\Delta V_{I N}}{V_{I N}}} \\
C_{\text {in }}=\frac{0.368 \cdot(5 \mu \mathrm{s})^{2}}{8 \cdot(10 \mu \mathrm{H}) \cdot(0.005)}=23 \mu \mathrm{F}
\end{gathered}
$$

\subsubsection{Output Capacitor Selection}

The output capacitor filters the boosted voltage of the converter. Required capacitance depends on desired ripple performance. Equation (4-9) shows the general approximation of 
output capacitance based on desired percent output voltage ripple. From this calculation, the standard value $22 \mu \mathrm{F}$ again provides the most similar standard value. This value represents a starting point for use in initial circuit simulation.

$$
\begin{gathered}
C_{\text {out }}=\frac{D}{R \cdot \frac{\Delta V_{\text {out }}}{V_{\text {ouT }}} \cdot 2 f} \\
C_{\text {out }}=\frac{0.368}{3.8 \cdot 0.01 \cdot 2(200 \mathrm{k})}=24.2 \mu \mathrm{F}
\end{gathered}
$$

\subsection{Modified Boost Converter Design}

For meaningful comparison of the two topologies, primary component calculations made for the standard boost provide the basis of the modified boost design. The addition of the feedback capacitor and filter inductors results in the modified design. Selection of the feedback capacitor value uses output capacitance as the limiting factor. This decision ensures the additional capacitor does not more significantly contribute to converter size and weight. The standard $22 \mu \mathrm{F}$ value meets this specification. Desired inductance per phase totals to the inductance value chosen for the standard design. Choosing the closest available inductance yields two $4.7 \mu \mathrm{H}$ inductors per phase. Table $4-1$ shows a summary of design parameters for the standard and modified boost design simulations.

Table 4-1. Parameters for Converter Simulation Using Behavioral Models 


\begin{tabular}{|c|c|c|c|}
\hline \multicolumn{2}{|c|}{ Standard Boost Design } & \multicolumn{2}{|c|}{ Modified Boost Design } \\
\hline $\mathbf{V}_{\mathbf{I N}}$ & $12 \mathrm{~V}$ & VIN $_{\text {IN }}$ & $12 \mathrm{~V}$ \\
\hline Vout & $19 \mathrm{~V}$ & Vout & $19 \mathrm{~V}$ \\
\hline Pout & $95 \mathrm{~W}$ & Pout & $95 \mathrm{~W}$ \\
\hline fsw & $200 \mathrm{kHz}$ & fsw & $200 \mathrm{kHz}$ \\
\hline $\mathbf{R}$ & $3.8 \Omega$ & $\mathbf{R}$ & $3.8 \Omega$ \\
\hline \multirow{2}{*}{$\mathbf{L}$} & \multirow{2}{*}{$10 \mu \mathrm{H}$} & $\mathbf{L}_{1}$ & $4.7 \mu \mathrm{H}$ \\
\hline & & $\mathbf{L}_{2}$ & $4.7 \mu \mathrm{H}$ \\
\hline \multirow{2}{*}{ C } & \multirow{2}{*}{$22 \mu \mathrm{F}$} & $\mathbf{C}_{\mathrm{cm}}$ & $22 \mu \mathrm{F}$ \\
\hline & & $\mathbf{C}_{\text {out }}$ & $22 \mu \mathrm{F}$ \\
\hline
\end{tabular}

\subsection{Behavioral Model Multiphase Boost Converter Simulation}

After initial calculation of the primary boost converter components, a simulation using behavioral models provides a view of anticipated converter performance. Controlling ideal switch models with control signals derived from operating frequency and duty cycle allows analysis without selecting a controller. Figure 4-1 shows the standard multiphase boost converter comprised of two uncoupled inductors, two switches, two diodes, one input capacitor, one output capacitor and a modeling resistance to represent the load.

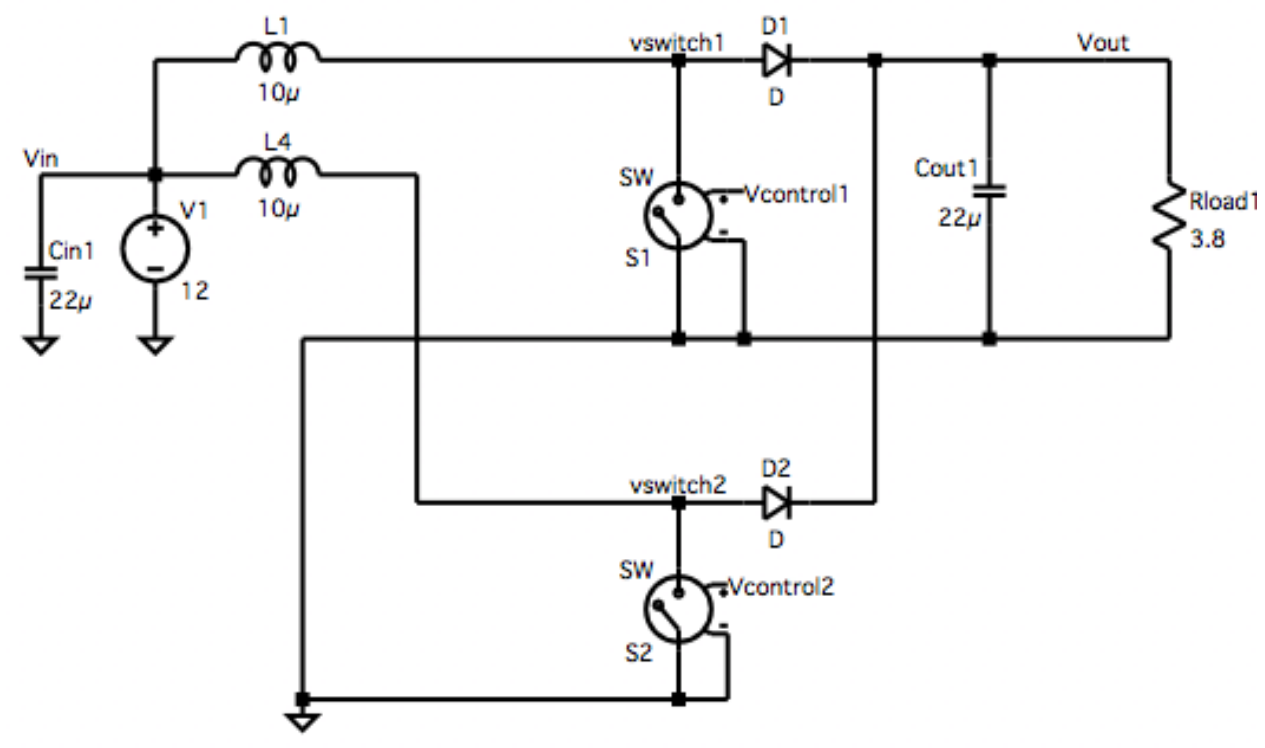


Figure 4-1. A Standard Multiphase Boost Converter

Figure 4-2 shows the small output ripple resulting from multiphase operation alongside corresponding switching signals operating out of phase. Figure 4-3 shows the undesirably large input current ripple through the inductor alongside output capacitor current and switch node voltage. Table 4-2 summarizes results of interest.

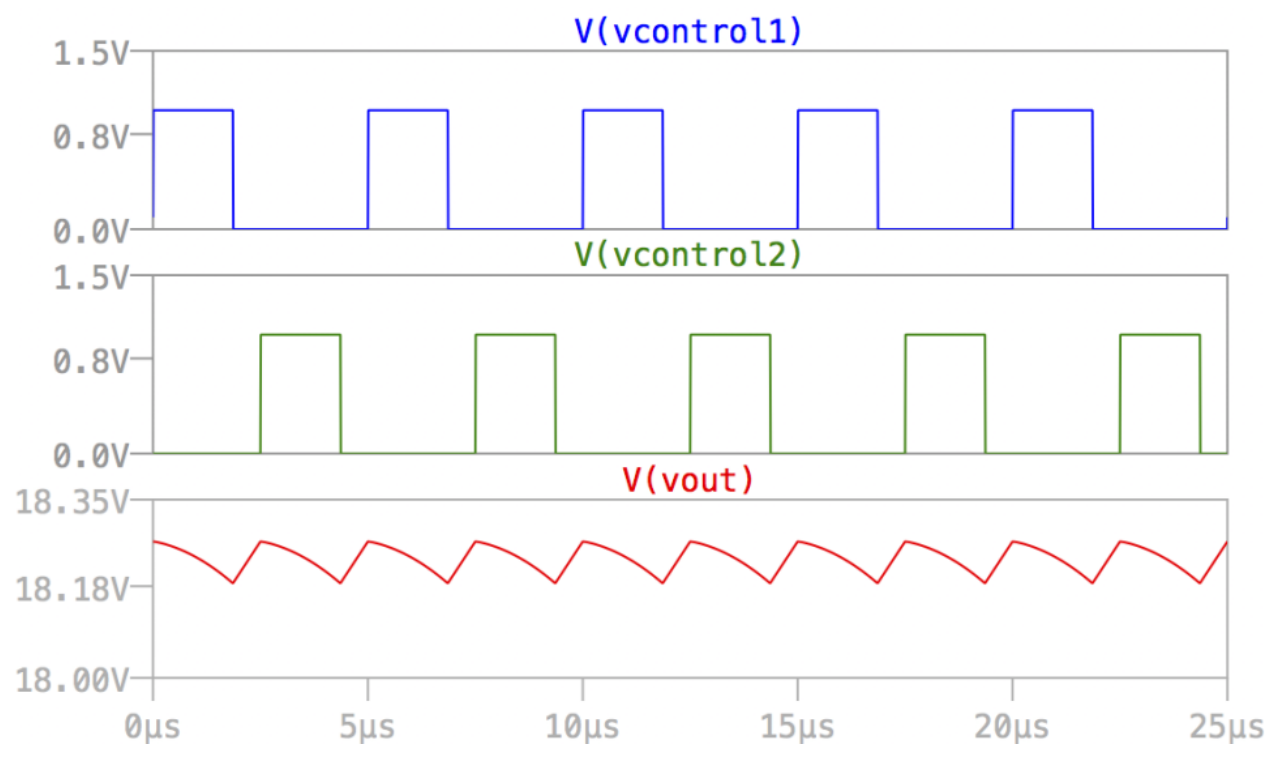

Figure 4-2. Output Voltage and Switch Control Signals of a Standard Multiphase Boost Converter

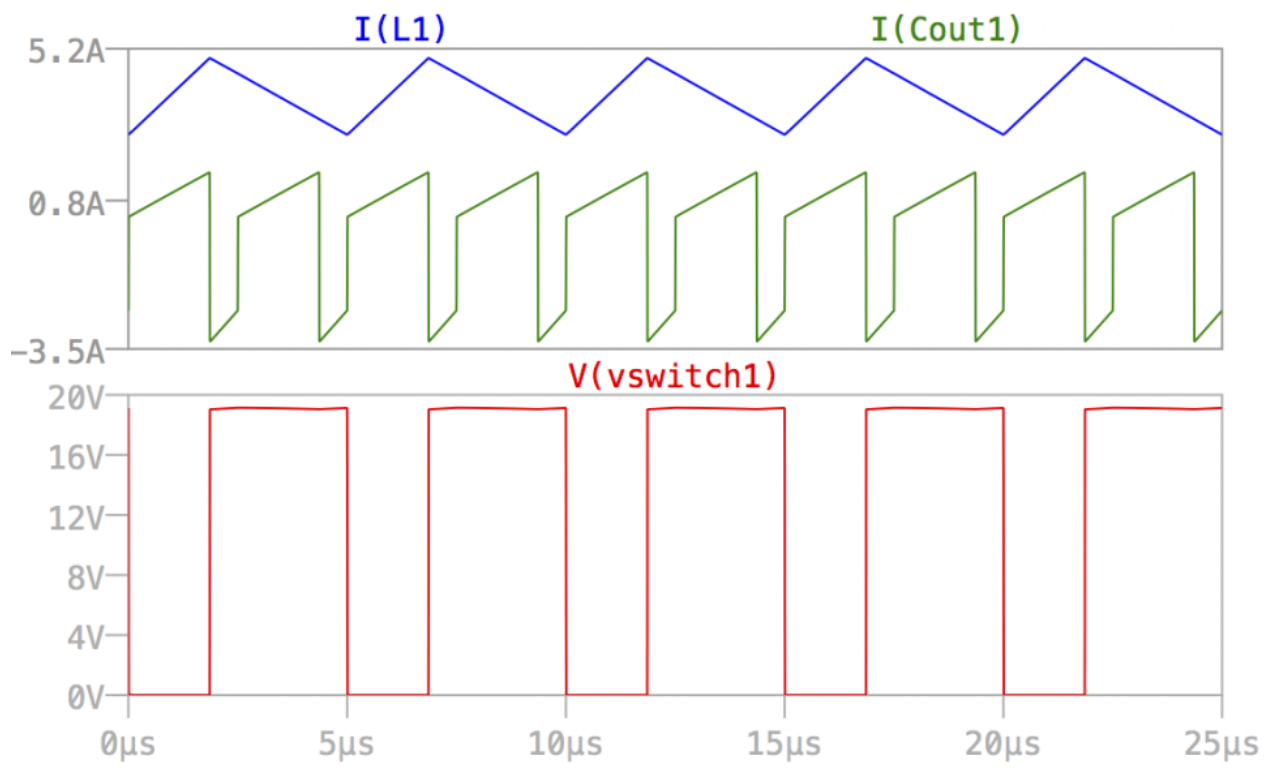


Figure 4-3. Switch Node Voltage, Inductor Current, and Output Capacitor Current of a Standard Multiphase Boost Converter

Table 4-2. Standard Multiphase Boost Converter Simulation Using Behavioral Switches Results

\begin{tabular}{|c|c|}
\hline $\begin{array}{c}\text { Standard Multiphase Boost } \\
\text { Parameter }\end{array}$ & $\begin{array}{c}\text { Simulated Value Using Behavioral } \\
\text { Switches }\end{array}$ \\
\hline$\Delta$ Vout (peak-peak) & $82.35 \mathrm{mV}$ \\
\hline$\Delta \mathbf{I}_{\mathbf{L} 1}$ (peak-peak) & $2.21 \mathrm{~A}$ \\
\hline IL1 $_{\text {(RMS) }}$ & $3.93 \mathrm{~A}$ \\
\hline IL1 $_{\text {(average) }}$ & $3.88 \mathrm{~A}$ \\
\hline ICin (RMS) & $101.89 \mathrm{pA}$ \\
\hline ICout $($ RMS) & $1.73 \mathrm{~A}$ \\
\hline
\end{tabular}

Using the primary design choices of the standard multiphase boost converter, splitting the inductors and adding feedback capacitors yields the modified multiphase boost design as shown in Figure 4-4. Inductors with smaller inductance values generally exhibit higher current ratings and smaller footprints. Figure 4-5 shows the output voltage and corresponding switching signals. The modification results in dramatically smaller input inductor current as shown in Figure 4-6.

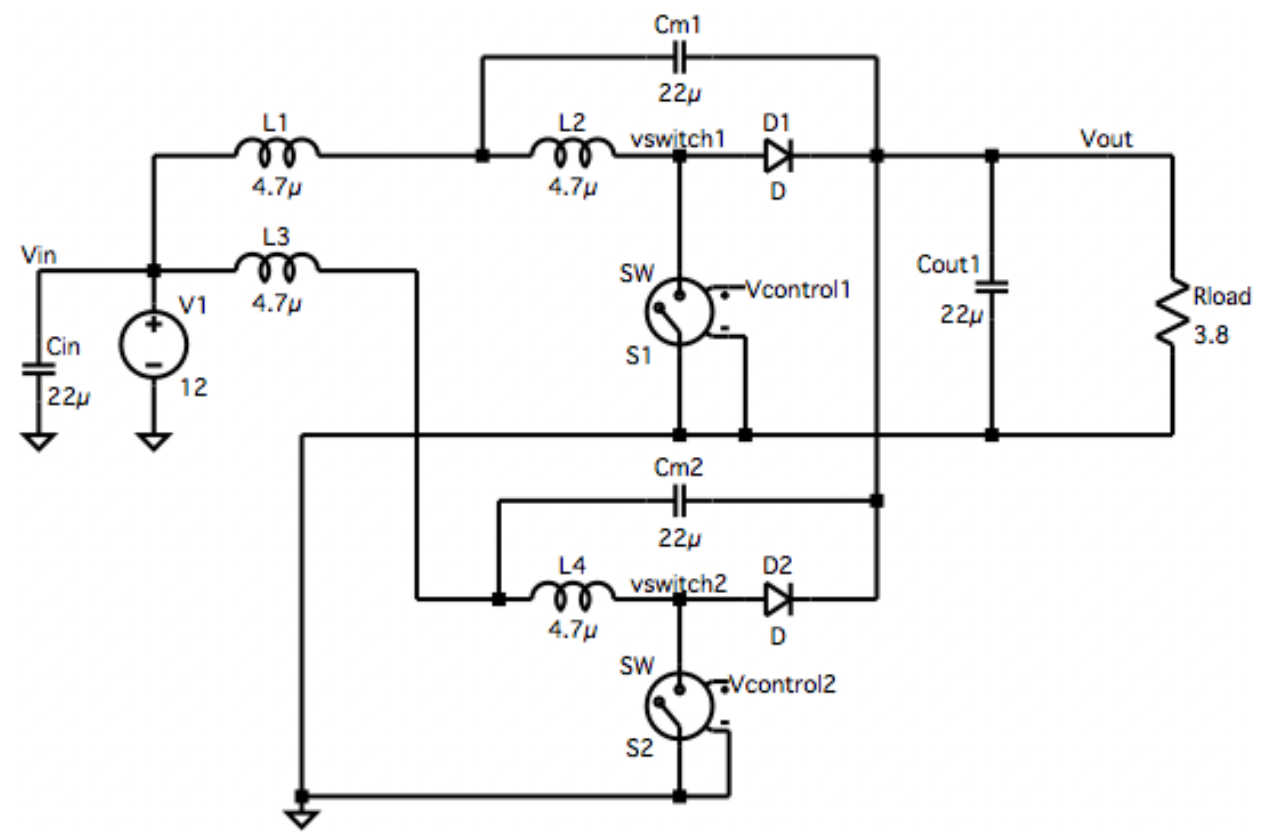

Figure 4-4. The Proposed Modified Multiphase Boost Converter 
While the modified design exhibits smaller input current ripple, basic converter operation remains similar to the standard converter. In addition to reduced input current ripple, the modified topology exhibits an altered shape of the output voltage ripple and corresponding output capacitor current. Other differences resulting from the modifications to the multiphase boost topology include slightly altered shape of the output voltage ripple and the corresponding current through the output capacitor as shown in Figures 4-5 and 4-6. Table 4-3 gives a summary of simulation results to aid in sizing components for the hardware implementation of the design.

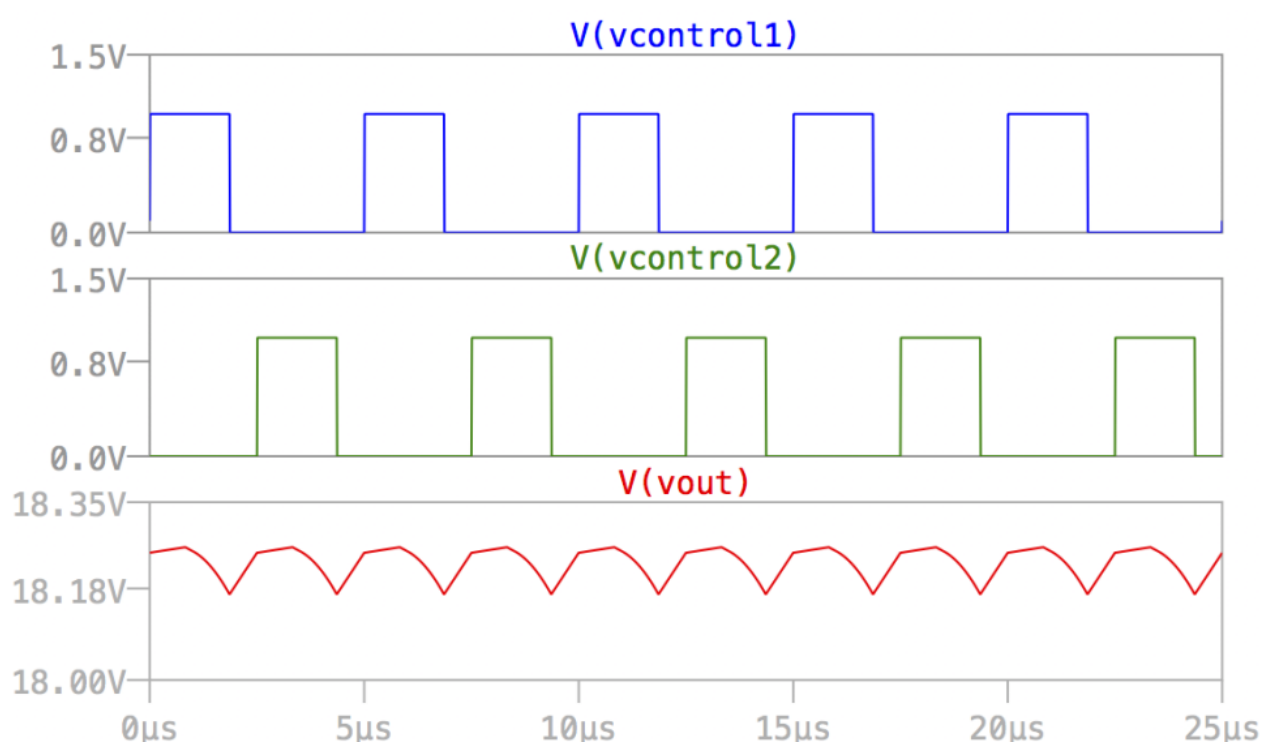

Figure 4-5. Output Voltage and Switch Control Signals of Modified Multiphase Boost Converter 

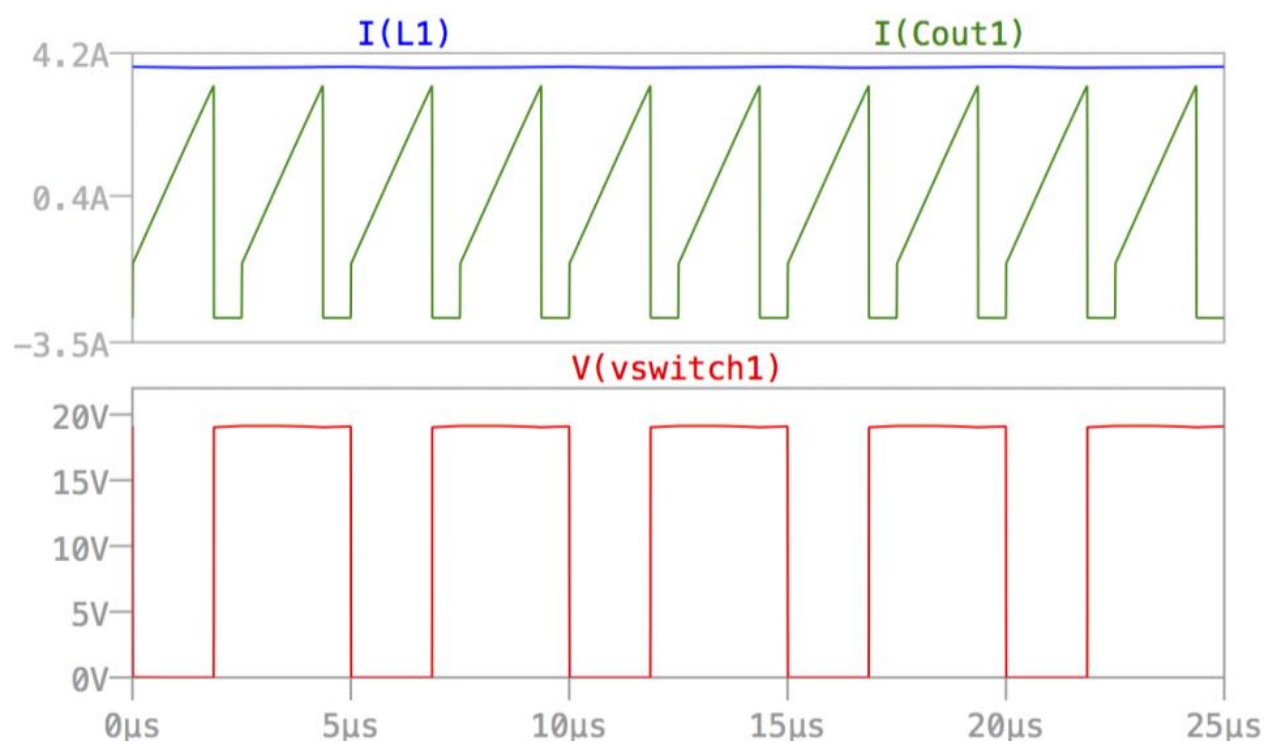

Figure 4-6. Switch Node Voltage, Inductor Current, and Output Capacitor Current of Modified Multiphase Boost Converter

Table 4-3. Modified Multiphase Boost Converter Simulation Using Behavioral Switches Results

\begin{tabular}{|c|c|}
\hline $\begin{array}{c}\text { Modified Multiphase Boost } \\
\text { Parameter }\end{array}$ & $\begin{array}{c}\text { Simulated Value Using Behavioral } \\
\text { Switches }\end{array}$ \\
\hline$\Delta \mathbf{V}_{\text {OUT }}$ (peak-peak) & $98.2 \mathrm{mV}$ \\
\hline$\Delta \mathbf{I}_{\mathbf{L} 1}$ (peak-peak) & $26.8 \mathrm{~mA}$ \\
\hline $\mathbf{I}_{\mathbf{L} 1}(\mathbf{R M S})$ & $3.83 \mathrm{~A}$ \\
\hline $\mathbf{I}_{\mathbf{L 1}}$ (average) & $3.82 \mathrm{~A}$ \\
\hline$\Delta \mathbf{I}_{\mathbf{L} 2}$ (peak-peak) & $4.74 \mathrm{~A}$ \\
\hline $\mathbf{I}_{\mathbf{L} 2}$ (RMS) & $4.19 \mathrm{~A}$ \\
\hline $\mathbf{I}_{\mathbf{L} 2}$ (average) & $3.951 \mathrm{~A}$ \\
\hline $\mathbf{I}_{\text {Cin }}$ (RMS) & $101.89 \mathrm{pA}$ \\
\hline $\mathbf{I}_{\text {Cout }}(\mathbf{R M S})$ & $2.05 \mathrm{~A}$ \\
\hline
\end{tabular}


Use of behavioral models for simulation provides a cursory evaluation of converter performance. Behavioral simulation allows confirmation of predicted component ratings. After establishing general requirements and design parameters, converter design proceeds with selection of a controller.

\subsection{Controller Design}

Parameters for controller selection consider cost, capabilities, and other features. The LT3782A provides two phases of operation. This part meets the specified power specifications with minimal unnecessary features. Controller operation requires a number of additional components to set converter behavior and provide feedback. Calculations of these components are specific to the controller and provided by the datasheet. Values of these components allow simulation with the actual controller model.

\subsubsection{Feedback Resistor Size}

The LT3782A uses a resistive divider from the output to monitor output voltage. A fraction of the output voltage inputs to the FB pin where it is compared to the controller's internal reference. Sufficiently high resistance, so as to not draw significant current from the output, and the relationship between output voltage and feedback resistors (4-10) guide feedback resistor selection.

$$
\begin{gathered}
V_{\text {OUT }}=2.44 *\left(1+\frac{R_{F 1}}{R_{F 2}}\right) \\
V_{\text {OUT }}=2.44 *\left(1+\frac{169 k}{24.9 k}\right)=19.0006 \mathrm{~V}
\end{gathered}
$$


Iterative calculation using available resistance values yields a close result to specified output voltage. Standard $1 \%$ resistor values of $169 \mathrm{k} \Omega$ and $24.9 \mathrm{k} \Omega$ set the output voltage.

\subsubsection{Sense Resistor Size}

In addition to voltage feedback from the output, the LT3782A uses sense resistors placed between the source of the MOSFETs and ground. The controller monitors the voltage at this node to approximate inductor current and prevents inductor saturation by shutting the gate off at a certain threshold. A simple RC filter filters out high frequency noise to prevent erroneously triggering switch shutoff. The controller limits the maximum voltage drop across the sense resistor to $63 \mathrm{mV}$. Current sense resistors are sized to allow the full output current without unintentionally triggering switch shutoff. Equation (4-11) provides parameters for maximum sense resistor calculation.

$$
\begin{gathered}
R \leq V_{\text {SENSE }(M A X)} \frac{1-D_{M A X}}{1.2 \frac{I_{O(M A X)}}{2}} \\
R \leq 63 \mathrm{mV} \frac{1-.371}{1.2 \frac{5}{2}}=13.2 \mathrm{~m} \Omega
\end{gathered}
$$

This equation provides a maximum value for the sense resistance. Using the calculated value as a starting maximum value, sense resistance is decreased until desired performance is achieved.

\subsubsection{Controller Simulation}

The simulation software LTspice provides models of various controllers, passive, and active components. Using calculated values, the planned circuit is built and analyzed. Figure 4-7 
shows the LTspice schematic of the standard version of the proposed multiphase boost converter. Notable variations between values shown in the schematic and those calculated from the generic equations include sense resistance, which requires reduction to $10 \mathrm{~m} \Omega$ to provide full output current. Additionally, parallel combinations of smaller capacitance values replace the single input and output capacitors. In the actual hardware implementation, capacitor selection requires consideration of ESR. This configuration places the ESR of each capacitor in parallel, reducing total ESR and associated losses. The simulation also uses a smaller soft start capacitor than hardware implementation for reduction in simulation time.

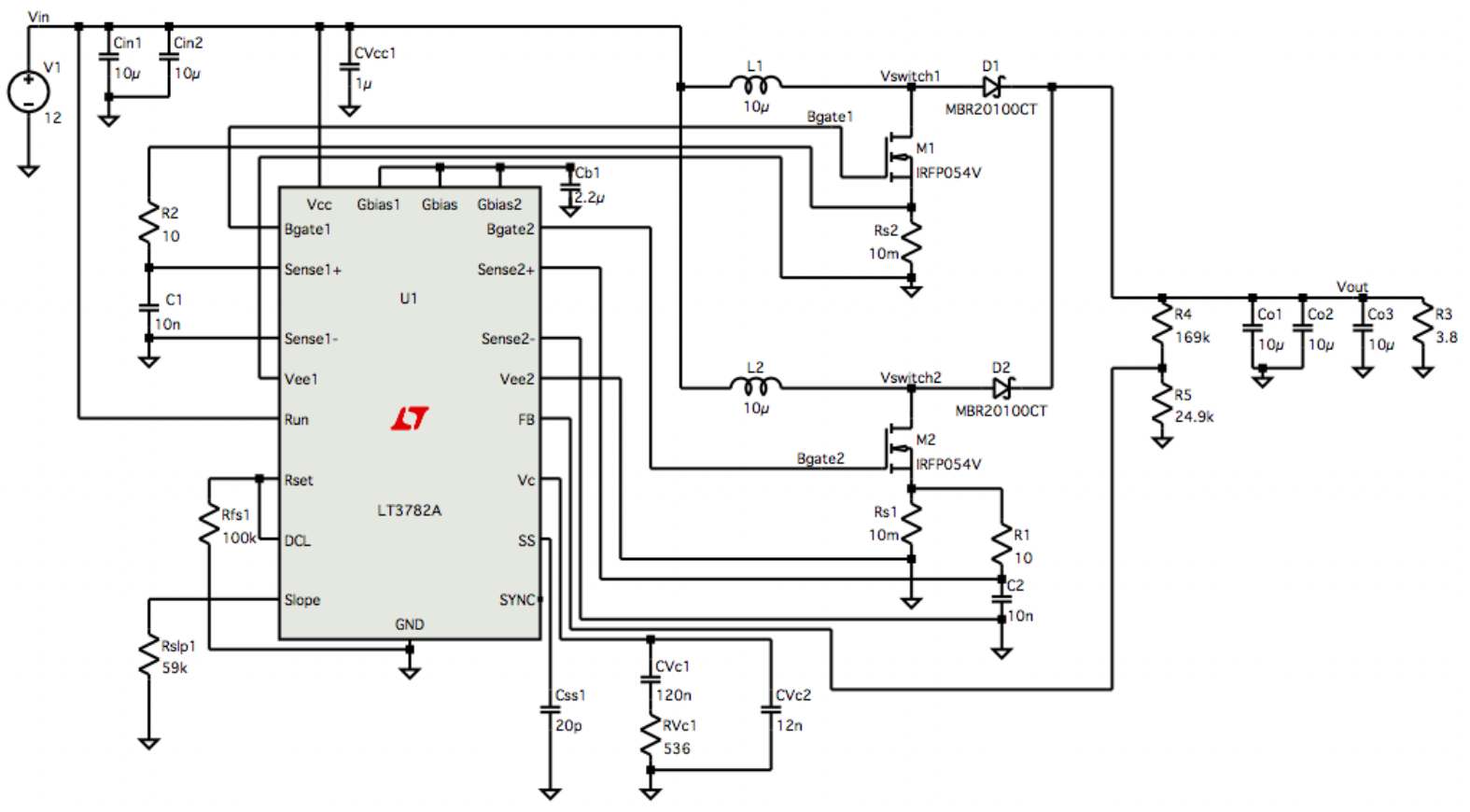

Figure 4-7. LT3782A Standard Multiphase Boost Converter Schematic

The simulation runs for $30 \mathrm{~ms}$ to verify stability. The converter reaches steady state after approximately $12 \mathrm{~ms}$. Observing a few cycles near the end of the simulation provides a good view of steady state behavior. Figure 4-8 shows the output voltage and the switching signals of the MOSFETS. Figure 4-9 shows the voltage at the first switch node, current through the 
inductor of the first phase, and current through the first output capacitor. Table 4-4 shows a summary of notable simulation results.

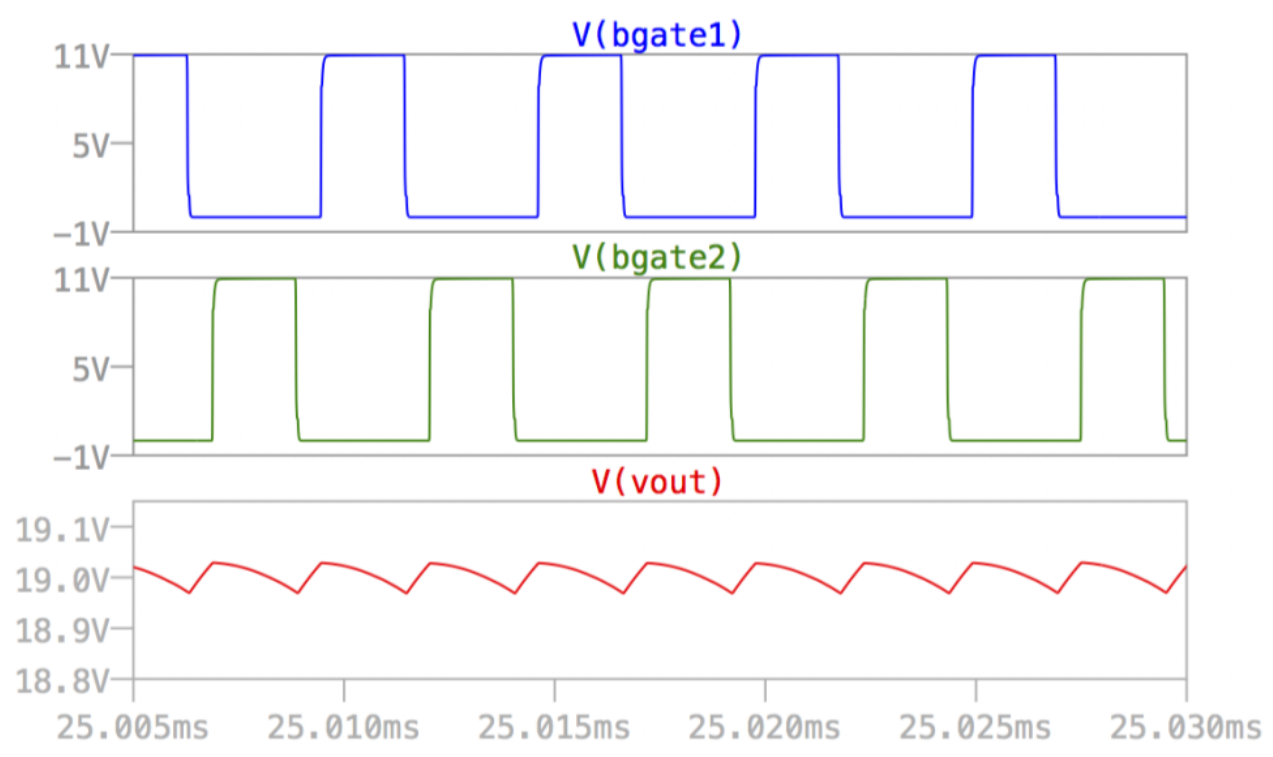

Figure 4-8. Output Voltage and Switch Control Signals of LT3782A Standard Boost Converter

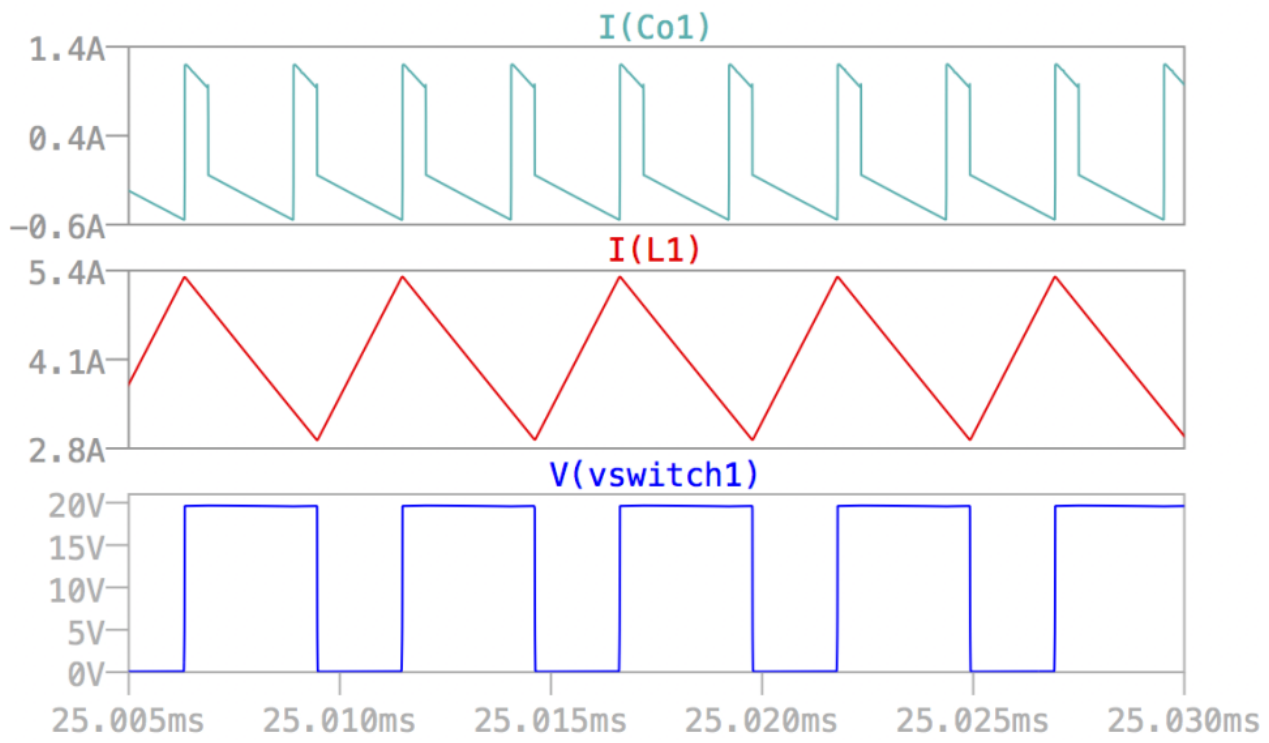

Figure 4-9. Switch Node Voltage, Inductor Current, and Output Capacitor Current of LT3782A Standard Boost Converter 
Table 4-4. Standard Multiphase Boost Converter Simulation Using Controller Model

\begin{tabular}{|c|c|}
\hline $\begin{array}{c}\text { Standard Multiphase Boost } \\
\text { Parameter }\end{array}$ & $\begin{array}{c}\text { Simulated Value Using LT3782A } \\
\text { Model }\end{array}$ \\
\hline$\Delta$ Vout (peak-peak) & $59.6 \mathrm{mV}$ \\
\hline$\Delta \mathbf{I}_{\mathbf{L} 1}$ (peak-peak) & $2.35 \mathrm{~A}$ \\
\hline $\mathbf{I}_{\mathbf{L} 1}$ (RMS) & $4.197 \mathrm{~A}$ \\
\hline IL1 $_{\text {(average) }}$ & $4.14 \mathrm{~A}$ \\
\hline ICin $_{\text {(RMS) }}$ & $39.61 \mathrm{pA}$ \\
\hline ICout (RMS) & $586.42 \mathrm{~A}$ \\
\hline$\Delta$ IIN (peak-peak) & $832.45 \mathrm{~mA}$ \\
\hline IIN (average) & $8.21 \mathrm{~A}$ \\
\hline
\end{tabular}

Simulation with the controller again exhibited the small output voltage ripple provided by the frequency increase from two phases of operation. Reading current through one of the inductors shows the undesirable large current ripple.

Simulation of the modified multiphase boost uses the same feedback components selected for the standard boost. As previously discussed, addition of the feedback capacitors and splitting of the inductors yields the modified design shown in Figure 4-10. Figure 4-11 shows the output voltage and the switching signals of the MOSFETS. The ripple exhibits a different shape than that of the standard due to the filtering effects of the additional components. Figure 4-12 shows the voltage at the first switch node, current through both inductors of the first phase, and current through the first output capacitor. 


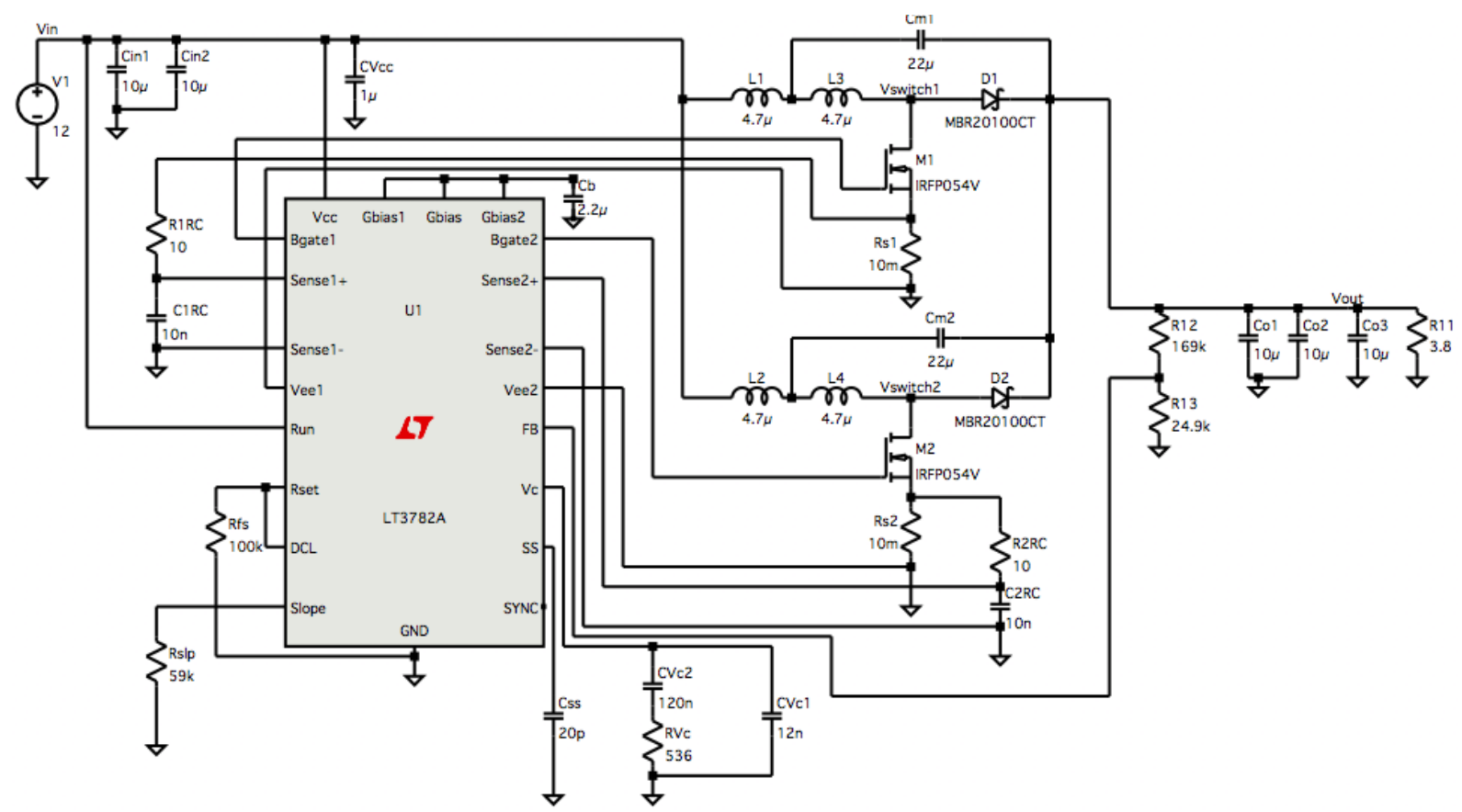

Figure 4-10. LT3782A Modified Multiphase Boost Converter Schematic
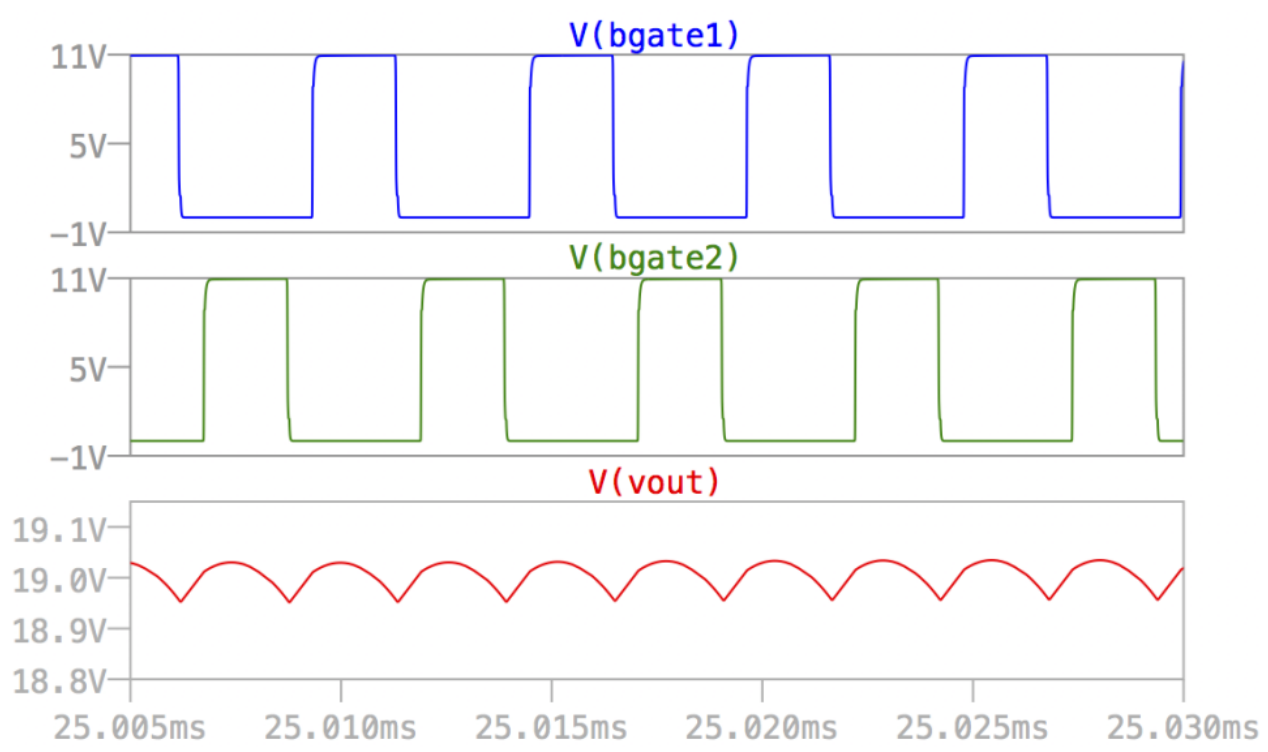

Figure 4-11. Output Voltage and Switch Control Signals of LT3782A Modified Multiphase Boost Converter 


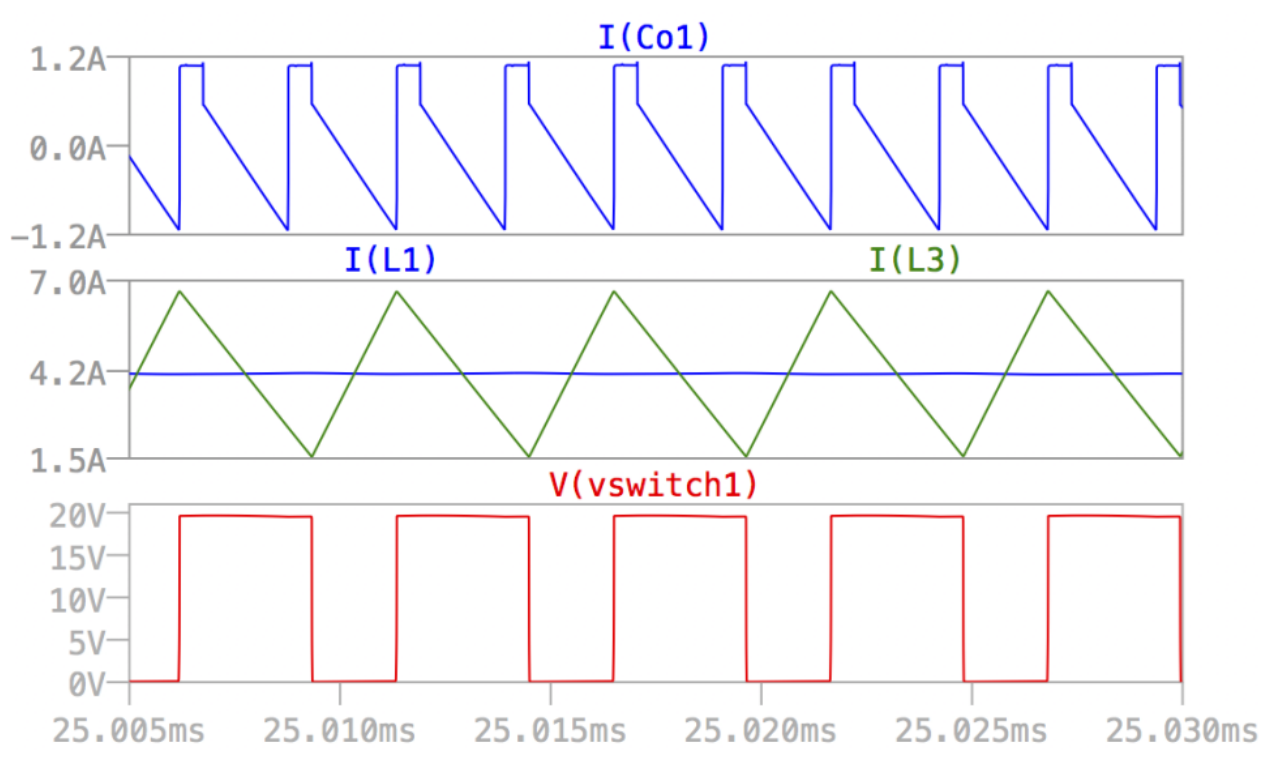

Figure 4-12. Switch Node Voltage, Inductor Current, and Output Capacitor Current of LT3782A Modified Multiphase Boost Converter

The modification provides dramatic reduction in input current ripple and a large current ripple in the second inductor. While the secondary inductor of the modified multiphase boost shows nearly twice the current ripple experienced by the inductors of the standard multiphase boost, the ripple remains internal to the converter and does not spread to the input or output nodes. Table 4-5 summarizes simulation measurements corresponding to required hardware component sizing. 
Table 4-5. Modified Multiphase Boost Converter Simulation Using Controller Model

\begin{tabular}{|c|c|}
\hline $\begin{array}{l}\text { Modified Multiphase Boost } \\
\text { Parameter }\end{array}$ & $\begin{array}{c}\text { Simulated Value Using LT3782A } \\
\text { Model }\end{array}$ \\
\hline$\Delta$ VouT (peak-peak) & $78.1 \mathrm{mV}$ \\
\hline$\Delta \mathrm{I}_{\mathrm{L1}}$ (peak-peak) & $32.7 \mathrm{~mA}$ \\
\hline IL1 $($ RMS $)$ & $4.12 \mathrm{~A}$ \\
\hline IL1 (average) & $4.12 \mathrm{~A}$ \\
\hline$\Delta \mathbf{I}_{\mathrm{L} 2}$ (peak-peak) & $5.1 \mathrm{~A}$ \\
\hline$I_{L 2}(R M S)$ & $4.41 \mathrm{~A}$ \\
\hline IL2 AVG (average) & $4.16 \mathrm{~A}$ \\
\hline ICin $_{\text {(RMS) }}$ & $48.14 \mathrm{pA}$ \\
\hline ICout (RMS) & $726.7 \mathrm{~mA}$ \\
\hline$\Delta \mathbf{I}_{\mathrm{IN}}$ (peak-peak) & $98.9 \mathrm{~mA}$ \\
\hline IIN (average) & $8.24 \mathrm{~A}$ \\
\hline
\end{tabular}

Measurements from simulation allow comparison of important metrics. Table 4-6 shows a summary of the simulation result parameters of interest. Results using the controller model agree with those provided by simulation with behavioral models. Simulations confirm the dramatic input current ripple reduction capabilities of the modified multiphase converter with minimal detriment to output voltage ripple.

Table 4-6. Summary of Simulation Results

\begin{tabular}{|c|c|c|c|c|}
\hline \multirow{2}{*}{$\begin{array}{c}\text { Simulation } \\
\text { Parameter }\end{array}$} & \multicolumn{2}{|c|}{ Standard Multiphase Boost } & \multicolumn{2}{c|}{ Modified Multiphase Boost } \\
\cline { 2 - 5 } & $\begin{array}{c}\text { Controller } \\
\text { Model }\end{array}$ & $\begin{array}{c}\text { Behavioral } \\
\text { Model }\end{array}$ & $\begin{array}{c}\text { Controller } \\
\text { Model }\end{array}$ & $\begin{array}{c}\text { Behavioral } \\
\text { Model }\end{array}$ \\
\hline$\% \Delta$ VouT & 0.313 & 0.476 & 0.411 & 0.546 \\
\hline$\% \Delta \mathbf{I}_{\text {LPhase1 }}$ & 56.76 & 56.95 & $0.793,122.5$ & $0.701,119.9$ \\
\hline$\% \Delta \mathbf{I}_{\text {IN }}$ & 10.13 & 11.85 & $1.2 \%$ & 0.331 \\
\hline
\end{tabular}

Simulation using the controller model allows comparison with simulation using behavioral switches. The results verify the controller's capability to provide the desired control signals. Probing of simulated switching signals reflect the desired switching frequency and exhibit the 
$180^{\circ}$ phase shift between phases as expected of multiphase operation. Use of the controller model confirms selected values for feedback resistors, sense resistors, and the frequency setting resistor. While values may require alteration in the hardware stage, simulation verifies initial component value selection. Simulated current and voltage waveforms provide another benchmark for sizing components and determining required ratings as required in the hardware design. Converter design proceeds with hardware implementation, aided by values determined by analysis and simulation. 


\section{HARDWARE}

Following initial component estimations, detailed analysis facilitates final component selection. Adequate voltage and current ratings as well as performance and availability determine acquisition of power components. A controller capable of multiphase operation and sufficient power delivery determines the remainder of the design. The datasheet describes external components required to set controller operation. Following PCB fabrication and population, testing allows observation and comparison of the standard and modified topologies.

\subsection{Power Component Selection}

Preliminary analysis of converter specifications provides a general description of the critical boost converter components. Suitable parts require current and voltage ratings higher than predicted by analysis and simulation to account for transient behavior as well as derating with change in temperature and applied voltage. The components of modified converter experience similar stresses to those of the standard, due to their similar mode of operation. Similar components also allow for more meaningful comparison of performance.

\subsubsection{Inductor Selection}

Calculations based on converter parameters in Section 4.1.1 yield the $10 \mu \mathrm{H}$ inductance value for standard multiphase boost design. For the modified multiphase boost, two $4.7 \mu \mathrm{H}$ inductors offer an effective total inductance comparable to the standard multiphase boost. In addition to inductance, expected current values determine inductor selection. Equation 5-1 approximates the peak anticipated current in the inductors to determine the minimum viable saturation current specification [17]. 


$$
\begin{gathered}
I_{S A T} \geq \frac{\Delta I_{L}}{2}+\frac{I_{I N}}{2}=70 \% \cdot \frac{I_{O U T(M A X)} \cdot V_{O U T}}{V_{I N(M I N)}} \\
I_{S A T} \geq 70 \% \cdot \frac{5 A \cdot 19 \mathrm{~V}}{10.8 \mathrm{~V}}=6.157 \mathrm{~A}
\end{gathered}
$$

For meaningful comparison of results, both designs use inductors from the same manufacturer and series [18]. The Wurth WE-HCC high current inductor series offers high DC current and saturation current ratings as well as the two desired inductance values. Table 5-1 shows the selected parts and their respective ratings.

Table 5-1. Inductor Selection WE-HCC High Current Inductor Series

\begin{tabular}{|c|c|c|c|c|c|c|}
\hline Part Number & Inductance & IDC & IsAT & DCRMAx & Tolerance & Size \\
\hline 7443320470 & $4.7 \mu \mathrm{H}$ & $15.5 \mathrm{~A}$ & $17 \mathrm{~A}$ & $7.9 \mathrm{~m} \Omega$ & $20 \%$ & $12.10 \mathrm{~mm} \times 11.40 \mathrm{~mm}$ \\
\hline 7443321000 & $10 \mu \mathrm{H}$ & $9 \mathrm{~A}$ & $10 \mathrm{~A}$ & $16.7 \mathrm{~m} \Omega$ & $20 \%$ & $12.10 \mathrm{~mm} \times 11.40 \mathrm{~mm}$ \\
\hline
\end{tabular}

The increased current ripple in the second inductor of the modified boost converter poses the greatest concern. The modified topology nearly doubles the current ripple in the second inductor. Based on simulation, the second inductor experiences a maximum of 4.1A, well within range of the $15.5 \mathrm{~A}$ rating of the selected part.

$$
\begin{gathered}
P_{R(\text { WINDING })}=\left(\frac{\frac{I_{O(M A X)}}{2}}{1-D_{M A X}}\right)^{2} \cdot R_{W} \\
P_{R(\text { WINDING }) \text { Standard }}=\left(\frac{\frac{5 A}{2}}{1-0.371}\right)^{2} \cdot 16.7 \mathrm{~m} \Omega=762.41 \mathrm{nW} \\
P_{R(\text { WINDING }) \text { Modified }}=\left(\frac{\frac{5 A}{2}}{1-0.371}\right)^{2} \cdot 7.9 \mathrm{~m} \Omega=360.66 \mathrm{nW}
\end{gathered}
$$


Equation 5-2 estimates power dissipated in the inductors based on multiphase boost converter operation [17]. The results indicate an acceptable amount of dissipation without excess, which could result in overheating and increased thermal resistance.

\subsubsection{Switch and Diode}

While ideal analysis of converter operation indicates voltage stress no greater than the output voltage level, the switching node often experiences ringing and overshoot during converter operation. Generously oversized components safeguard against these conditions. Power dissipation, determined by factors such as gate capacitance of the switch and forward voltage drop of the diode, also influences component selection. Based on converter operation, the switches and diodes of each topology must conduct the same DC current. Table 5-2 lists the selected parts and compares their current and voltage ratings to anticipated requirements. These ratings are derived from boost converter operation and the expected duty cycle of the switch [19] [20].

Table 5-2. Switch and Diode Selection

\begin{tabular}{|c|c|c|c|c|c|}
\hline Component & Part Number & $\begin{array}{c}\text { Rated } \\
\text { Voltage }\end{array}$ & $\begin{array}{c}\text { Rated } \\
\text { Current }\end{array}$ & $\begin{array}{c}\text { Expected } \\
\text { Voltage }\end{array}$ & $\begin{array}{c}\text { Expected } \\
\text { Current }\end{array}$ \\
\hline MOSFET & IRF60B217-ND & $60 \mathrm{~V}$ & $60 \mathrm{~A}$ & $19 \mathrm{~V}$ & $0.921 \mathrm{~A}$ \\
\hline Diode & MBR10100GOS-ND & $100 \mathrm{~V}$ & $10 \mathrm{~A}$ & $19 \mathrm{~V}$ & $1.58 \mathrm{~A}$ \\
\hline
\end{tabular}

Anticipated forward diode voltage at specified output current from the datasheet allows approximation of power dissipation [17] [19].

$$
P_{\text {Diode }}=\frac{I_{O(M A X)}}{2} \cdot V_{D}=\frac{5}{2} \cdot 550 m V=1.375 W
$$


While the calculation according to Equation 5-3 yields a substantial quantity, the MBR10100GOS-ND specified one of the smallest forward voltages amongst other diodes of similar voltage and current ratings. The total $2.75 \mathrm{~W}$ of the $95 \mathrm{~W}$ output also represents a small percentage of output power.

The IRF60B217-ND specifies a 6V to $10 \mathrm{~V}$ drive voltage, a value compatible with most standard controllers. The part also exhibits a desirably minimal on resistance compared to similarly rated MOSFETs. Equation 5-4 estimates power dissipation in the switch based on converter operation and switch parameters [17].

$$
\begin{gathered}
P_{F E T}=\left(\frac{\frac{I_{O(M A X)}}{2}}{1-D_{M A X}}\right)^{2} \cdot R_{D S(O N)} \cdot D_{M A X} \cdot \rho_{T}+k \cdot V_{O}^{2} \cdot \frac{\frac{I_{O(M A X)}}{2}}{1-D_{M A X}} \cdot C_{R S S} \cdot f \quad(5-4) \\
P_{F E T}=\left(\frac{\frac{5 A}{2}}{1-0.371}\right)^{2} \cdot 7.9 \mathrm{~m} \Omega \cdot 0.371 \cdot 0.4 \% /{ }^{\circ} \mathrm{C}+1.7 \cdot 19 \mathrm{~V}^{2} \cdot \frac{\frac{5 A}{2}}{1-0.371} \cdot 140 \mathrm{pF} \cdot 200 \mathrm{kHz} \\
=58.694 \mathrm{~mW}
\end{gathered}
$$

\subsubsection{Capacitors}

After selection of capacitance value, voltage and RMS current ratings determine capacitor selection. Ceramic capacitors provide low profile and low ESR. Parallel combinations of smaller valued capacitances provide desired total capacitance with additional reduction in ESR. An additional bulk electrolytic capacitor on the output provides improved stability. Table 5-3 shows the two types of capacitors acquired for the converters and their specifications. Table 5-4 lists the required boost converter capacitors, the worst-case RMS current observed during simulation, and the configuration of parts to supply the desired capacitance. 
Table 5-3. Capacitor Selection

\begin{tabular}{|c|c|c|c|c|c|}
\hline Part Number & Capacitance & Rated Voltage & Type & Tolerance & Package \\
\hline 1276-6767-1-ND & $10 \mu \mathrm{F}$ & $50 \mathrm{~V}$ & X7R & $10 \%$ & 1206 \\
\hline UVR1V470MDD & $22 \mu \mathrm{F}$ & $50 \mathrm{~V}$ & $\begin{array}{c}\text { Aluminum } \\
\text { Electrolytic }\end{array}$ & $20 \%$ & Radial \\
\hline
\end{tabular}

Table 5-4. Capacitor Selection Configurations

\begin{tabular}{|c|c|c|c|c|}
\hline Component & Capacitance & $\begin{array}{c}\text { Worst-Case } \\
\text { RMS Current }\end{array}$ & Configuration & Part Number \\
\hline Input Capacitor & $20 \mathrm{uF}$ & $48.14 \mathrm{pA}$ & $10 \mathrm{uF} \times 2$ & $1276-6767-1-\mathrm{ND}$ \\
\hline $\begin{array}{c}\text { Modified Feedback } \\
\text { Capacitor }\end{array}$ & $30 \mathrm{uF}$ & $1.47 \mathrm{~A}$ & $10 \mathrm{uF} \times 3$ & $1276-6767-1-\mathrm{ND}$ \\
\hline $\begin{array}{c}\text { Output Capacitor and } \\
\text { Bulk Capacitance }\end{array}$ & $20 \mathrm{uF}$ & $726.7 \mathrm{~mA}$ & $10 \mathrm{uF} \times 2$ & $1276-6767-1-\mathrm{ND}$ \\
\hline
\end{tabular}

The parallel configuration allows reuse of one type of capacitor at different stages of the converter reducing part count. The 1206 package size offers increased component robustness and exhibits less leakage current than smaller packages. ESR reduction by parallel configuration minimizes losses in the capacitors.

\subsection{Controller Design}

Operation of the multiphase converter requires two phase shifted gate drive signals. A variety of controllers provide multiphase operation or could be synchronized with one controller per phase. The LT3784A provides multiphase operation and senses inductor current indirectly using a resistor in the switch path as opposed to direct sensing through a resistor in the inductor path. Configuration of the controller provides enough flexibility for use in both topologies. In addition to external power components, a number of external passives determine converter 
behavior. The datasheet estimates power dissipation in the controller as a function of the supply voltage, as well as gate capacitance of the selected switches. Equations 5-5 and 5-6 use these parameters to approximate the controller power dissipation [17].

$$
\begin{gathered}
I_{Q(\text { (тOT) }} \approx I_{Q}=f \cdot Q_{G} \\
P_{I C}=V_{I N} \cdot\left(I_{Q}+f \cdot Q_{G}\right) \\
I_{Q(T O T)} \approx I_{Q}=200 \mathrm{kHz} \cdot 44 \mathrm{nC}=8.8 \mathrm{~mA} \\
P_{I C}=12 \mathrm{~V} \cdot(11 \mathrm{~mA}+200 \mathrm{kHz} \cdot 44 \mathrm{nC})=237.6 \mathrm{~mW}
\end{gathered}
$$

\subsubsection{Voltage Feedback}

The LT3784A uses a reference voltage and voltage divider to set output voltage as discussed in Chapter 4. Resistors for the feedback network require large enough values to prevent excessive power dissipation while providing an accurate output voltage. From Equation $4-10$, the standard $1 \%$ resistor values of $169 \mathrm{k} \Omega$ and $24.9 \mathrm{k} \Omega$ provide an output voltage within the required tolerance.

\subsubsection{Operating Frequency}

An external resistor connected between the FREQ pin and ground sets the switching frequency of each phase. Figure 5-1 shows the relationship between resistance and switching frequency as provided by the datasheet. A $100 \mathrm{k} \Omega$ resistor produces a switching frequency close to the desired $200 \mathrm{kHz}$. 


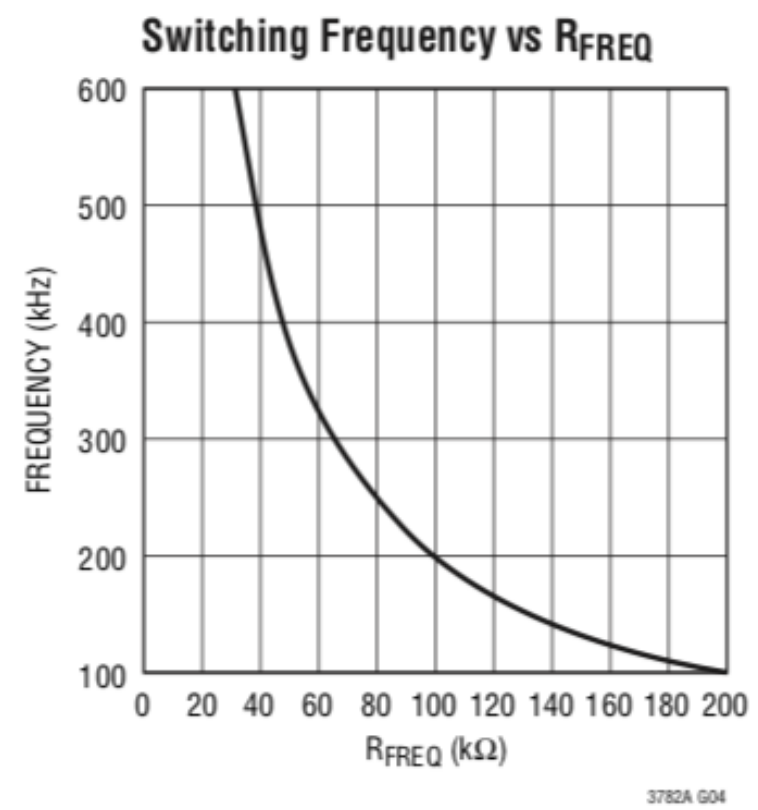

Figure 5-1: Switching Frequency vs $\mathrm{R}_{\text {freq }}[17]$

\subsubsection{Current Sensing}

In addition to voltage feedback from the output, the controller monitors inductor current using sense resistors place between the MOSFET source and ground. The controller limits voltage drop across the sense resistor to approximately $63 \mathrm{mV}$ while the switch conducts [17].

Figure 5-2 shows the connection of the sensing resistor, RSENSE, to the MOSFET for one phase of the controller. Components $\mathrm{R}_{1}$ and $\mathrm{C}_{1}$ form a low pass filter for prevention of current limit triggering caused by noisy or transient current spikes. 


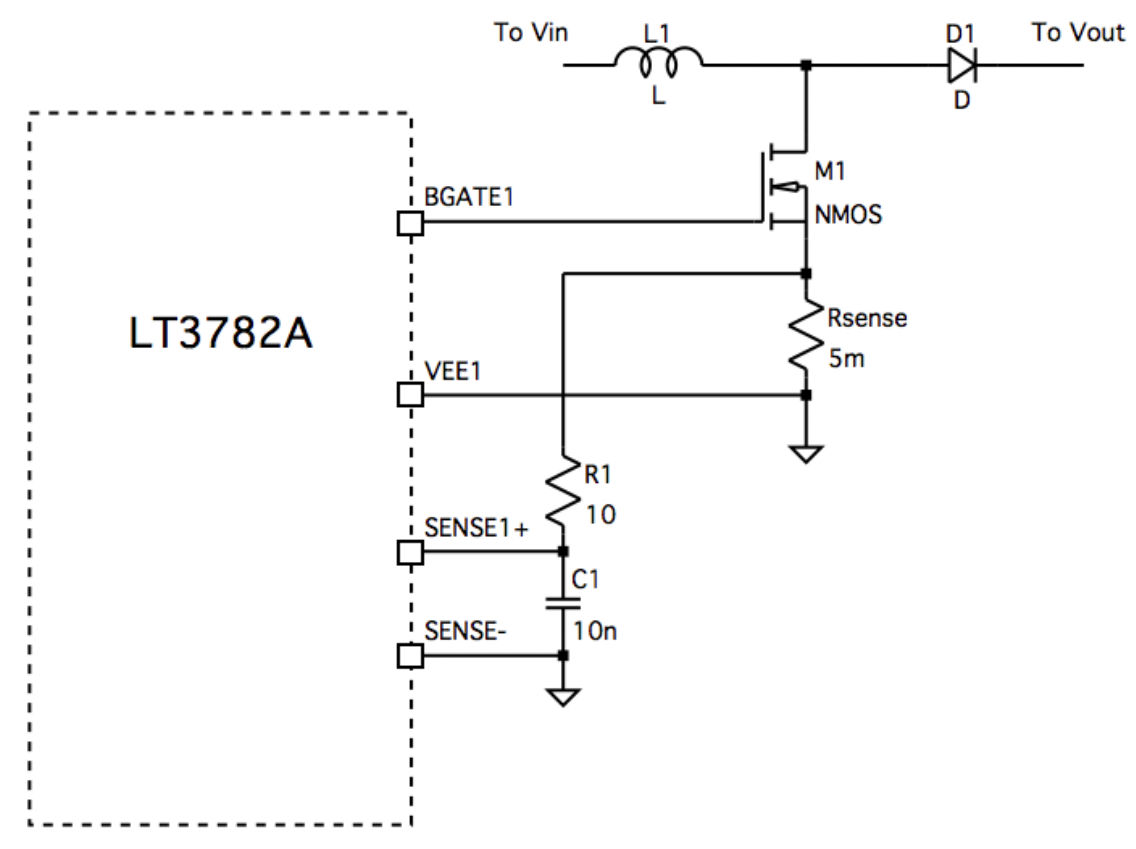

Figure 5-2: LT3286A External Current Sensing Component Connections

As discussed in Chapter 4, Equation 4-1 estimates the maximum sense resistance to be around $13 \mathrm{~m} \Omega$. Due to actual converter operation and load conditions, the equation provides a minimum value. During physical implementation the value $5 \mathrm{~m} \Omega$ provides the desired output current limit. Equation 5-7 estimates power dissipated in the sense resistors [17].

$$
P_{R(S E N S E)}=\left(\frac{\frac{I_{O(M A X)}}{2}}{1-D_{M A X}}\right)^{2} \cdot R \cdot D_{M A X}=\left(\frac{\frac{5 A}{2}}{1-0.371}\right)^{2} \cdot 5 m \Omega \cdot 0.371=29.3 m W \quad(5-7)
$$

\subsubsection{Controller Startup}

The LT3286 provides soft start by connecting a capacitor to ground on the SS pin. The relationship between capacitance and startup time is shown in Equation 5-8 as provided by the datasheet [17]. A 6800pF capacitor provides a datasheet recommended startup time of $1.659 \mathrm{msec}$. 


$$
t=\frac{C \cdot 2.44 \mathrm{~V}}{10 \mu \mathrm{A}}=\frac{6800 \mathrm{pF} \cdot 2.44 \mathrm{~V}}{10 \mu \mathrm{A}}=1.659 \mathrm{msec}
$$

The controller allows programmable run voltage to only start up when presented with adequate input voltage. The controller activates only when the voltage on $\mathrm{V}_{\text {RUN }}$ exceeds $2.45 \mathrm{~V}$ and shuts down at a voltage lower than $0.3 \mathrm{~V}$ with $80 \mathrm{mV}$ of hysteresis. A voltage divider between the input and run pin controls converter turn on [17]. The standard $1 \%$ values of $835 \mathrm{k} \Omega$ and $274 \mathrm{k} \Omega$ provide turn on at $9.91 \mathrm{~V}$ and turn off at $1.21 \mathrm{~V}$.

\subsubsection{Compensation}

Additional components provide loop compensation for the controller. The $\mathrm{V}_{\mathrm{C}}$ pin (pin 15) is the output of the error amplifier, which compares the divided down output voltage on the FB pin (pin 16) to the internal reference voltage. Equation 5-9 shows the approximation of the right half plane zero based on the converter specifications [5]. Equation 5-10 defines the desired crossover frequency a decade below the right half plane zero.

$$
\begin{gathered}
f_{z-R H P}=\frac{R\left(\frac{V_{I N}}{V_{\text {OUT }}}\right)^{2}}{2 \pi \cdot L} \\
f_{c} \approx \frac{f_{z-R H P}}{10} \\
f_{z-R H P}=\frac{(3.8 \Omega)\left(\frac{12 \mathrm{~V}}{19 \mathrm{~V}}\right)^{2}}{2 \pi \cdot(10 \mu \mathrm{H})} \approx 24.12 \mathrm{kHz} \\
f_{c} \approx \frac{24.12 \mathrm{kHz}}{10} \approx 2.4 \mathrm{kHz}
\end{gathered}
$$


Type-II loop compensation places a pole two decades below the crossover frequency, the dominant zero at the crossover frequency, and a second zero a decade above the crossover frequency as shown in Equations 5-11, 5-12 and 5-13.

$$
\begin{gathered}
f_{p-\text { comp }}=\frac{1}{2 \pi \cdot C_{\text {comp }} R_{\text {out }}} \approx \frac{f_{c}}{100} \\
f_{z-c o m p 1}=\frac{1}{2 \pi \cdot C_{\text {comp } 1} R_{\text {comp }}} \approx f_{c} \\
f_{z-c o m p 1}=\frac{1}{2 \pi \cdot C_{\text {comp } 2} R_{\text {comp }}} \approx f_{c} * 10
\end{gathered}
$$

Using standard value components and approximating the output resistance of the amplifier to $50 \mathrm{k} \Omega$ provides the desired compensation. Capacitors of $120 \mathrm{nF}$ and $12 \mathrm{nF}$ and a resistor of $536 \Omega$ form the compensation network. Figure 5-3 shows the placement of external components to provide controller feedback and their connections to the chip's internal block diagram [1].

$$
\begin{aligned}
& f_{p-\text { comp }}=\frac{1}{2 \pi \cdot(120 \mathrm{nF})(50 \mathrm{k} \Omega)}=26.52 \mathrm{~Hz} \\
& f_{z-\text { comp } 1}=\frac{1}{2 \pi \cdot(120 \mathrm{nF})(536 \Omega)}=2.47 \mathrm{kHz} \\
& f_{z-\text { comp } 2}=\frac{1}{2 \pi \cdot(12 \mathrm{nF})(536 \Omega)}=24.7 \mathrm{kHz}
\end{aligned}
$$




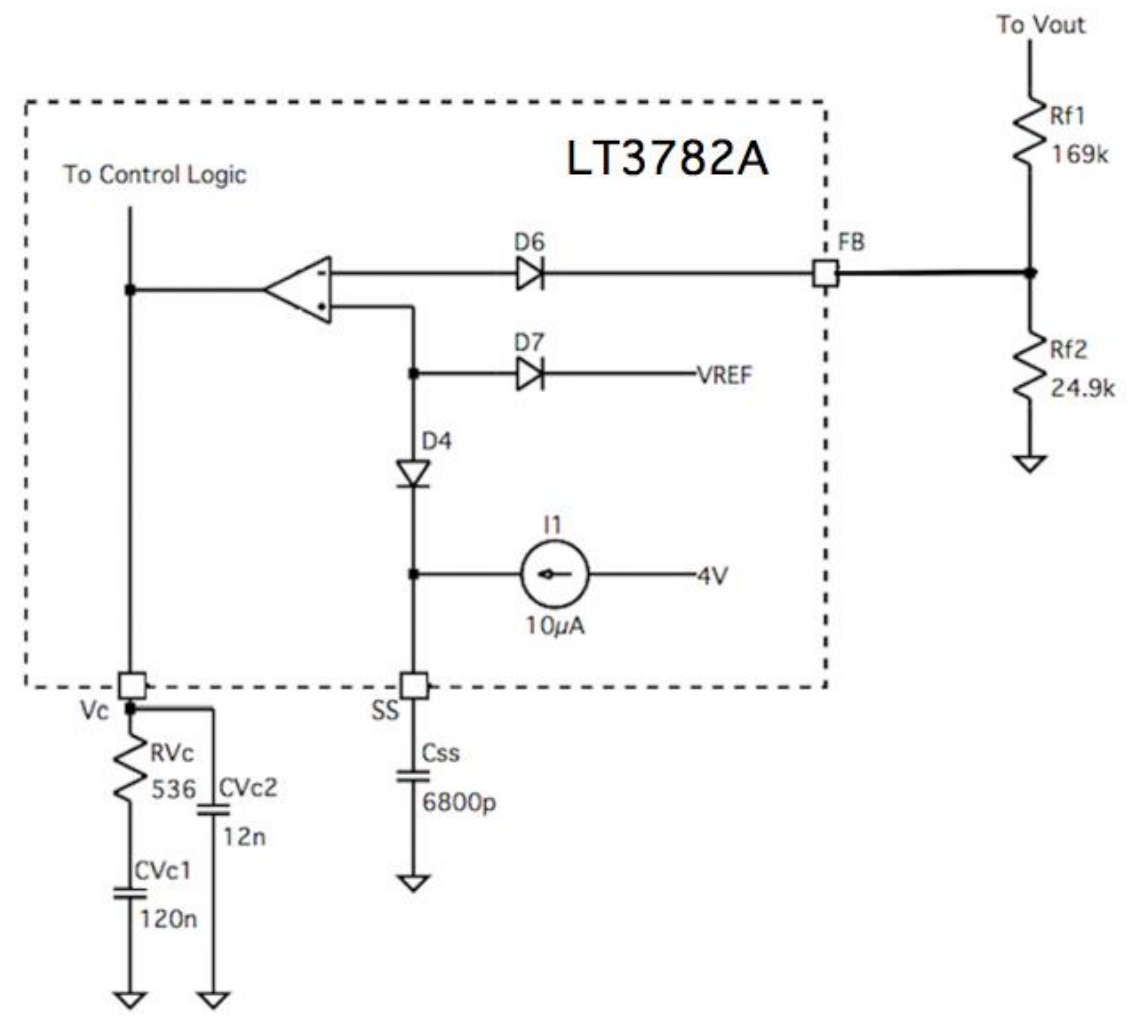

Figure 5-3: LT3286A External Control Component Connections

The combination of power dissipation calculations for each component provides an efficiency estimation for the converter. While the calculation shown in Equation 5-14 does not account for all for all potential losses in the converter, such as ESR losses in capacitors, the calculation represents a decent approximation factoring in the dominant contributing factors [17].

$$
\begin{gathered}
\% \text { Efficiency }=100 \%-\frac{P_{I C}+P_{F E T}+P_{R(S E N S E)}+P_{R(\text { WINDING })}+P_{\text {DIODE }}}{P_{I N}} \quad(5-14) \\
\frac{237.6 \mathrm{~mW}+(58.694 \mathrm{~mW} \cdot 2)+(29.3 \mathrm{~mW} \cdot 2)+(762.41 \mathrm{nW} \cdot 2)+(1.375 \mathrm{~W} \cdot 2)}{12 \mathrm{~V} \cdot 7.949 \mathrm{~A}} \\
\% \text { Efficiency } \text { Standard }_{\text {Standard }}=96.68 \%
\end{gathered}
$$


Due to the use of the same components, with the exception of the inductors, the calculation for the standard converter can similarly represent the maximum anticipated efficiency for the modified boost converter as well.

\subsection{Assembly and Testing}

Board layout plays an important role in converter operation. Proper controller supply bypassing mandates capacitor placement in close proximity to the controller pins. Arrangement of the components facilitates power flow in one direction across the board to minimize current loops. Layout incorporates elements for observation of the systems main power components. The components labeled IL1, IL2, IL3, and IL4 provide places for soldering wire loops to observe current through each inductor. Turrets M1 and M2 provide test points at the gate drive signal for each phase. The test points X1 and X2 provide a node at the input side of the feedback capacitor, between the first and second inductors of the modified boost converter. Subtracting the voltage at this test point from voltage at the output node provides the waveform imposed on the feedback capacitors. One board design supports implementation of both converters. The standard design simply leaves two inductor pads and the feedback capacitor pads non-populated. 


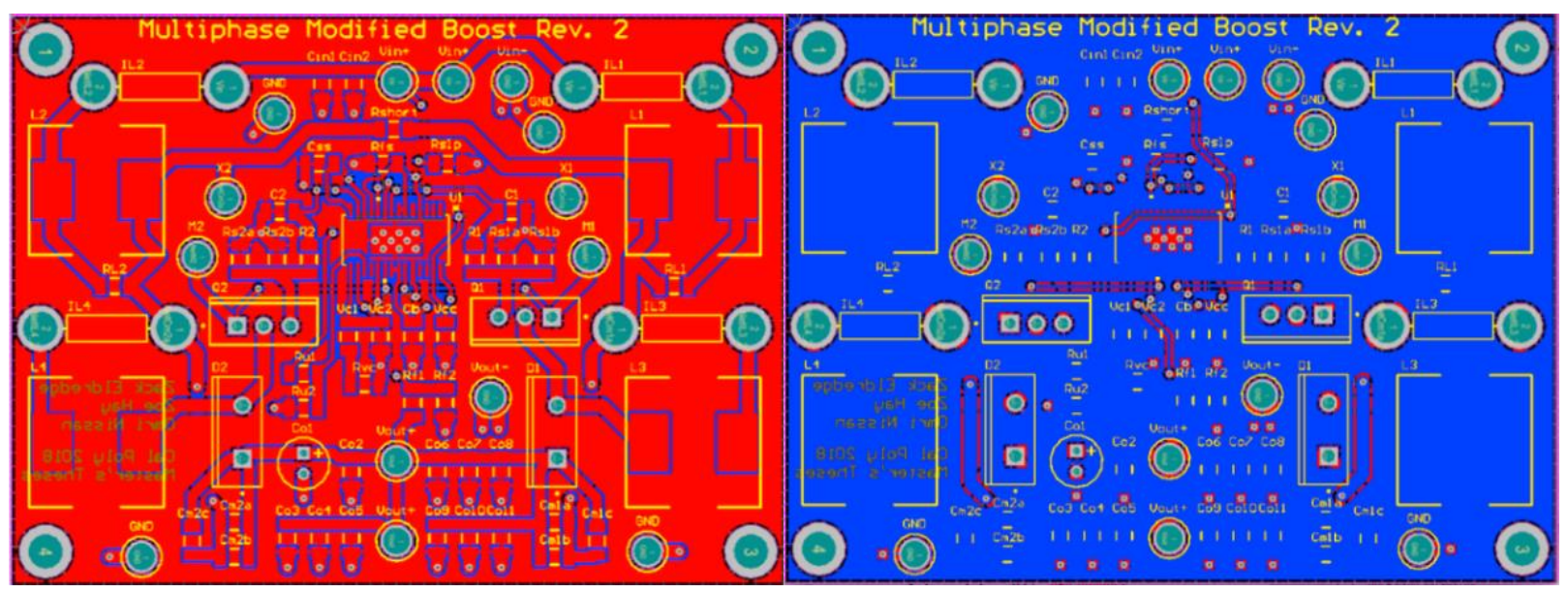

Figure 5-4. Top and Bottom Layers of Final PCB

Figure 5-4 shows the top and bottom layers of the PCB used for hardware testing. Figures 5-5 and 5-6 show the constructed and tested circuits. A small wire soldered to the bottom of Co2 on each board provides a ground connection for probing VouT+ to obtain a less noisy output ripple waveform.

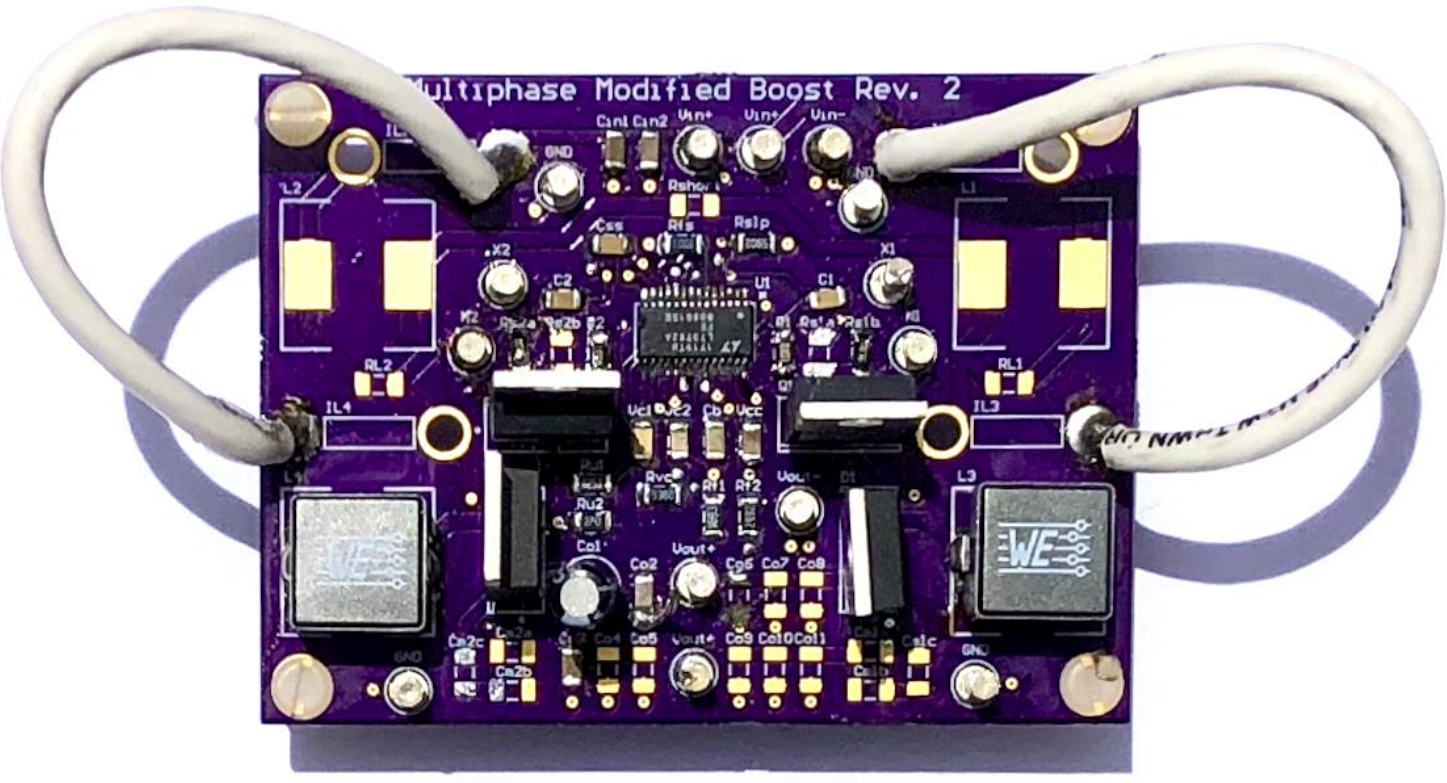

Figure 5-5. Standard Multiphase Boost Hardware 


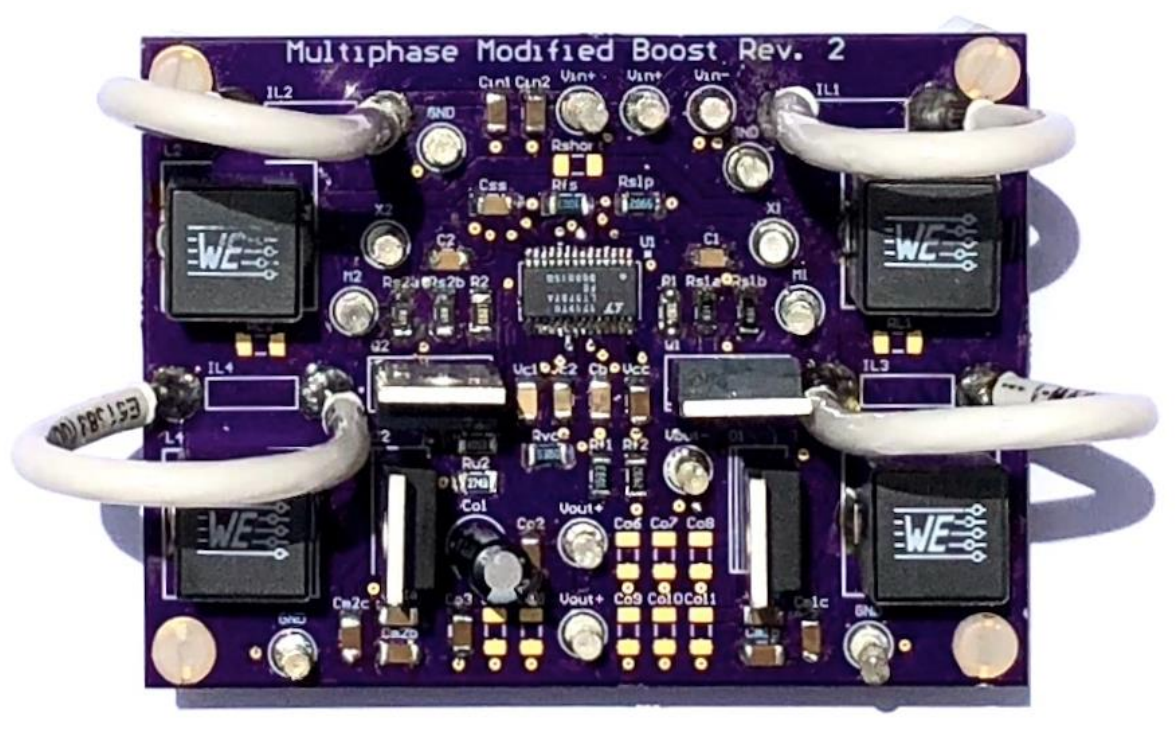

Figure 5-6: Modified Multiphase Boost Hardware

\subsubsection{Test Configuration}

Two Rigol DP832 Programmable DC Power Supplies provided input power during testing. Each converter offers two channels capable of $30 \mathrm{~V}$ at $3 \mathrm{~A}$ each. Two channels from the two supplies connected parallel provide the necessary input current. Two Rigol DM3052 Digital Multimeter take voltage measurements at the input and output. Use of separate multimeters as opposed to reading measurements off the DC power supply and electronic load provides greater measurement precision. A BK Precision 8540 150W DC Electronic Load electronic load connects to the converter output. Waveform captures use a Teledyne LeCroy HDO4104 oscilloscope. Aside from efficiency characterization, the oscilloscope enables measurement of most converter characteristics. 


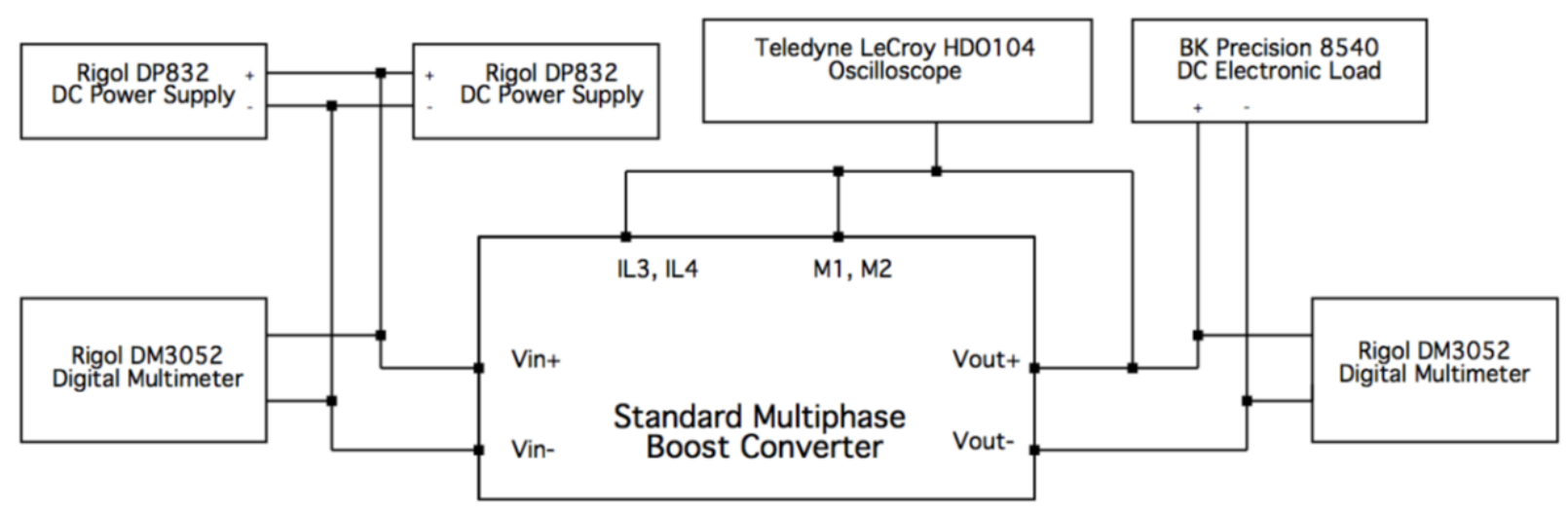

Figure 5-7: Standard Multiphase Converter Test Configuration

Figure 5-7 shows connections to the standard multiphase converter. Channels one and two connect to the gate drive signals of the switches at turrets M1 and M2 and provide triggering. Channel three observes output voltage ripple. The current probe connects to channel four for observation of the current through each inductor. The setup for the modified multiphase converter, shown in Figure 5-8, keeps the connections consistent with the exception of the additional measurements of the modification components. Figure 5-9 shows the test configurations setup in the lab. As shown in the lab setup, two channels from two Rigol DP832 Programmable DC Power Supplies operate in parallel to provide power for testing.

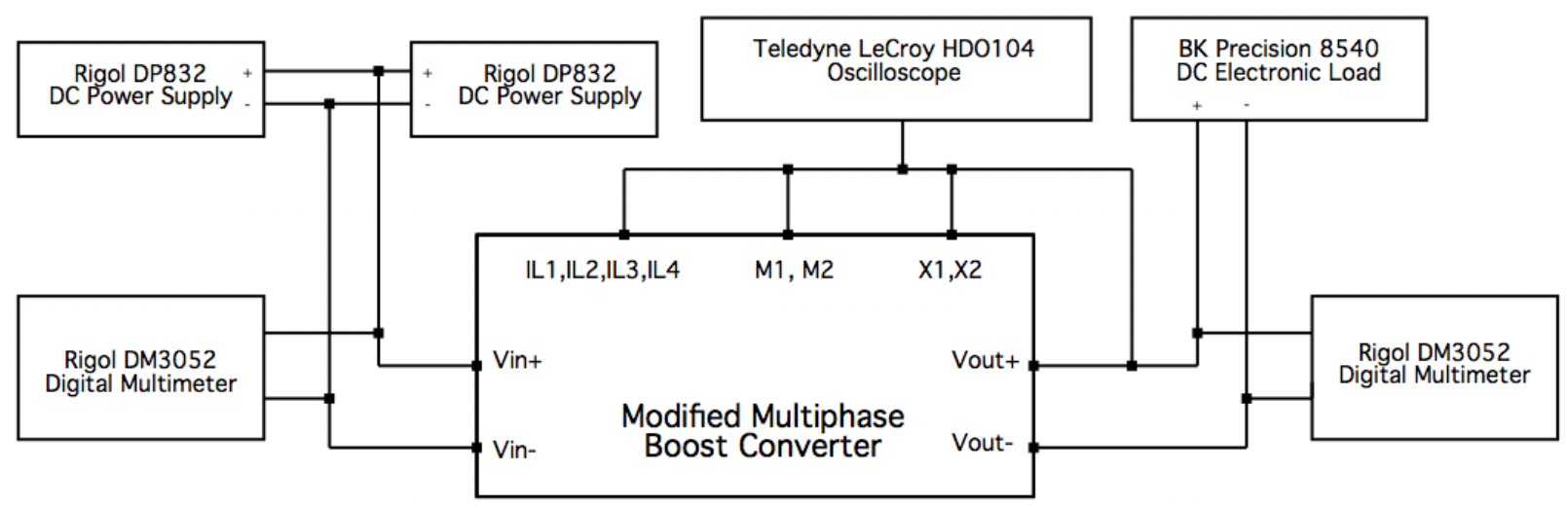

Figure 5-8: Modified Multiphase Converter Test Configuration 


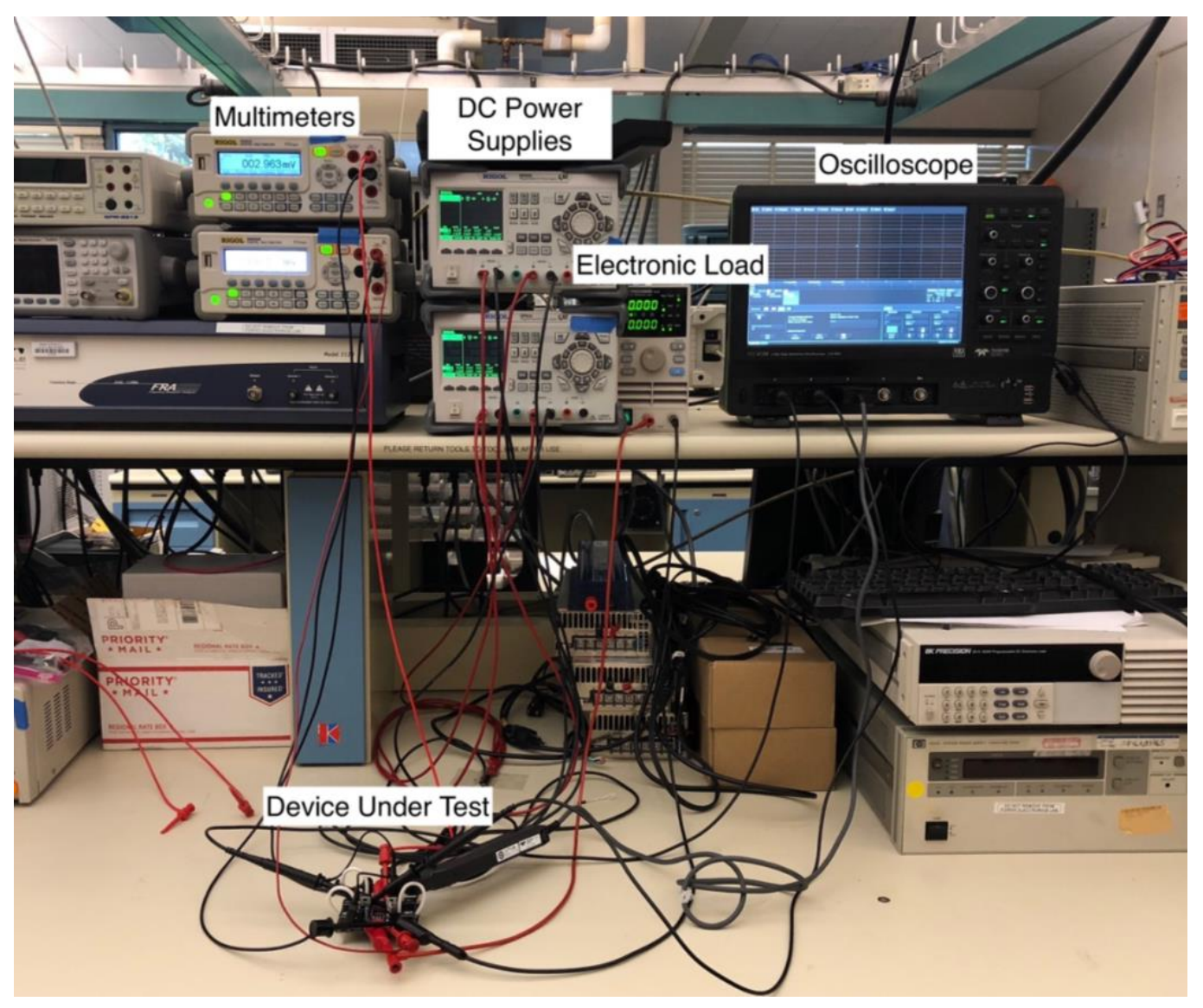

Figure 5-9: Laboratory Test Configuration

\subsubsection{Hardware Results}

After board assembly and establishment of testing procedure, data collection allowed characterization of each device. During initial testing of the converters, both failed to reach full output voltage at higher load conditions. Increased inductor current ripple triggers gate shut down by action of the sense resistors as previously described. Reduction of the sense resistors from $10 \mathrm{~m} \Omega$, as selected based on simulation results, to $5 \mathrm{~m} \Omega$ results in anticipated converter performance.

Table 5-5 compares the general converter characteristics of the standard and modified multiphase converters at full load. Due to parasitic components and switching losses, neither 
converter achieved near the previously calculated maximum possible efficiency. The modified multiphase boost converter demonstrated only $0.53 \%$ lower efficiency. The addition of parasitic components from the two inductors and feedback capacitors intuitively suggest a decrease in efficiency as reflected by the results.

Table 5-5. Hardware Full Load DC Characteristics Comparison

\begin{tabular}{|c|c|c|c|c|c|c|c|}
\hline & $\begin{array}{c}\text { VIN } \\
(\mathbf{V})\end{array}$ & $\begin{array}{c}\text { IIN } \\
(\mathbf{A})\end{array}$ & $\begin{array}{c}\text { PIN } \\
(\mathbf{W})\end{array}$ & $\begin{array}{c}\text { Vout } \\
(\mathbf{V})\end{array}$ & $\begin{array}{c}\text { IouT } \\
(\mathbf{A})\end{array}$ & $\begin{array}{c}\text { Pout } \\
(\mathbf{W})\end{array}$ & Efficiency \\
\hline $\begin{array}{c}\text { Standard } \\
\text { Multiphase Boost }\end{array}$ & 11.557 & 8.74 & 101.012 & 18.905 & 5 & 94.528 & $93.58 \%$ \\
\hline $\begin{array}{c}\text { Modified } \\
\text { Multiphase Boost }\end{array}$ & 11.564 & 8.82 & 101.994 & 18.945 & 5.01 & 94.914 & $93.05 \%$ \\
\hline
\end{tabular}

Observation of input current and voltage combined with output voltage while stepping current to the electronic load allows efficiency characterization of both converters. Output voltage data collection at different input voltages allows line regulation calculations. The oscilloscope provides mean and RMS measurements. Cursors allow more precise peak to peak measurements. Exporting saved waveform data files allows plotting of the exact data points in MATLAB.

Figure 5-10 shows the inductor currents of the standard multiphase boost converter with both gate drive signals. The inductors exhibit the characteristic charging and discharging shapes as controlled by the two gate signals operated out of phase from one another. 


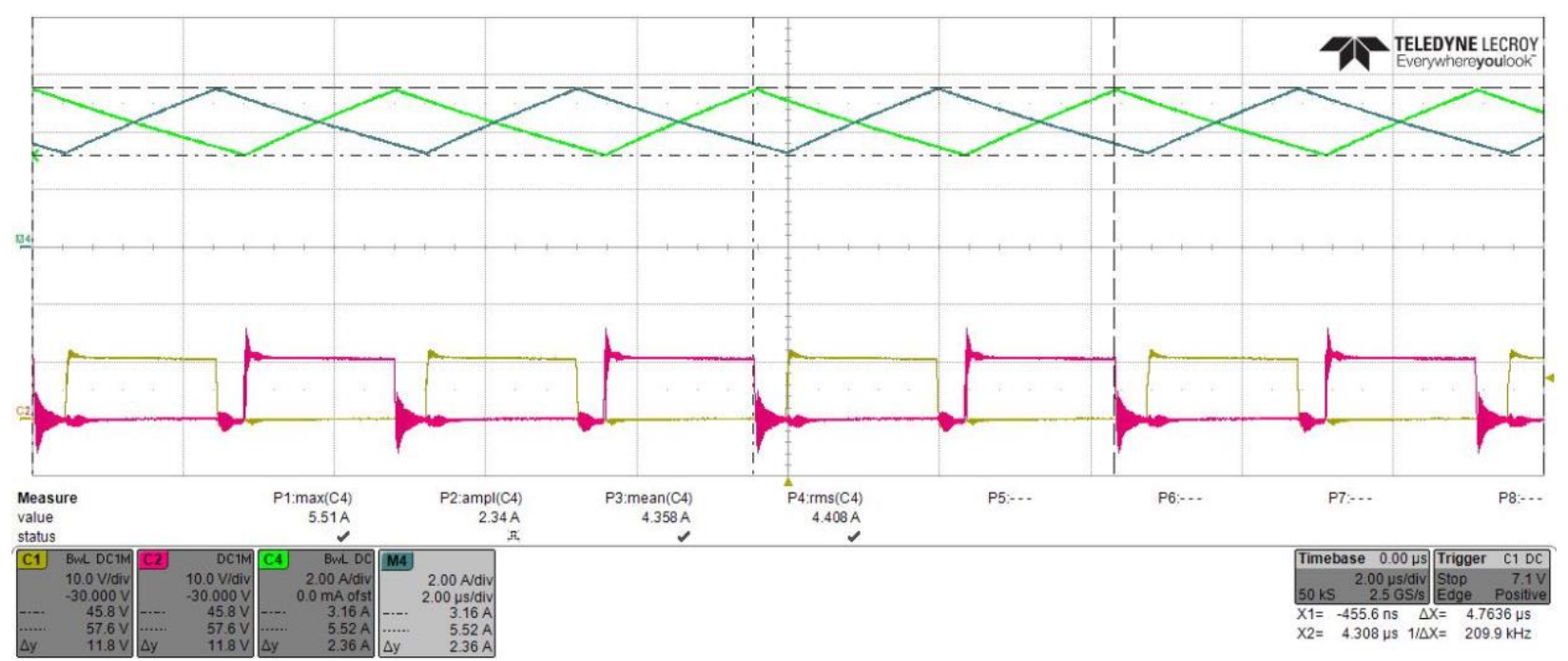

Figure 5-10: Standard Multiphase Boost Inductor Current (C1:M1, C2:M2, C4:L4, M4:L3)

Figure 5-11 depicts the output voltage ripple of the standard multiphase boost. The converter exhibits the low ripple of a multiphase topology with some parasitic ringing. Cursor measurements of each phase indicate $41.0 \%$ and $40.2 \%$ duty cycles for each phase. Parasitic losses in the inductor and line impedances provide an explanation for these larger than previously calculated values.

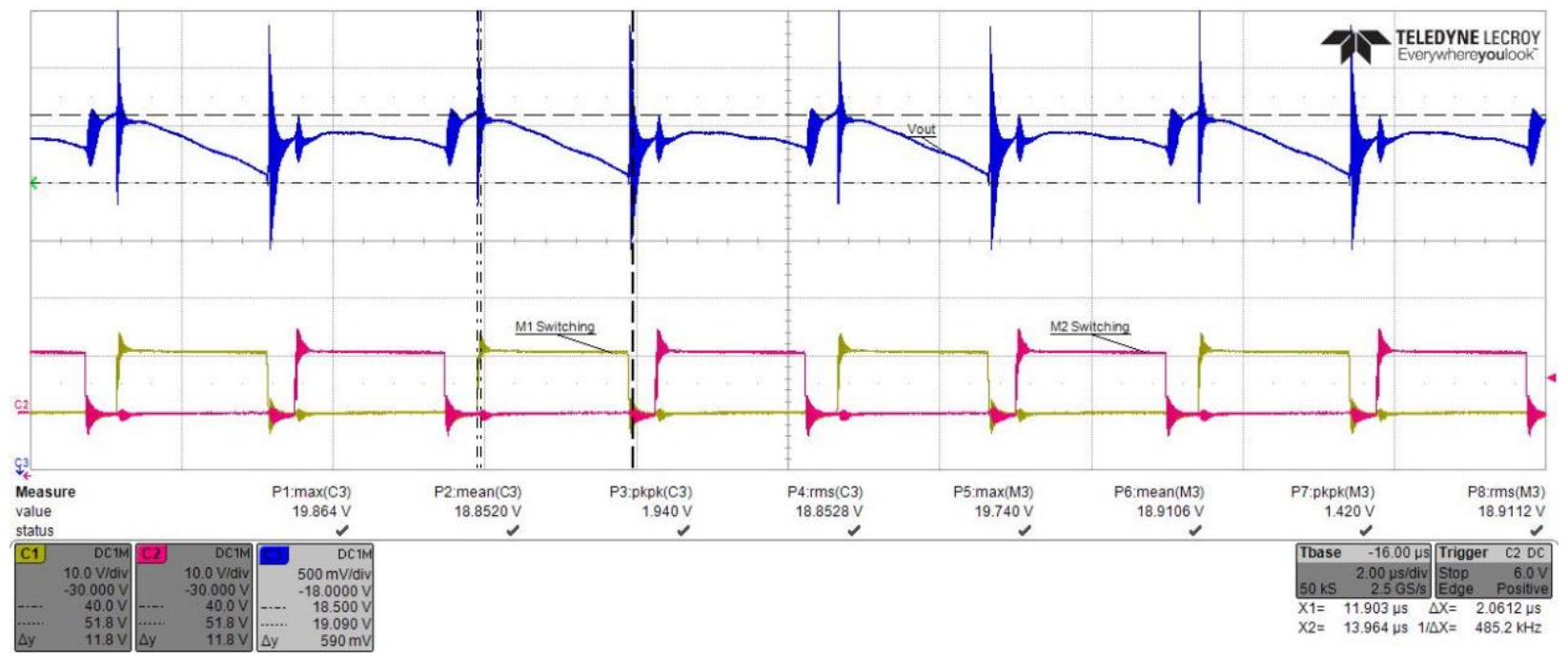

Figure 5-11: Standard Multiphase Boost Output Voltage 
Table 5-6 summarizes characteristics of the standard multiphase boost converter operating at full load. A fairly even split of total current between the two phases reduces component stress. The interleaving of the two phases provides input current ripple cancellation as well as lower output voltage ripple.

Table 5-6. Standard Boost Converter Hardware Test Results

\begin{tabular}{|c|c|c|c|}
\hline & Phase 1: IL3 (A) & Phase 2: IL4 (A) & VouT (V) \\
\hline Peak-Peak & 2.32 & 2.34 & 0.590 \\
\hline Average & 4.337 & 4.358 & 18.852 \\
\hline RMS & 4.386 & 4.408 & 18.852 \\
\hline Max & 5.56 & 5.51 & 19.864 \\
\hline \%ipple & $53.49 \%$ & $53.69 \%$ & $3.129 \%$ \\
\hline
\end{tabular}

Figure 5-12 shows the currents through the two input inductors of the modified multiphase boost with triggering provided by the gate drive signals. As shown by the oscilloscope measurements, the input inductors exhibit a $288.82 \mathrm{~mA}$ average current mismatch. Component tolerances and mismatched parasitic contribute to this imperfect current sharing.

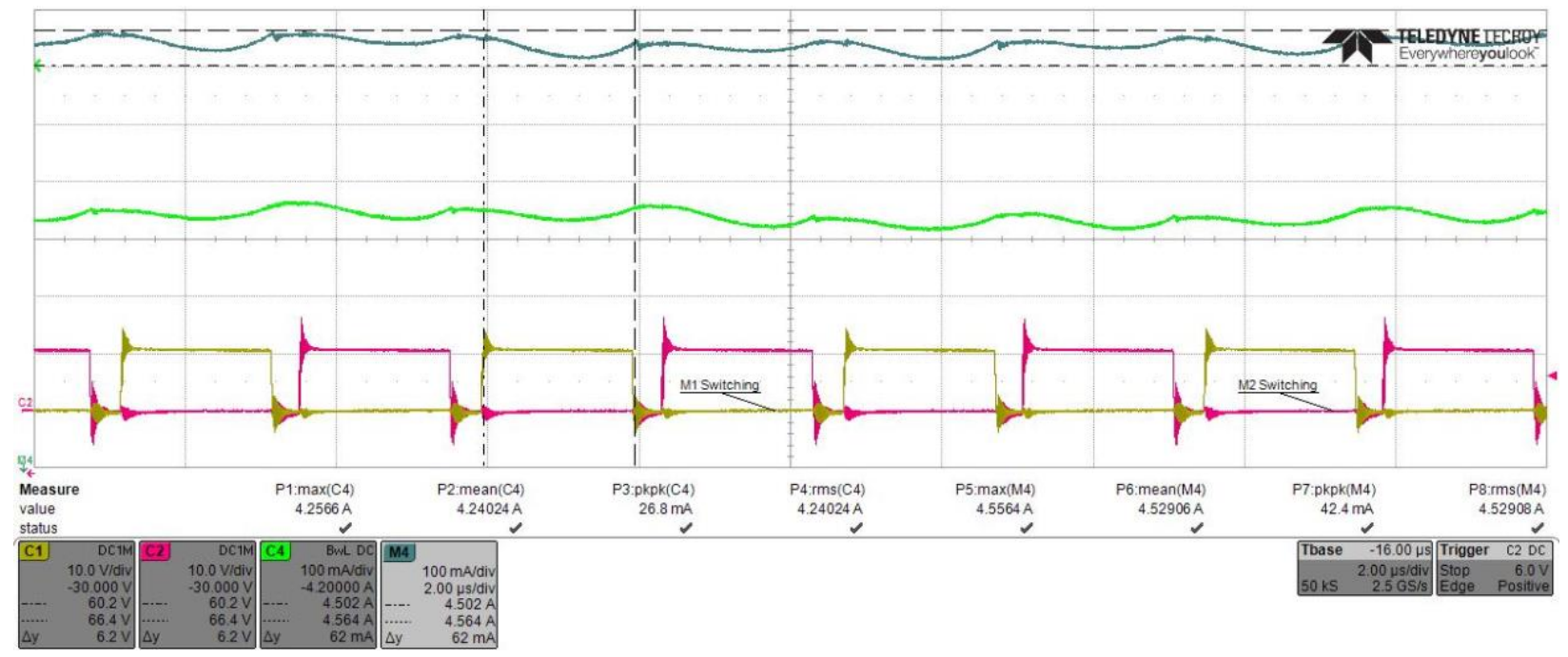

Figure 5-12: Modified Multiphase Boost Input Inductor Currents (C1:M1, C2:M2, C4:L2, M4:L1) 
Figure 5-13 shows currents through the secondary inductors of the modified multiphase boost. Both inductors exhibit the anticipated triangular charging and discharging waveforms with increased ripple as caused by operation of the modified topology.

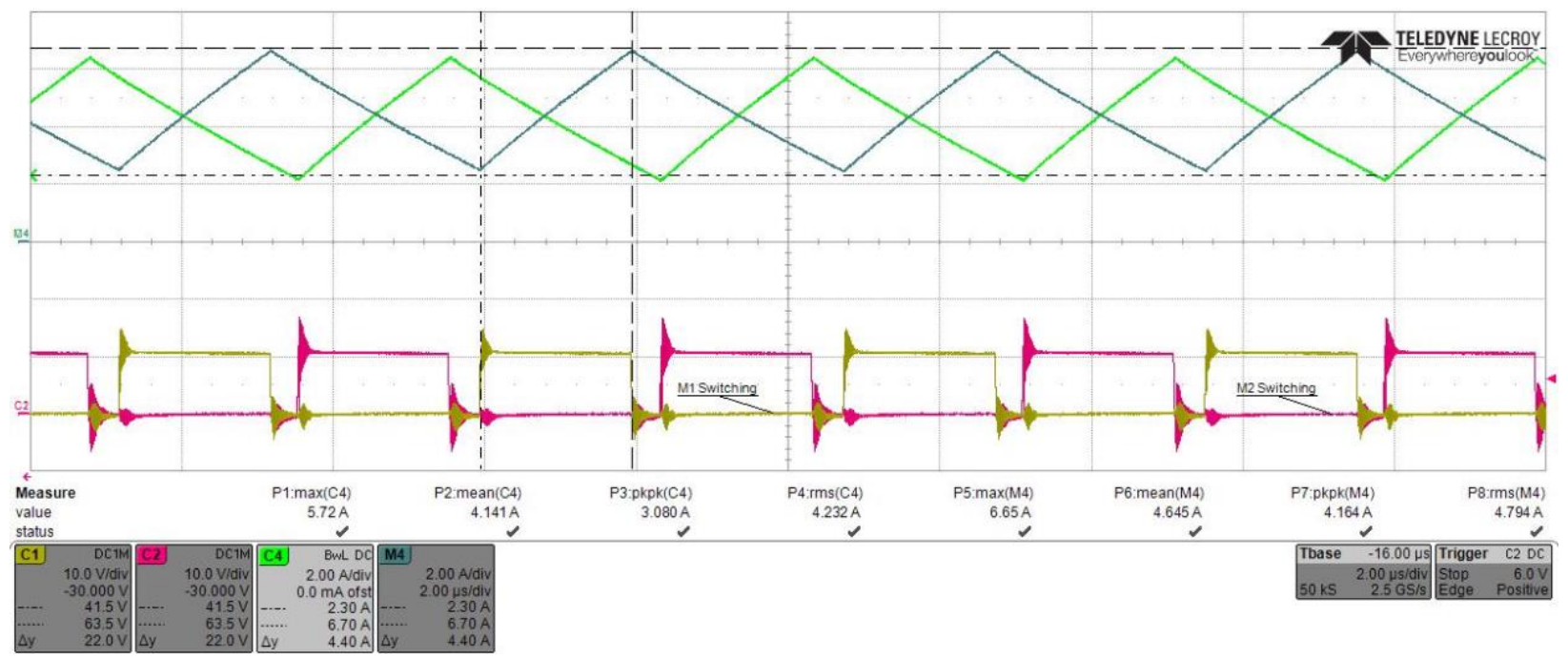

Figure 5-13: Modified Multiphase Boost Secondary Inductor Currents (C1:M1, C2:M2, C4:L4, M4:L3)

Extrapolation of the voltage across the feedback capacitors uses subtraction of the voltage at the X1 and X2 nodes from the output voltage waveform. Figures 5-14 and 5-15 show these measurements and matched with the gate drive signals as well as the mathematical operation F1 which approximates feedback capacitor voltage. While contaminated by parasitic ringing, the resulting waveform loosely reflects the shape predicted by simulation and verifies the feedback capacitors do not experience excessive voltage stress. 


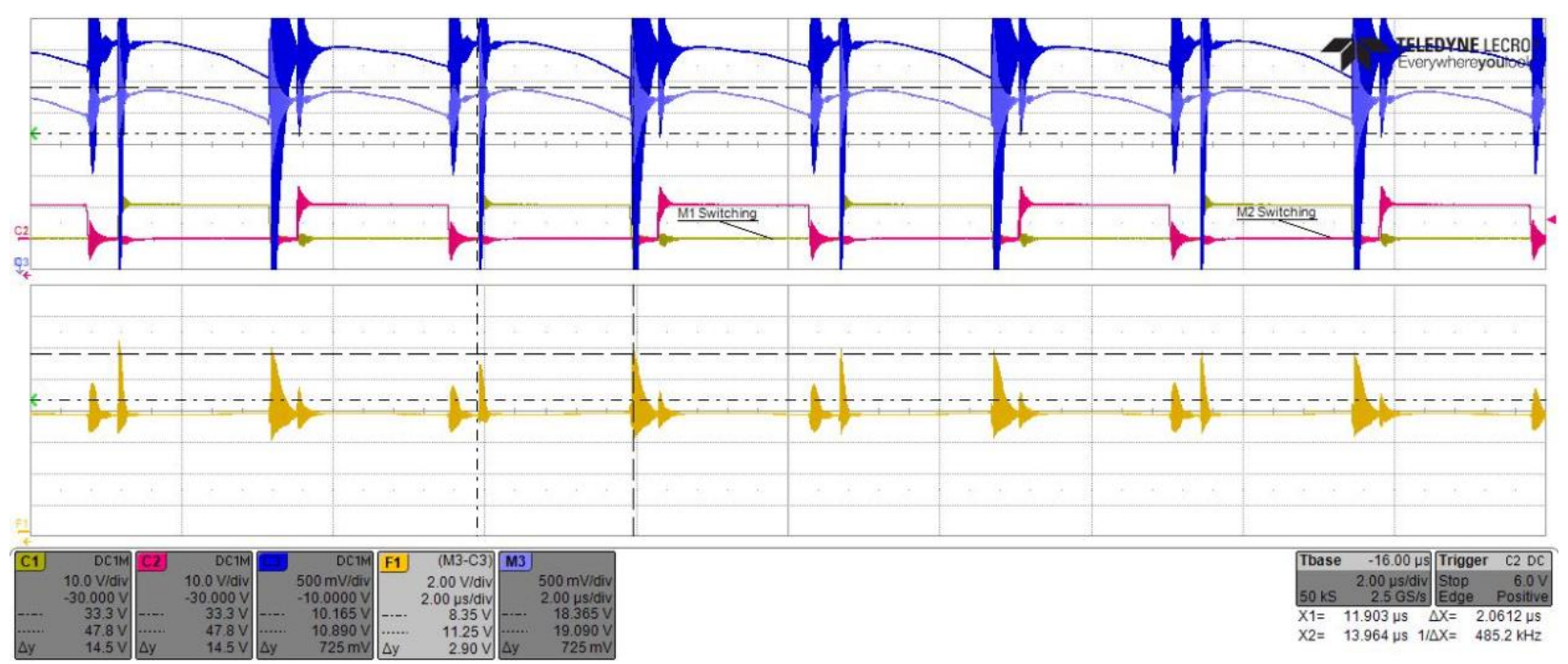

Figure 5-14: Modified Multiphase Boost Feedback Phase 1 Capacitor Voltage (C1:M1, C2:M2, C3:X1, M3:Vout, F1:Vout-X1)

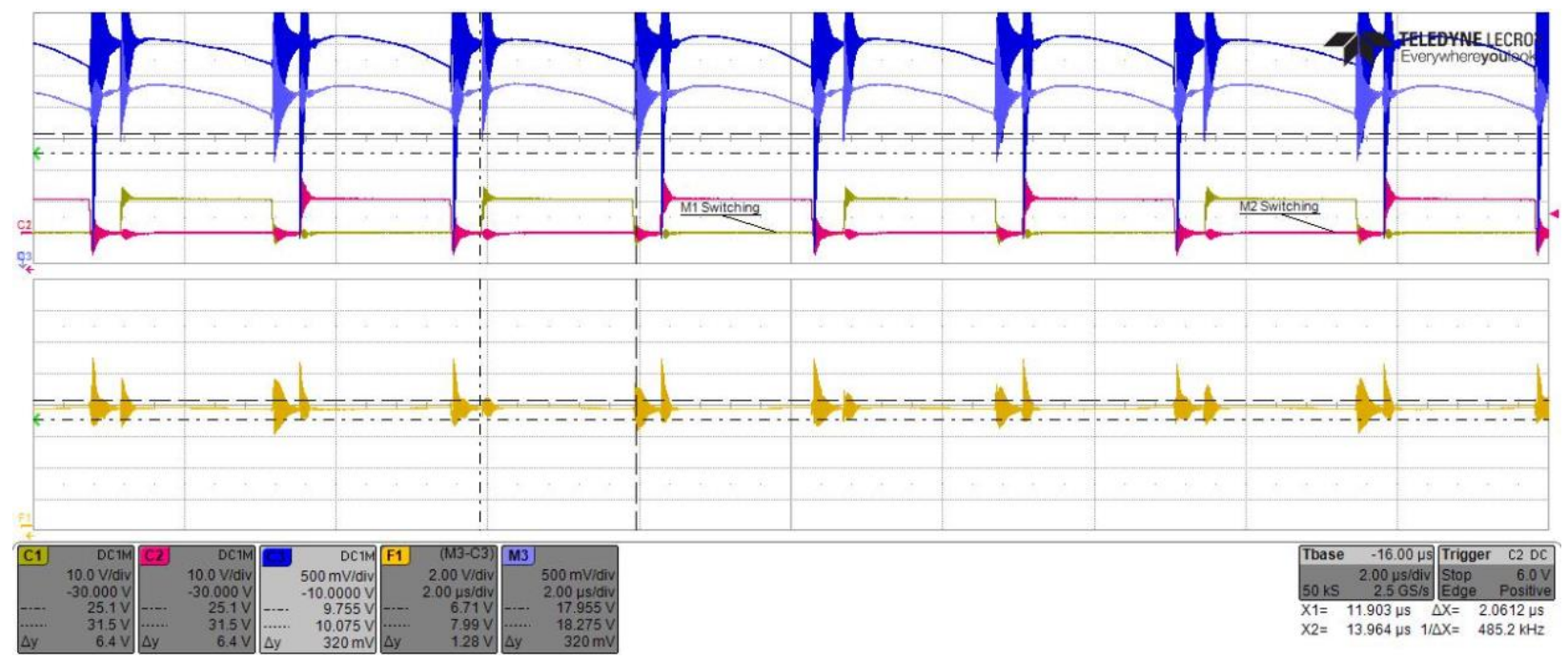

Figure 5-15: Modified Multiphase Boost Phase 2 Feedback Capacitor Voltage (C1:M1, C2:M2, C3:X2, M3:Vout, F1:Vout-X2)

Figure 5-16 shows the output voltage ripple of the modified multiphase boost converter.

Despite parasitic ringing at the switch transitions, the output voltage exhibits the anticipated shape and high frequency. 


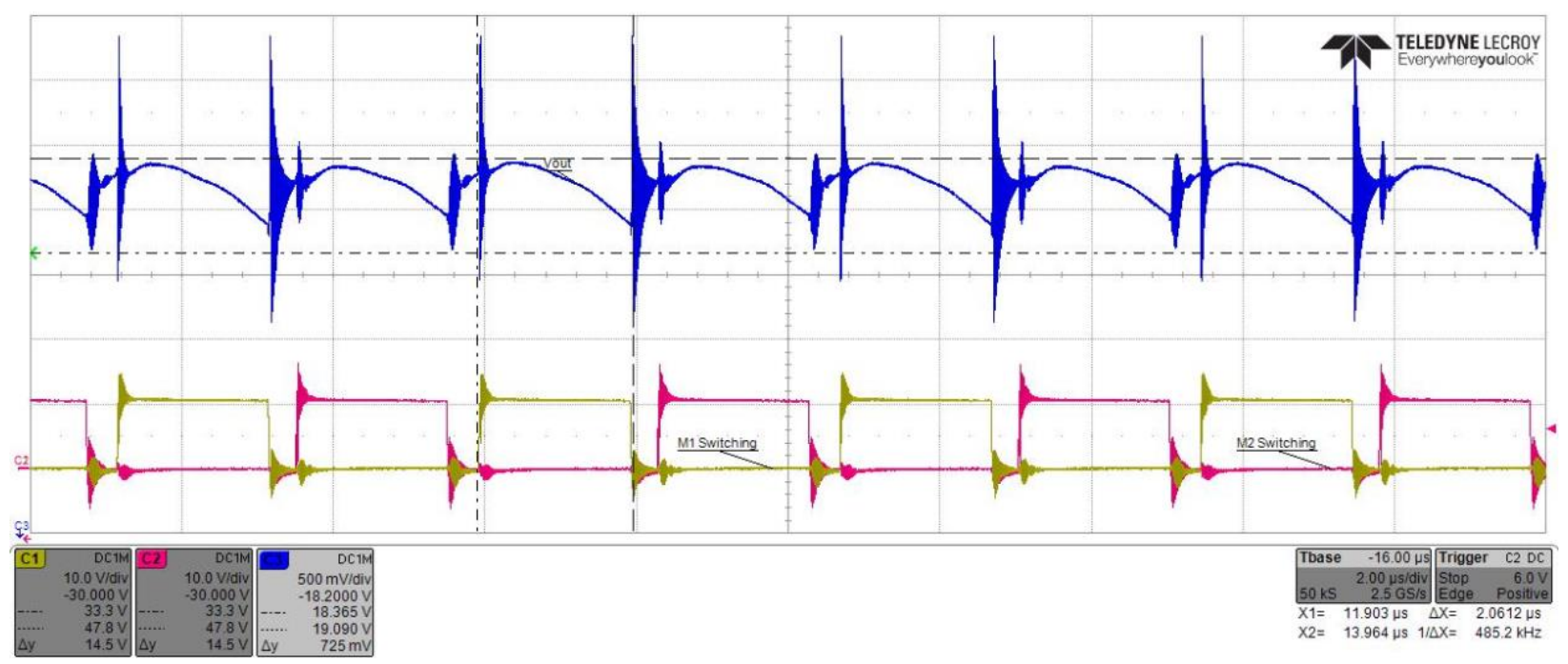

Figure 5-16: Modified Multiphase Boost Output Voltage

Table 5-7 presents the observed currents through each inductor of the modified multiphase boost converter and the characteristics of the output voltage. As shown by the waveforms, imperfect component matching between phases results in a mismatch in inductor currents. The modified topology also exhibits a slightly larger output voltage ripple.

Table 5-7. Modified Boost Converter Hardware Test Results

\begin{tabular}{|c|c|c|c|c|c|}
\hline & $\mathbf{I}_{\mathbf{L 1}}(\mathbf{A})$ & $\mathbf{I}_{\mathbf{L 2}}(\mathbf{A})$ & $\mathbf{I}_{\mathbf{L} 3}(\mathbf{A})$ & $\mathbf{I}_{\mathbf{L 4}}(\mathbf{A})$ & VouT(V) \\
\hline Peak-Peak & $42.4 \mathrm{~mA}$ & $26.8 \mathrm{~mA}$ & 4.164 & 3.080 & 0.725 \\
\hline Average & 4.52906 & 4.24024 & 4.645 & 4.141 & 18.894 \\
\hline RMS & 4.5908 & 4.24024 & 4.794 & 4.232 & 18.895 \\
\hline Max. & 4.5564 & 4.2566 & 6.65 & 5.72 & 19.256 \\
\hline \% Ripple & $0.936 \%$ & $0.632 \%$ & $89.64 \%$ & $74.37 \%$ & $3.837 \%$ \\
\hline
\end{tabular}




\subsection{Performance Comparison}

Figure 5-17 compares the standard multiphase boost efficiency to the modified boost efficiency over output current. As previously discussed, the standard shows a slightly higher efficiency due to the reduced total component count.

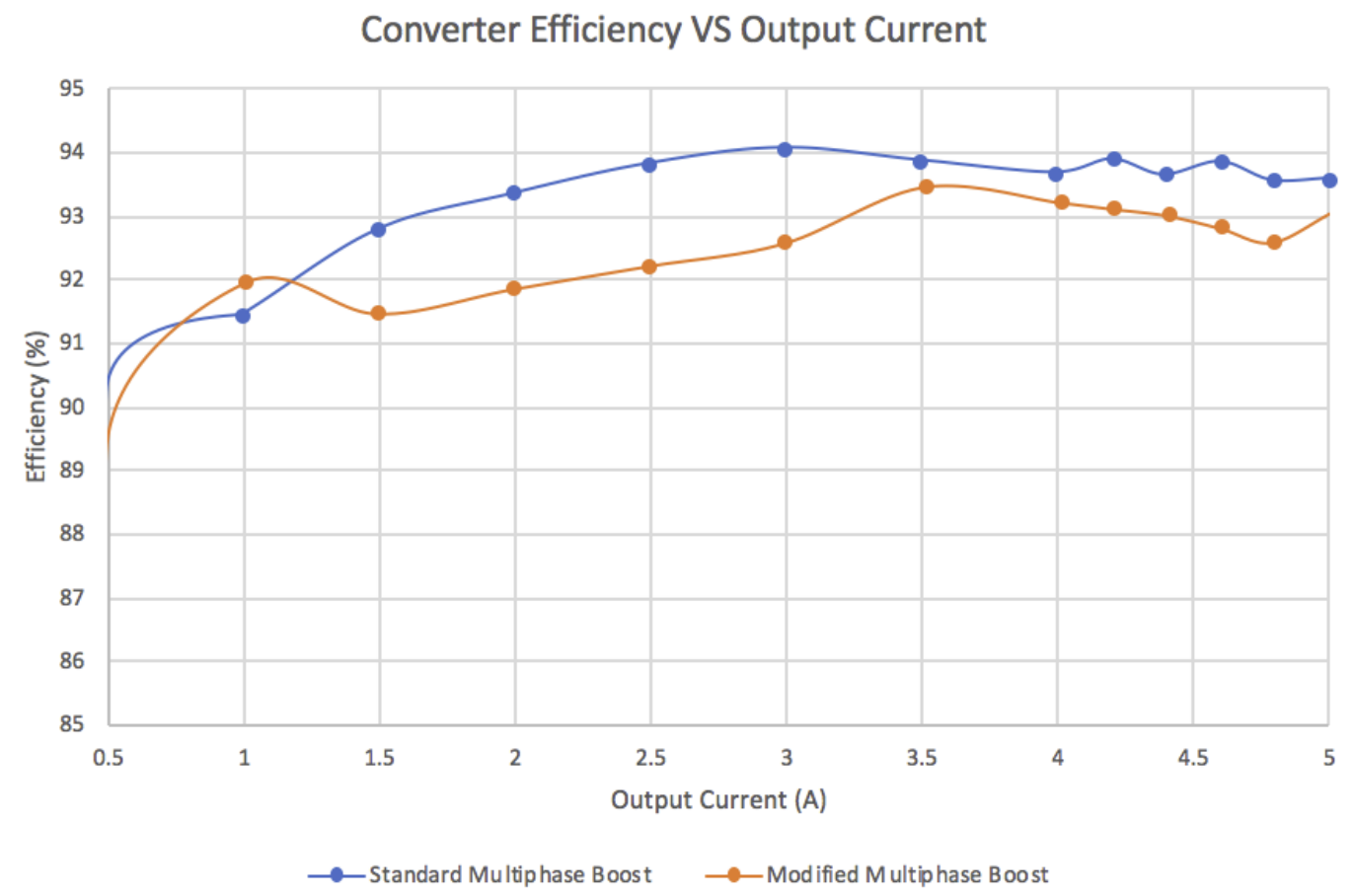

Figure 5-17: Hardware Efficiency VS Output Current Comparison

Table 5-8 records the output voltages of each converter under different input and load conditions for the calculation of line and load regulation as explained in Equations 3-4 and 3-5. Due to performance of the DC Power Supply, setting VIN at the desired $13.2 \mathrm{~V}$ and $10.8 \mathrm{~V}$ resulted in only $12.8 \mathrm{~V}$ and $10.29 \mathrm{~V}$ measured at the input to the converter. Despite this condition caused by the supply, both converters fall well within the maximum specified line and load regulation design requirements. 
Table 5-8. Hardware Line and Load Regulation Comparison

\begin{tabular}{|c|c|c|c|c|c|c|}
\hline & $\begin{array}{c}\text { Vout at } \\
\text { VIN= } \\
\mathbf{1 3 . 2 V}\end{array}$ & $\begin{array}{c}\text { Vout at } \\
\text { VIN= } \\
\mathbf{1 0 . 8 V}\end{array}$ & $\begin{array}{c}\text { Line } \\
\text { Regulation }\end{array}$ & $\begin{array}{c}\text { Vout at } \\
\text { IouT =1A }\end{array}$ & $\begin{array}{c}\text { Vout at } \\
\text { IouT =5A }\end{array}$ & $\begin{array}{c}\text { Load } \\
\text { Regulation }\end{array}$ \\
\hline $\begin{array}{c}\text { Standard } \\
\text { Multiphase } \\
\text { Boost }\end{array}$ & 18.906 & 18.901 & $0.026 \%$ & 18.935 & 18.905 & $0.158 \%$ \\
\hline $\begin{array}{c}\text { Modified } \\
\text { Multiphase } \\
\text { Boost }\end{array}$ & 18.945 & 18.944 & $0.005 \%$ & 18.959 & 18.945 & $0.073 \%$ \\
\hline
\end{tabular}

Exportation of the current waveforms measured through each input inductor of the standard and modified multiphase boost converters allows processing in MATLAB. Figure 5-18 plots the captured inductor current waveforms for both phases of the standard multiphase boost shown in blue. The orange traces show the current through both input inductors of the modified multiphase boost. Because these inductors connect directly to the input, the sum of the two waveforms represents the total input current as seen by the supply powering the converter. 


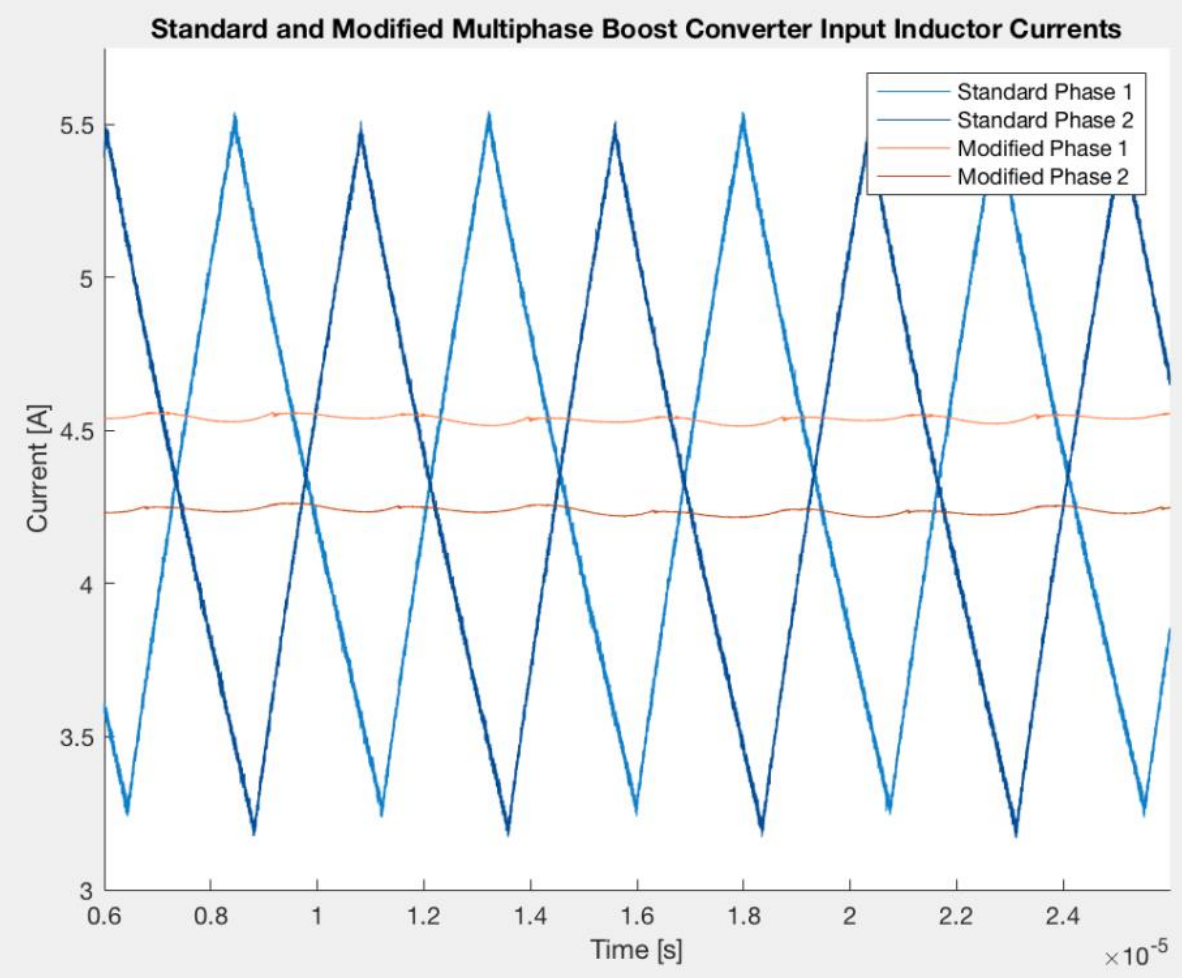

Figure 5-18: Hardware Inductor Current Comparison

Addition of the two waveforms allows accurate representation of input current. Figure 5-

18 shows the resulting total input current waveforms of the standard multiphase boost and the modified multiphase boost. The blue trace of the standard multiphase boost demonstrates the input current ripple cancelation provided by the interleaved operation of the two phases. As shown by the orange trace, the modified multiphase boost topology dramatically reduces the input current ripple. Operation of the modified topology also almost entirely eliminates the characteristic triangular shape caused by the charging and discharging of the inductors. 


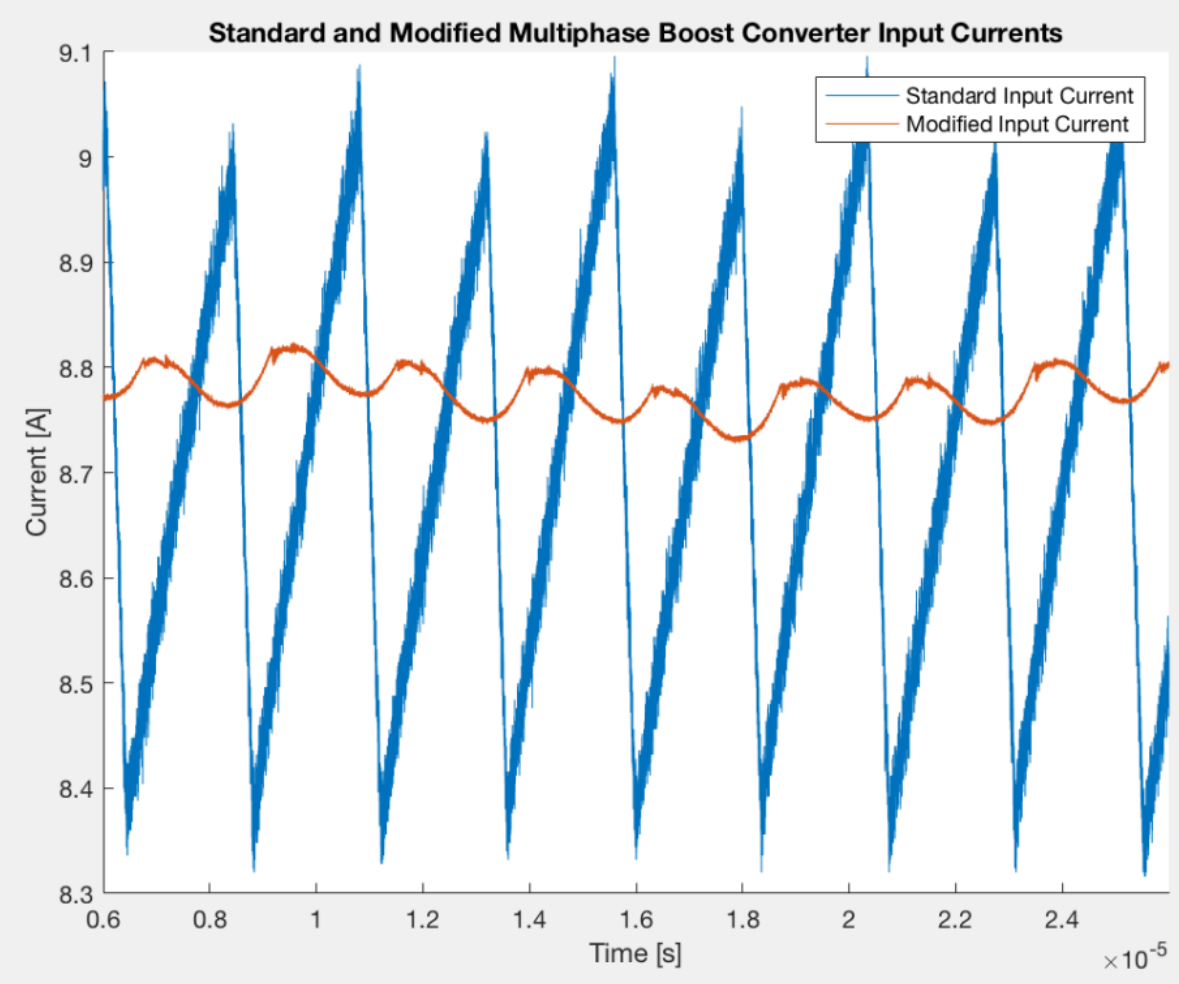

Figure 5-19: Hardware Input Current Comparison

Table 5-9 presents a summary of the input current characteristics observed in the standard and modified multiphase boost converters and comparison to the simulated values. Current measurements as listed in the table correspond to MATLAB calculated values and agree with waveform measurements performed by the oscilloscope. The simulated values use the controller's LTspice model, as discussed in Chapter 4.

Table 5-9. Hardware Input Current Ripple Comparison

\begin{tabular}{|c|c|c|c|c|}
\hline $\begin{array}{c}\text { Input } \\
\text { Current } \\
\text { Measurement }\end{array}$ & $\begin{array}{c}\text { Standard } \\
\text { Hardware }\end{array}$ & $\begin{array}{c}\text { Standard } \\
\text { Simulation }\end{array}$ & $\begin{array}{c}\text { Modified } \\
\text { Hardware }\end{array}$ & $\begin{array}{c}\text { Modified } \\
\text { Simulation }\end{array}$ \\
\hline Average & $8.6946 \mathrm{~A}$ & $8.21 \mathrm{~A}$ & $8.7764 \mathrm{~A}$ & $8.24 \mathrm{~A}$ \\
\hline Peak-Peak & $780 \mathrm{~mA}$ & $832 \mathrm{~mA}$ & $96.8 \mathrm{~mA}$ & $98.9 \mathrm{~mA}$ \\
\hline \%Ripple & $9.096 \%$ & $10.13 \%$ & $1.103 \%$ & $1.2 \%$ \\
\hline
\end{tabular}


The hardware results of the two converters reflect the similar principles of operation as well as effort to select similar components for each. Both converters meet desired efficiency at full load operation with $93.58 \%$ for the standard multiphase boost and $93.05 \%$ for the modified multiphase boost. The modified results reflect losses characteristic of the additional modification components. The converters exhibit excellent line regulation with $0.026 \%$ for the standard and $0.005 \%$ for the modified. Load regulation measurements also reflect sturdy performance with $0.158 \%$ for the standard and $0.073 \%$ for the modified. Neither converter meet the desired $2 \%$ output voltage ripple as defined by the design parameters. The standard multiphase boost exhibits a $3.129 \%$ output voltage ripple while the modified multiphase boost demonstrates a similar but slightly higher $3.837 \%$. The greater than anticipated output voltage ripple could be explained by the lower than nominal input voltage provided by the DC Power Supply when powering the converters at full load. The modified multiphase boost dramatically reduces input current ripple at the cost of increased current ripple in the secondary inductors. The standard and modified hardware results provide a comparable improvement in input current ripple as predicted by simulation. 


\section{CONCLUSION}

Implementation of a modified multiphase boost converter demonstrates notable input current ripple reduction. Operation of the modification to the boost converter relies on the principles derived in a single-phase modified boost converter as demonstrated in [16]. Simulations with behavioral models as well as with the selected controller model in LTspice verify converter design and allow prediction of design performance.

Hardware construction and testing reflect similar behavior as predicted by simulation. A number of variations between simulation and hardware results reflect non-idealities in components. Specific indicators of system losses include a greater switch duty cycle as well as lower overall converter efficiency. Parasitic ringing corresponding with switching also interfered with clean waveform observation.

The results and issues presented by this project provide opportunities for future improvements. Different testing equipment could produce more accurate results. As previously mentioned, line impedances and DC power supply performance resulted in lower than nominal input voltages to the converter under test. Providing an input voltage lower than specified by the converter's design results in increased switch duty cycle and potentially sub-optimal performance. Drop in supply voltage could be attributed to line impedance which could be considerable at higher currents. Use of a single supply would allow adjustment of the voltage present at the input of the device under test as well as simplify input current measurements. The DC power supply also only measures supply current to a $0.01 \mathrm{~A}$ accuracy. This could produce inaccurate efficiency calculations for the converter, especially at low load conditions with a small supply current split between four channels of the DC power supply. The electronic load presents another issue of measurement accuracy. The electronic load also provides current 
measurement to a $0.01 \mathrm{~A}$ accuracy. Load current also occasionally fluxuates within this tolerance. The electronic load could also lead to inaccurate efficiency calculations and skew comparison between the standard and modified topologies.

Different component selections could also produce improved results. As previously mentioned, implementation required lowering of the sense resistor value for full output voltage. Both standard and modified converters also exhibit some current mismatching between the two phases as indicated by inductor current measurements. Inductor current measurements at full load show a $0.021 \mathrm{~A}$ mismatch in the standard converter and $0.504 \mathrm{~A}$ mismatch in the modified. Mismatched current induces unequal stress on components and may degrade performance. Component tolerances contribute to unequal current sharing in multiphase converters. While the hardware implementations use $1 \%$ tolerance sense resistors, tighter tolerance of components could reduce current sharing issues. With $93.58 \%$ for the standard converter and $93.05 \%$ for the modified, neither module met the desired efficiency. The diodes represent the greatest source of losses in both converter topologies. The selected diode offered the lowest forward voltage at comparable current and voltage rating available on Digi-Key, the main source for components. Searching other suppliers for a more efficient diode could significantly improve efficiency for both converters. Moreover, at relatively high power, a synchronous rectifier using additional MOSFETs instead of diodes could produce still greater efficiency.

Overall, the modified converter demonstrated dramatic reduction in input current ripple. Input current to the modified converter shows $1.103 \%$ ripple compared to the standard at 9.096\%. This improvement comes at cost of additional components which provide the filtering effect but demonstrate small impact on overall efficiency. Numerous applications benefit from low input current ripple. Reduced noise seen by the supply and other devices on a shared bus is 
important in applications sensitive to noise. Sources such as batteries also function more optimally when sourcing a low noise current. Low input current ripple shows benefit for other renewable energy applications, such as maximizing efficiency of PV arrays.

This implementation provides proof of concept of extension of the modified topology into a multiphase application. Multiphase capabilities translate the benefits of the modified topology to higher power applications. Theory behind the modified topology promises other configurations to investigate for optimization of the many trade-offs involved in converter design. 


\section{REFERENCES}

[1] Taufik, Introduction to Power Electronics, 13 ed., San Luis Obispo, CA, 2016.

[2] B. Mammano and B. Carsten, Understanding and Optimizing Electromagnetic Compatability in Switchmode Power Supplies, Texas Instruments.

[3] J. Rice, D. Gehrke and M. Segal, Understanding Noise-Spreading Techniques and their Effects in Switch-Mode Power Applications, Texas Instruments.

[4] K. Koo, J. Kim and J. Kim, "Impact of PCB Design on Switching noise and EMI of Synchronous DC-DC buck Converter," in 2010 IEEE International Symposium on Electromagnetic Compatibility (EMC), Fort Lauderdale, FL, USA, 2010.

[5] M. H. Rashid, Power Electronics Handbook, Butterworth-Heinemann LTD, 2001.

[6] K. Suryanarayana and H. Nagaraja, "Multiphase Boost Converter Model for Source Current Ripple Reduction," 2014.

[7] M. Zivanov, B. Sasic and M. Lazic, "Desing of Multiphase Boost Converter for Hybrid Fuel Cell/Battery Power Sources," in Paths to Sustainable Energy, D. A. Ng, Ed., InTech, 2010, pp. pp. 359-404.

[8] D. Baba, Benefits of a Multiphase Converter, Texas Instruments, 2012.

[9] O. Hegazy, Y. Talaat, A. Amin and P. Lataire, "Control and Analysis of Multiphase Interleaved DC/DC Boost Converter for Photovoltaic Systems," in Ninth Int. Conf. on Ecological Vehicles and Renewable Energies (EVER), Monte-Carlo, 2014.

[10] T. Taufik, T. Gunawan, D. Dolan and M. Anwari, "Design and Analysis of Two-Phase Boost DC-DC Converter," International Journal of Electrical and Computer Engineering, vol. 4, no. 7, pp. pp. 1065-1069, 2010.

[11] K. Vishwas, K. Suryanarayana, N. M. Renukappa and L. V. Prabhu, "Modeling of Multiphase Boost Converter for Solar Battery Charging System," in 2014 IEEE Students' Conference on Electrical, Electronics and Computer Science, 2014.

[12] J. Wang, W. G. Dunford and K. Mauch, "A Comparison between Two Proposed Boost Topologies and Conventional Topologies for Power Factor Correction," in Industry Applications Conference, 1996. Thirty-First IAS Annual Meeting, IAS '96., Conference Reco of the 1996 IEEE, San Diego, CA, USA, 1996. 
[13] Y.-S. Lee, W.-T. Hong and T.-H. Chou, "Multiphase high gain boost converter with switche capacitor and coupled-inductor," in Future Energy Electronics Conference (IFEEC), 20131 International, Tainan, Taiwan, 2013.

[14] F. Renken, I.-M. Pop-Calimanu and U. Schurmann, "Novel Multiphase Hybrid Boost Conv€ with Wide Conversion Ratio," Power Electronics and Motion Control Conference (PEMC) 2016 IEEE International , pp. pp. 158-167, 2016.

[15] G. Kishor, D. Subbarayudu and S. Sivanagaraju, "Multiphase Boost Converter with Reducer Input Current Ripple Using Direct Coupled Inductors," Int. Journal of Engineering Researci and Applications, vol. 4, no. 2, pp. pp. 274-279, February 2014.

[16] N. H. Lentz, A Modified Boost Converter with Reduced Input Current Ripple, San Luis Obis California, 2017.

[17] Linear Technology, "LT3782A Datasheet and Product Info | Analog Devices," [Online]. Available: http://www.analog.com/media/en/technical-documentation/datasheets/3782afc.pdf?domain=www.linear.com.

[18] Wurth Electronics Inc., "WE-HCC SMD High Current Cube Inductor," 21 May 2015. [Onli] Available: https://katalog.we-online.com/pbs/datasheet/7443321000.pdf. [Accessed 30 Apri 2018].

[19] ON Semiconductor, "SCHOTTKY BARRIER RECTIFIERS 10 AMPERES, 80 to 100 VOLTS," January 2012. [Online]. Available: http://www.onsemi.com/pub/Collateral/MBR1080-D.PDF. [Accessed 30 April 2018].

[20] Infineon Technologies, " IR MOSFET StrongIRFETTM IRF60B217," 0501 2016. [Online] Available:

https://www.infineon.com/dgdl/irf60b217.pdf?fileId=5546d462533600a4015355e42b3719c [Accessed 3005 2018].

[21] D. Baba, "Texas Instruments," 2012. [Online]. Available: http://www.ti.com/lit/an/slyt449/slyt449.pdf. [Accessed 20 April, 2017].

[22] T. Hegarty, "Benefits of Multiphasing Buck Converters - Part 1," National Semiconductor, 1 Nov 2007. [Online].

[23] Wurth Electronics Inc., " WE-HCC SMD High Current Cube Inductor," 2105 2015. [Onlint Available: http://katalog.we-online.de/pbs/datasheet/7443320470.pdf. [Accessed $3005201 \varepsilon$

[24] Samsung Electro-Mechanics, "Spec sheet_CL31B106KBHNNNE," 1 March 2013. [Online] Available: http://www.samsungsem.com/kr/support/product- 
search/mlcc/_icsFiles/afieldfile/2017/10/14/Spec\%20sheet_CL31B106KBHNNNE.pdf. [Accessed 30 April 2018].

[25] Texas Instruments, "AN-1286 Compensation for the LM3478 Boost Controller," Apr 2013. [Online]. Available: http://www.ti.com/lit/an/snva067c/snva067c.pdf.

[26] G. Kishor, D. Subbarayudu and S. Sivanagaraju, "Multiphase Boost Converter with Reducec Input Current Ripple Using Direct Coupled Inductors," Int. Journal of Engineering Researci and Applications, vol. 4, no. 2, pp. pp.274-279, February 2014. 
APPENDIX - A

\section{Altium Schematic}

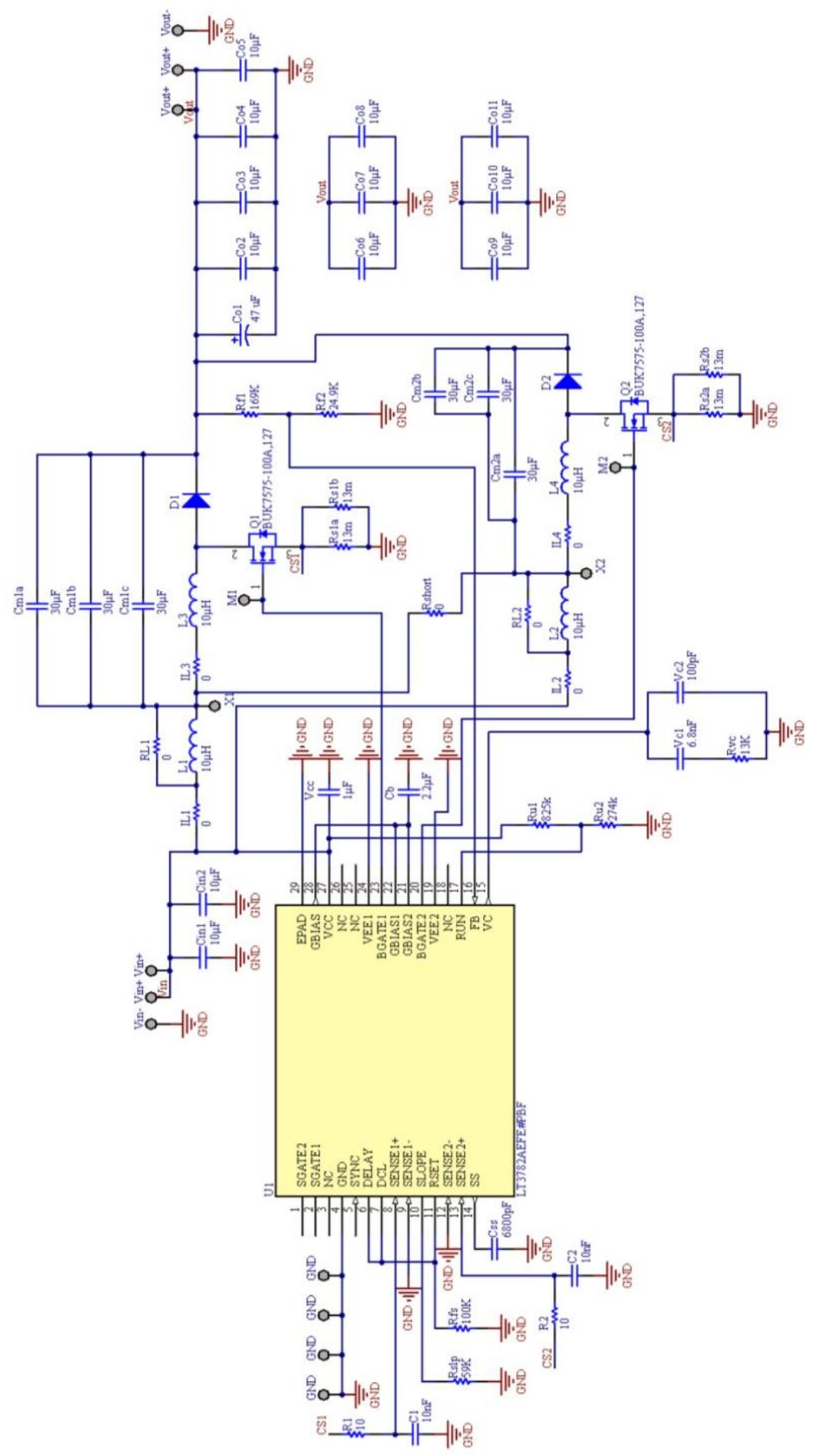

Figure A-1. Multiphase Boost Converter Altium Schematic 


\section{Altium PCB Layout}

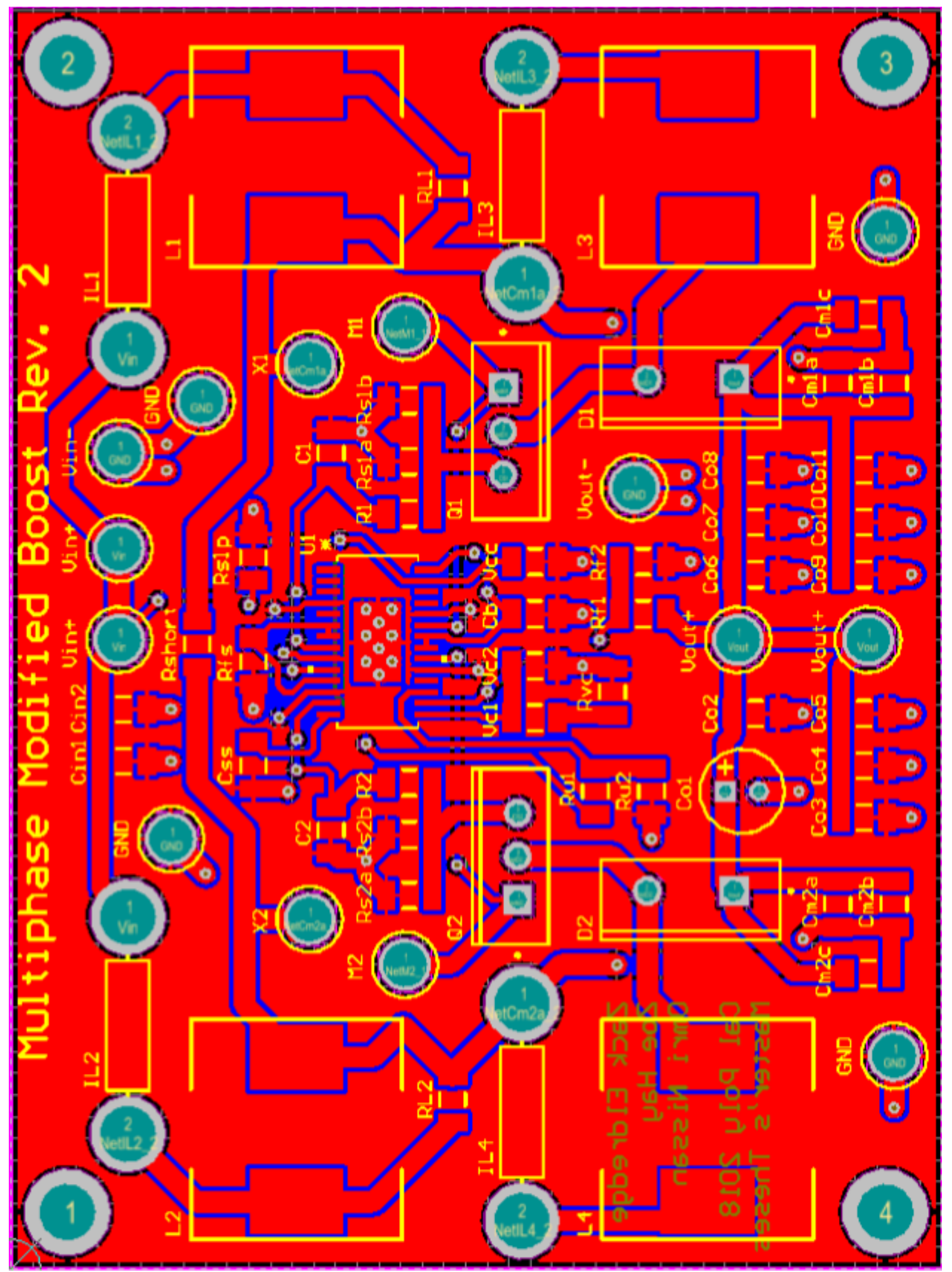

Figure A-2. Top PCB Layer 


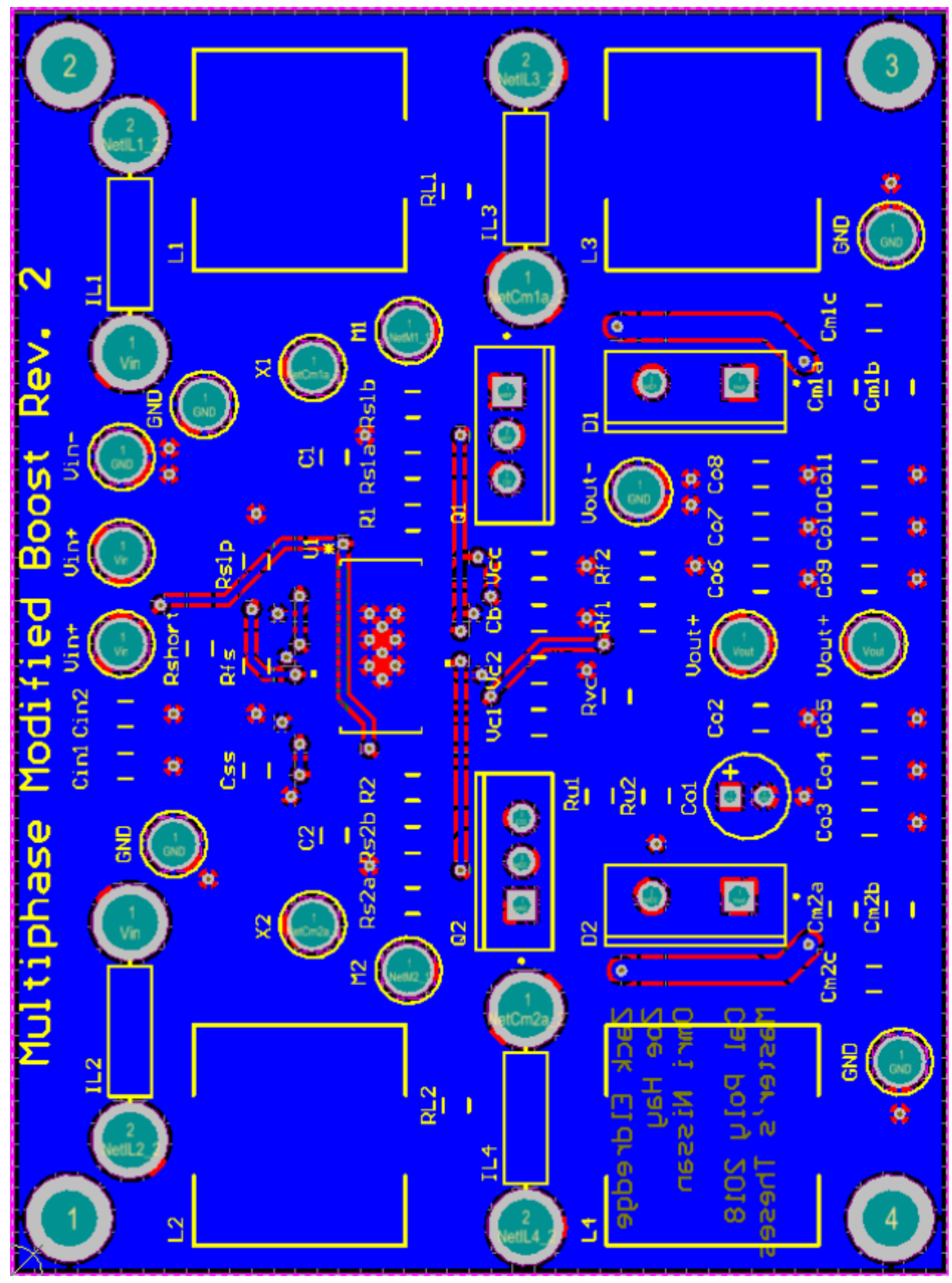

Figure A-3. Bottom PCB Layer 


\section{APPENDIX -- B}

\section{Bill of Materials}

Table A-1. Electrical Bill of Materials

\begin{tabular}{|c|c|c|c|c|}
\hline Designator & Description & Quantity & Manufacturer & Part No. \\
\hline $\mathrm{C} 1, \mathrm{C} 2$ & CAP CER 10000PF 100V X7R 1206 & 4 & Murata & 490-10753-1-ND \\
\hline $\mathrm{Cb}$ & CAP CER 2.2UF 16V X7R 1206 & 2 & Murata & 490-1799-1-ND \\
\hline $\mathrm{Cin} 1, \mathrm{Cin} 2, \mathrm{Co} 2, \mathrm{Cm} 1$ & CAP CER 10UF 50V X7R 1206 & 9 & $\begin{array}{l}\text { Samsung Electro- } \\
\text { mechanics }\end{array}$ & 1276-6767-1-ND \\
\hline Css & CAP CER 6800PF 100V X7R 1206 & 2 & Murata & 490-11619-1-ND \\
\hline D1, D2 & $\begin{array}{l}\text { Diode Schottky 100V 10A Through } \\
\text { Hole TO-220-2 }\end{array}$ & 4 & ON Semiconductor & MBR10100GOS-ND \\
\hline $\begin{array}{l}\text { GND, M1, M2, Vin+, } \\
\text { Vin-, X1, X2 }\end{array}$ & $\begin{array}{l}\text { TERM TURRET SINGLE L=5.56MM } \\
\text { TIN }\end{array}$ & 24 & Keystone Electronics & 36-1502-2-ND \\
\hline $\mathrm{L} 1, \mathrm{~L} 2$ & $\begin{array}{l}\text { 10 } \mu \mathrm{H} \text { Shielded Wirewound Inductor } \\
\text { 9A } 16.7 \text { mOhm Max Nonstandard }\end{array}$ & 2 & Wurth Electronics & 732-2145-1-ND \\
\hline L1, L2, L3, L4 & $\begin{array}{l}\text { 4.7 } \mu \mathrm{H} \text { Shielded Wirewound Inductor } \\
\text { 15.5A 7.9 mOhm Max Nonstandard }\end{array}$ & 4 & Wurth Electronics & 732-2142-1-ND \\
\hline Q1, Q2 & $\begin{array}{l}\text { N-Channel 60V 60A }(\mathrm{Tc}) 83 \mathrm{~W}(\mathrm{Tc}) \\
\text { Through Hole TO-220AB }\end{array}$ & 4 & Infineon Technologies & IRF60B217-ND \\
\hline $\mathrm{R} 1, \mathrm{R} 2$ & RES SMD 10 OHM 1\% 1/4W 1206 & 4 & $\begin{array}{l}\text { Samsung Electro- } \\
\text { Mechanics }\end{array}$ & 1276-3513-1-ND \\
\hline Rf1 & RES SMD 169K OHM 1\% 1/4W 1206 & 2 & Vishay-Dale & 541-169KFCT-ND \\
\hline Rf2 & $\begin{array}{l}\text { RES SMD 24.9K OHM 1\% 1/4W } \\
1206\end{array}$ & 2 & Vishay-Dale & 541-24.9KFCT-ND \\
\hline Rfs & RES SMD 100K OHM 1\% 1/4W 1206 & 2 & Vishay-Dale & 541-100KFCT-ND \\
\hline $\begin{array}{l}\text { Rs1a, Rs1b, Rs2a, } \\
\text { Rs2b }\end{array}$ & RES 0.01 OHM 1\% 1/2W 1206 & 8 & Vishay-Dale & 541-2745-1-ND \\
\hline Rslp & RES SMD 59K OHM 1\% 1/4W 1206 & 2 & Vishay Dale & 541-59.0KFCT-ND \\
\hline Rvc & RES SMD 536 OHM 1\% 1/4W 1206 & 2 & Vishay Dale & 541-536FCT-ND \\
\hline U1 & $\begin{array}{l}\text { Boost Regulator Positive Output Step- } \\
\text { Up DC-DC Controller IC 28-TSSOP- } \\
\text { EP }\end{array}$ & 2 & $\begin{array}{l}\text { Linear Technology/Analog } \\
\text { Devices }\end{array}$ & $\begin{array}{l}\text { LT3782AEFE\#PBF- } \\
\text { ND }\end{array}$ \\
\hline Vc1 & CAP CER 0.012UF 100V X7R 1206 & 2 & $\begin{array}{l}\text { Murata Electronics North } \\
\text { America }\end{array}$ & 490-16825-1-ND \\
\hline $\mathrm{Vc} 2$ & CAP CER 0.12UF 50V X7R 1206 & 2 & AVX Corporation & 478-1557-1-ND \\
\hline Vec & CAP CER 1UF 50V X7R 1206 & 2 & $\begin{array}{l}\text { Murata Electronics North } \\
\text { America }\end{array}$ & 490-3908-1-ND \\
\hline Ru1 & RES SMD 825K OHM 1\% 1/4W 1206 & 2 & $\begin{array}{l}\text { Panasonic Electronic } \\
\text { Components }\end{array}$ & P825KFCT-ND \\
\hline Ru2 & RES SMD 274K OHM 1\% 1/4W 1206 & 2 & $\begin{array}{l}\text { Panasonic Electronic } \\
\text { Components }\end{array}$ & P274KFCT-ND \\
\hline $\mathrm{n} / \mathrm{a}$ & $\begin{array}{l}\text { Standoffs \& Spacers HEX SPACER 4- } \\
401 / 2 "\end{array}$ & 8 & Keystone Electronics & $534-1902 \mathrm{C}$ \\
\hline $\mathrm{n} / \mathrm{a}$ & $\begin{array}{l}\text { Screws \& Fasteners 1/4 4-40 NYLON } \\
\text { PAN }\end{array}$ & 8 & Keystone Electronics & $534-9327$ \\
\hline
\end{tabular}


